Portland State University

PDXScholar

\title{
"A Listening Child." The Language Life History of an American of Mexican Descent
}

Alexandra Guerra Alvarez

Portland State University

Follow this and additional works at: https://pdxscholar.library.pdx.edu/open_access_etds

Part of the Bilingual, Multilingual, and Multicultural Education Commons Let us know how access to this document benefits you.

\section{Recommended Citation}

Alvarez, Alexandra Guerra, "'A Listening Child." The Language Life History of an American of Mexican Descent" (1994). Dissertations and Theses. Paper 4820.

https://doi.org/10.15760/etd.6696

This Thesis is brought to you for free and open access. It has been accepted for inclusion in Dissertations and Theses by an authorized administrator of PDXScholar. Please contact us if we can make this document more accessible: pdxscholar@pdx.edu. 


\section{THESIS APPROVAL}

The abstract and thesis of Alexandra Guerra Alvarez for the Master of Arts in TESOL were presented August 5, 1994, and accepted by the thesis committee and the department.

COMMITTEE APPROVALS:

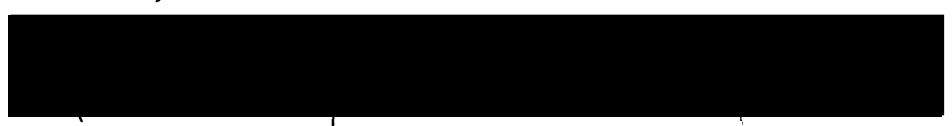

Kimberley A, Brown, Chair
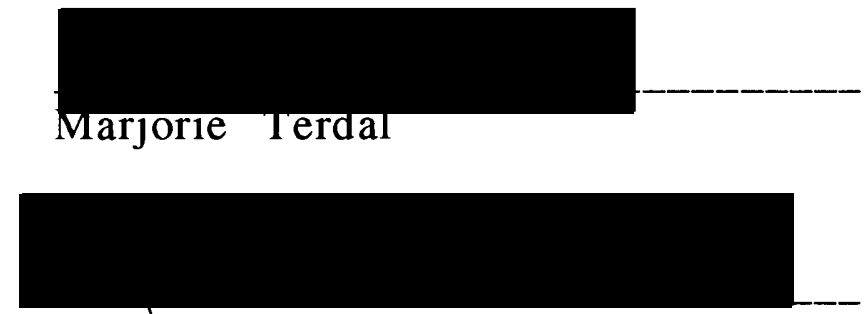

Joan Strouse

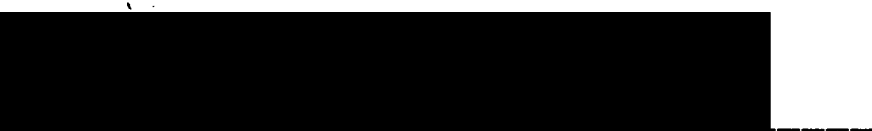

Maria Wilson-Figueroa

Representative of the Office of Graduate Studies

DEPARTMENT APPROVAL

James R. Nattinger, Chair

Department of Applied Linguistics

$* * * * * * * * * * * * * * * * * * * * * * * * * * * * * * * * * * * * * * * * * * * * * * * * * * * * * * * * * * * * * * * * * * * * * * * * *$

ACCEPTED FOR PORTLAND STATE UNIVERSITY BY THE LIBRARY

by

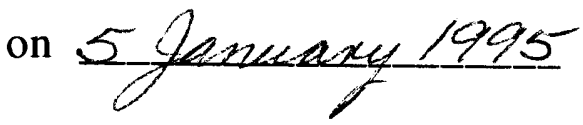




\section{ABSTRACT}

An abstract of the thesis of Alexandra Guerra Alvarez for the Master of Arts in TESOL presented August 5, 1994.

Title: "A Listening Child." The Language Life History of an American of Mexican Descent.

This case study presents the language life history of an American woman of Mexican descent. The informant describes the ways in which her two languages, English and Spanish, developed and have been used throughout her life. She narrates how living with two languages has affected her in each period of her life.

The informant's language life history provides insight into the ways in which immigrants who come to the United States live and adapt to a new country, culture, and language. The informant's narrative is a testimony of a person divided between two languages and two cultures.

The methods used to elaborate the informant's language life history were ethnographic interviewing, observing, and event/network analysis.

This language life history will promote understanding of issues such as bilingualism and its relationship to immigration in the United States, language maintenance or loss, language shift, and language choice and use. 
In the area of Teaching English as a Second Language, teachers are constantly faced with the above issues in their teaching environment. A more thorough comprehension of the experiences of second language learners could improve the skills of those teaching English as a Second Language. 
"A LISTENING CHILD"

THE LANGUAGE LIFE HISTORY OF AN AMERICAN OF MEXICANDESCENT

by

ALEXANDRA GUERRA ALVAREZ

A thesis submitted in partial fulfillment of the requirements for the degree of

MASTER OF ARTS

in

TESOL

Portland State University

1994 


\section{TABLE OF CONTENTS}

PAGE

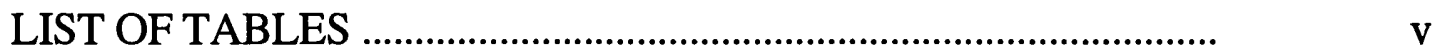

LIST OF FIGURES ..................................................................... vi

\section{CHAPTER}

I INTRODUCTION

Language and Life Histories ............................... 3

Background to this Study ..................................... 5

Statement of Research Questions ...................... 6

Definition of Terms ............................................... 8

Organization of this Thesis ................................... 9

I I REVIEW OF THE LITERATURE ....................................... 11

Bilingual Patterns and Immigration .............. 14

Language Maintenance or Loss, Language

Shift, and Language Use .................................... 25

I I I METHODS _............................................................................ 40

Qualitative Research .......................................... 40

Life Histories ....................................................... 41

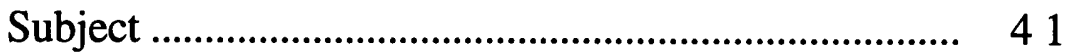

Gaining Entry ….................................................... 42

Procedures ............................................................... 43

Ethical Considerations ......................................... 48 
Limitations to this Study ..................................... 49

I V ROSE'S LANGUAGE LIFE HISTORY .............................. 51

Rose's Background ............................................ 53

First Memories of Language.............................. 73

A Listening Child ................................................ 75

Differentiating English and Spanish ............... 86

New Challenges, New Realizations ................... 93

Reactions to Rodriguez' and Hoffman's

Readings ................................................................... 115

Event/Network Analysis ................................ 125

V ANALYSIS AND CONCLUSIONS .................................. 133

Statement of the Hyphotheses

for this Study ...................................................... 133

Analysis of Rose's Language History ............. 136

Conclusions …...................................................... 155

Rose's Comments on Her Language

Life History ......................................................... 164

Implications for Language Educators ............ 164

A Final Thought ............................................... 166

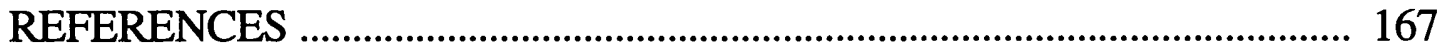

APPENDICES

A Language Use Charts .................................................. 171

B Rodriguez's and Hoffman's Readings ...................... 174

C Interaction Form ...................................................... 181

D Rose's House in Stockton ...................................... 183 
E Map of Stockton ....................................................... 185

F Rose's Family Tree .................................................... 187

G Rose's Office ................................................................... 189 


\section{LIST OF TABLES}

TABLE

PAGE

I Rose's Languge Domains .................................... 138 


\section{LIST OF FIGURES}

\section{FIGURE}

PAGE

$1 \quad$ Rose's Workplace Social Network ..................... 129 


\section{CHAPTER I}

\section{INTRODUCTION}

This thesis is a case study that inquires into the life of a bilingual woman of Mexican descent and into the ways in which her two languages, English and Spanish, developed and have been used throughout her life. An examination of an individual's language life history can give insight into the ways that immigrants who come to the United States use their native languages and the language of the new country. The life experiences of a person from an immigrant family growing up in the United States can lead to reflection on the different factors surrounding the bilingual development of immigrant children, language use, language shift, and the maintenance or loss of native languages.

The issues of language maintenance or loss, language use, and language shift are controversial. Educators, sociolinguists, and politicians, among others, have debated the advantages and disadvantages of fostering the maintenance of native languages in this country. According to Hakuta (1986), in its short history, the United States has received more immigrant people than any other country in the world. Yet, Hakuta (1986) adds, despite the fact that new immigrants bring their languages, their bilingualism is extremely unstable. In a matter of three generations, the shift to 
English is complete for most of them. Therefore, the rate of loss of native languages in the United States is high.

As language educators, it is important to try to understand what many of our immigrant students go through while acquiring English. Understanding the process of language development, language use, and the factors involved in the bilinguals' uses of their languages can help teachers to better meet the needs of their students. Thus, it is essential for teachers to learn about the experiences of people from immigrant groups. A very effective and meaningful way of learning about these experiences is by reading a life history. Life histories rely on the testimonies of individuals, and so cannot be matched by other types of research, such as quantitative research.

Life histories penetrate into the personal world of people and their relation to their environment. Language life histories present individuals specifically in their language environment, providing a unique way for a language educator to understand how their students live and how they feel about language. With a language life history, teachers can see their students' experiences in a very different way, from another perspective. Not only will a life history provide teachers with the knowledge of a powerful life experience, but it may also shed light on issues such as the cause of such effective language shift in the United States, the actual process of language shift, the experiences of immigrants while in the process of language shift, and the effects of this process on their lives. 
Language research typically involves human beings, and to better comprehend their experiences with language, it is useful to enter into their personal world. For Dobbert (1982), "human beings in everyday life are not objective" (p. 6). They behave based on their social rules and values. Detached objective observation cannot capture the complexity of human behavior nor of language behavior. In contrast, qualitative research attempts to reveal the values, the culture, and the background of people as a way to understand their behavior, needs, and problems. Because the informant's language situation could not be fully researched by using quantitative methods, the use of a language life history was an appropriate approach for gaining understanding of her linguistic development.

\section{LANGUAGE AND LIFE HISTORIES}

Life histories have been applied as a means of using informants to research the cultural patterns and values of groups. The informant chosen is considered a "representative of the culture" (Dobbert, 1982, p. 146). The informant for this study was chosen because of the characteristics of her bilingual development.

In life histories, informants are followed throughout their lives or careers. These histories yield details and patterns of peoples' lives, careers, and education. In this type of research, issues are approached from the perspective of individuals in real life. This is the unique importance of life histories.

The theoretical issues of language use, language maintenance or loss, language shift, and the bilingual development of minority 
children do not give a clear picture by themselves of the real experiences of immigrants and their families. It is important to know and understand how individuals feel and perceive their lives as immigrants or as members of immigrant families. The insight life histories provide into the experience of a human being is invaluable and helps in understanding the problems of immigrants and their children in a new country and society.

Some language life histories have been published before. For example, Lost in Translation by Eva Hoffman (1989) and Hunger of Memory by Richard Rodriguez (1982) depict the issues that emerge in the transition of immigrant children into a new language and culture. Hoffman and Rodriguez enrich our perspectives with the accounts of their lives, languages, cultures, and the challenges they encountered while growing up. Both authors share their lives, their family experiences, their ties to their mother culture and tongue, and their feelings and conflicts with their adaptation and assimilation to a new society and language.

Barker (1972) notes that the use of life histories has been important in the understanding of societal cultural patterns. He believes that using the life history method in the study of language use in different periods of a bilingual's life "would seem to offer a new approach to the individual's value system and to the events in his life which are of greatest sociological significance" (p. 50). Such a study could answer many questions regarding people's use of language, their attitudes toward their native language and culture, 
and the ways in which the use of another language in a new country affects their lives.

The aim of presenting the informant's language life history in this thesis is to attain a better understanding of language acquisition, language use, and language loss through the real life experiences of an informant.

\section{BACKGROUND TO THIS STUDY}

While working for a Portland organization, I met an American woman of Mexican descent. She showed an interest in my background and Spanish because of her own background. I assumed that she would speak Spanish because her family was Mexican, but every time we spoke, even if I spoke in Spanish, she replied in English. This happened a number of times, and I began to wonder why she did not use Spanish with me, even though she had indicated that she knew "some Spanish."

How could I find the answer to my question? The idea of conducting a language life history began to emerge because this seemed the most suitable way of studying her language development and the uses she had given to English and Spanish throughout her life. The nature of the problem, the reticence to speak Spanish, required utilizing this woman as an informant to narrate her life experiences. Using qualitative methods of research was the most effective way to achieve the goal of recording the experiences of my informant. This is the main reason that I chose to do a life history. 
After defining my goal and my research method, I asked Rose to help me by being my informant. Rose (her pseudonym for the study) and I started working, and she narrated, in interviews, her life and her experiences with her Spanish and English. The results of her account are presented in this thesis.

Rose was born and raised in California. Her family immigrated during the 1940's to the United States, where her father worked as a medical doctor in Stockton, California. Rose's family was composed of her father, mother, and eight brothers and sisters. As Rose narrates in her language history, the language used by the family after their immigration was initially Spanish but, as time went by, English began to be used more often, especially by the children. Rose narrates events in her life which help in understanding her language development, her use of English and Spanish, and her language shift to English.

\section{STATEMENT OF RESEARCH QUESTIONS}

The following research questions are divided into two groups. The questions in the first group were formulated before the interviewing process started. Those in the second group were formulated during the interviewing process.

\section{Group 1}

The following are the research questions that guided this study at the beginning: 
1. What were the subject's experiences as a Mexican American in the United States?

2. What were the subject's choices regarding language?

3. What factors affected the subject's choices regarding language?

4. What were the effects of these choices in the life of the subject?

5. What insights can be drawn from the subject's life history regarding language shift, language maintenance or loss, and the causes for these phenomena?

\section{Group 2}

The following are questions that emerged during the interviewing process and helped in the formulation of hypotheses, which will be presented in Chapter V:

1. Are changes in language use related to the various stages of the subject's life?

2. How is the subject's language use related to changes in her social environment at different periods of her life?

3. How do attitudes from the subject's community towards her ethnic origin affect her language use and attitudes?

4. How does language use affect language shift, language maintenance, and language loss? 


\section{DEFINITION OF TERMS}

The definitions of the following terms originate from the various sources consulted for this study, especially Grosjean (1982) and Hoffmann (1991):

Immigrant person or immigrant group. These terms refer to any person or group of persons who arrive in a country as newcomers with the intention of staying permanently. The term "immigrant" is used in this case study because Rose, the informant, immigrated with her family from Mexico to the United States. Other groups such as refugees or migrant workers are not considered in this study because Rose does not belong to any of these groups.

Minority group. This term refers to a group of people within the United States whose members do not use English as their primary language. For this study, a minority group is a linguistic minority group who uses a language other than English. An immigrant group would be considered a minority group if its members do not use English as their primary language.

Minority language or native language. These terms are used interchangeably to refer to the language used by a linguistic minority group within the United States.

Majority group. This term designates the group in the United States whose members use English as their native language and who dominate the society which newcomers enter. In this study, the majority group is mainly a linguistic majority group whose members speak English. 
Majority language. This term is used for the language used by the members of the majority group. In this study, the majority language is English because it is the language spoken by most people in the United States.

Language domain. This term is defined as a cluster of social situations typically constrained by a common set of behavioral rules (Fishman, 1972).

Bilingual. This term is applied to any native speaker of one language who makes use of another language, however partially or imperfectly (Halliday, 1970).

Life history. This term is defined as a way of using informants to learn about the details of an individual's life to find out about cultural patterns (Dobbert, 1982). In this study the terms life history, language life history, language history, and language narrative are used interchangeably to refer to the informant's life history.

\section{ORGANIZATION OF THIS THESIS}

This thesis has been divided into five chapters:

Chapter I has introduced the main issues under study and the approach taken for this thesis.

Chapter II presents a review of the literature on bilingualism and immigration, language use, language shift, and language maintenance or loss. It provides the theoretical foundations for the analysis and discussion of the informant's language life history. 
Chapter III delineates the methods of research utilized for this study, and a description of the methods and procedures employed for interviewing and composing the language life history of the informant.

Chapter IV chronicles Rose's narrative of her language life history, and is exclusively dedicated to Rose's life with Spanish and English. This chapter also reports the results of an event/network analysis of language use in the informant's workplace.

Chapter $\mathrm{V}$ presents the analysis of and conclusions drawn from Rose's language life history. Specifically, this chapter analyzes Rose's language development, language use, and the ways in which her language experiences relate to theoretical issues such as language shift and language maintenance or loss. Implications of this study for language educators are also presented at the end of the chapter.

Finally, there are seven appendices, which include language use charts, and maps and diagrams elaborated by the informant during the course of the interviewing process. These add to the understanding of her experiences and are helpful, for example, in locating Rose in her home, in her family tree, or in Stockton. 


\section{CHAPTER II}

\section{REVIEW OF THE LITERATURE}

\section{Introduction}

The study of languages in contact has been a field of inquiry for many researchers. A multitude of issues have been investigated in this area. In the case of the United States, there are large numbers of languages in contact with English. These languages are brought by the many immigrants that have come and are still coming to this country. In this new situation, the immigrants' native language has to share its areas of use with English. The question then becomes whether the native language will survive or not. The study of these issues involving English and minority languages can promote an understanding of bilingual development and its relationship to immigration, language choice and use, language shift, and language maintenance or loss.

According to Fase, Jaespaert and Kroon (1992), the question of language maintenance and language loss is intimately linked to language use and language proficiency. In order for a language to be maintained, its speakers have to be proficient in it and use it in their everyday lives. Native language loss occurs when the speakers no longer possess an adequate level of language proficiency, and they do not use the language in their daily communication events. 
Placing the problem on a continuum, there is language maintenance at one end and language loss at the other. Between these two points, a process of gradual change in language use and proficiency takes place in the speakers of the language. This gradual process is referred to by Clyne (1992) as the gradual development of shifting from one language to another, described in "terms of domains, skills, main language or dominant language" (p.18).

According to Fishman (1972), the study of language maintenance and language shift is linked to "the relationship between change or stability in language usage patterns..." (p. 76).

In order to understand these processes of language use, language shift, and language maintenance, it is necessary to examine the ways bilingualism develops in immigrant situations, the factors that affect the use of the language by the members of the group, the relationships between the members of the group, the language development of children in the group, and the way the majority language influences the children's language use, especially in school and in the social sphere. These considerations help to provide an understanding of how minority languages are maintained or lost due to changes in language use by the members of the immigrant group.

In this study, the considerations of bilingualism and immigration, language use, language shift, and language maintenance or loss, are very important in understanding Rose's language history. For this review of the literature several issues regarding these topics have been selected because they are intimately related to Rose's experiences with Spanish and English while growing up. 
This chapter is divided into two main sections. The first section discusses the bilingual patterns of immigrants. Topics addressed are patterns within immigrant families (like Rose's) and across different generations of immigrants, bilingual development in immigrant children, especially regarding the pressures they receive from the community to acquire the majority language, language differentiation in bilingual children, and the ways their languages influence their cognitive development in school. These topics are addressed because Rose was one of these children living with two languages.

The last topic addressed in this section is bilingualism across the life-span. In this study, considerations of the bilingual's variations in language proficiency and in language use are very important in analyzing the changes Rose experienced with Spanish and English throughout her life.

The second section of this chapter relates to language maintenance or loss, language use, and language shift. The minority languages that immigrant groups bring to the United States come into contact with English in everyday use by the members of these groups. For the purposes of Rose's language history, her Spanish comes into contact with English, and the two languages begin sharing different areas of her life. This section reviews topics such as the factors that affect language maintenance and language shift, the different determinants for language use in bilinguals, and the relationship between language use and language shift. These theoretical perspectives are important for Rose's language life history because it could not be fully understood without considering her 
language use and its effect on her native language maintenance.

Only by observing her bilingualism in conjunction with these theoretical considerations can a full understanding of her linguistic development throughout her life be gained. The end of this section reviews language shift among Hispanic Americans for the purpose of understanding the ways that language shift is affecting this population, to which Rose belongs.

\section{BILINGUAL PATTERNS AND IMMIGRATION}

\section{Bilingualism and Immigration}

When an immigrant family settles in a new country, usually the adults are the ones who keep the native language. The children are the ones who begin learning the majority language through school, friends, and other community contacts. The children are the ones faced with using the native language at home and using the majority language at school and with friends.

According to Bossard (1945), the immigrant family learns the majority language in a pattern which usually starts with the children, then the father, who generally works outside the home, and finally the mother, who many times remains at home.

The patterns of language in the immigrant family, according to Grosjean (1982), can become very complex. First, there are the parents, who are foreign born and monolingual in the minority language. When they arrive in the United States, they begin to learn English in order to find a job and find their way around in the 
country. In some cases, if there is no real need to learn the country's language, they remain monolingual. In most cases, they become at least partially bilingual, using the minority language at home or with friends or neighbors, if they can. Only on rare occasions do they become monolingual in the new country's language. This can only happen if they are absolutely isolated from speakers of the minority language, and if they decide to speak only the majority language with the children and even between husband and wife.

Second, there are the children. They are usually the first ones to become bilingual in the majority and the minority languages. What these children ultimately do with their two languages has been the focus of much research. This linguistic problem involves not only bilingualism, but also language use, and the maintenance or loss of native languages caused by language shift.

All these factors are important in analyzing Rose's language history because the circumstances of her upbringing resemble the ones described above.

\section{Bilingual Patterns throughout Generations}

Bilingual patterns in immigrant families relate not only to how the majority and minority languages are used within the family, but also to how these languages behave throughout different generations of the family. This is interesting to review because in language life histories, bilingual patterns involve not just one individual in one generation, but several individuals in several generations. 
According to Hoffmann (1991), the bilingual patterns that immigrant families follow are predictable. Her research found that by the fourth generation of immigrants, the original native language of the first generation disappears. The first generation, usually the foreign-born parents, speak mostly the native language, with some of the second language. The second generation, their children, speak both, the native and the second language. The third generation, the grandchildren, speak or at least understand some of the native language, but use primarily the second language. Finally, the fourth generation, the great grandchildren, speak only the second language.

Hansen (1938) also studied immigrants over generations. $\mathrm{He}$ found that third generation immigrants usually look back to their roots and try to regain them. In his studies he observed that first generation immigrants are the newcomers, who have strong attachments to their native culture and language, and who learn the host country's language only for practical uses (such as work) or for contact with people outside the group. The second generation shows strong feelings of assimilation to the host country's culture. Although they might be reasonably proficient in their parents' language, they learn the host country's language quite rapidly, and they show a desire to belong to the new society. The third generation, Hansen (1938) found, speaks the host country's language natively and is assimilated to the host country's society. However, they seem to consistently show a desire to go back to their roots by learning their grandparents' language and culture; they show a longing to recover their past. 
This theory aptly describes Rose because her children are learning Spanish and are being schooled in a Spanish immersion program. Although Rose belongs to the second generation of immigrants, she is interested in her children's awareness of their past. As the third generation, her children will feel compelled to preserve their grandparents' language and cultural heritage.

\section{Bilingualism and the Second Generation Immigrants}

This section reviews the characteristics of the language patterns of children in the second generation of immigrants. These characteristics are important later because Rose belongs to this generation.

The second generation children are born in the host country, but in their first few years of life they learn the native language. When they reach school age, the playground and the classroom become the sources of the second language. The native language sphere then is limited to the family circle and, sometimes, the neighborhood.

In this pattern, bilingualism becomes a transitional phase between monolingualism in the native language and monolingualism in the second language. As Grosjean (1982) says, "Bilingualism in the United States is transitional in nature. It stretches across one or several generations, linking monolingualism in the original minority language to English monolingualism" (p. 55).

The maintenance of bilingualism in the second generation of immigrants rests upon several factors. Several researchers have 
addressed this issue (Fishman, 1972; Grosjean, 1982; Hakuta, 1986; Hoffmann, 1991). They believe that the maintenance of bilingualism depends upon factors such as the environment where the children live, the parents' attitudes towards the minority language and the majority language, the parents' willingness to maintain the minority language and teach it to the children, and the pressures of society to learn the majority language. There are also the pressures that come directly to the children from their peers at school, and the attitudes they perceive towards their group of origin from the society at large. On the other hand, the minority group is sometimes strong enough to foster the maintenance of both the native language and its culture. The child may remain bilingual if there are enough psycho-social factors encouraging the maintenance of the language.

Fishman (1965) reports that native language maintenance is affected by the children's age. The older children are, the more retentive of the native language they are. Conversely, the younger the children are, the less retentive they are. Older children tend to maintain the language because they have been exposed to it for a longer period of time. They might have even lived in the native country. The younger children, on the other hand, have had less experience with the native language and, therefore, be more prone to shift to the majority language.

The combination of these factors shape the bilingual development of children. These factors mainly relate to the social environment of children, suggesting that the surrounding 
environment is of crucial importance in studying bilingual development.

\section{Types of Bilinguals}

In order to understand how children become bilingual and maintain their bilingualism, it is necessary to analyze the different types of bilinguals. Children become bilingual under different circumstances. The nature of these circumstances influences whether or not they keep their bilingualism throughout life.

In the research on bilingualism, many classifications of types of bilingualism have been developed. For this study, the classification put forth by Skutnabb-Kangas (1984) was chosen because it is the most appropriate to the issues addressed in Rose's life history and her immigrant background.

Skutnabb-Kangas (1984) identifies four types of bilinguals. She developed her classification based upon the different social factors involved in the development of bilingualism in children, such as the pressures to become bilingual that they face, the route followed in their bilingual development, and the consequences of becoming bilingual. The four types are summarized below.

a) Elite bilinguals. These are the ones who have freely chosen to become bilingual. In the case of children, the choice has been made by their parents. The acquisition of the second language is unhindered. This type of bilingual receives wide support from society. 
b) Children from linguistic majorities. These children learn a minority language at school, either in immersion programs or in foreign language classes. The learning of a second language usually is considered prestigious and enhancing to education. There is no pressure to become bilingual, and the failure rate is low.

c) Children from bilingual families. These children have parents who speak different languages. The children will learn the predominant language in the country in order to attain success in the society in which they live. The children generally feel little motivation to become bilingual. Bilingualism in this case is used for contact with the parents.

d) Children from linguistic minorities. These children have parents who belong to a linguistic minority. They generally experience external pressure (such as in school) to learn the majority language. Usually their native language is not officially recognized, and there may not be bilingual education programs available for them. They usually become bilingual to a certain degree.

Sometimes, their educational and future opportunities are hampered because of their linguistic problems. Usually, they need to learn the majority language as soon as possible.

In many cases, the acquisition of the majority language in these children happens at the expense of the native language. Hoffmann (1991) and Allard and Landry (1992) describe this type of bilingualism as subtractive. Children gradually become more proficient in the majority language than in the minority language, the end result being language shift. However, if children maintain 
proficiency in both the majority and the minority languages, their bilingualism will be additive, because they are "adding" a language to their linguistic repertoire rather than losing one of them as in the case of subtractive bilingualism.

\section{Linguistic Competence and Cognitive Functioning}

When minority children start their schooling, they are faced with new linguistic challenges. If there is no program or provision for educating them in their own language, they will be required to use the majority language in their classes, with their classmates, and with their teachers. Prior to attending school, these children have usually been exposed only to their native language at home. Therefore, they lack the language proficiency in the majority language to attend regular classes and perform on the level of native speakers.

Skutnabb-Kangas (1984) conducted research among Finnish immigrant children in Sweden. She found that in addition to developing poor language skills in their native language at home, these Finnish children also have below average proficiency in Swedish when compared with monolingual Swedish-speaking children with similar intellectual ability at school. Skutnabb-Kangas (1984) observed that while the children appeared to be very fluent in Swedish, they lacked the conceptual linguistic knowledge needed to succeed in school.

In this same line of research, Cummins $(1979,1980)$ developed a theoretical explanation to the problem minority children face in 
school. He proposed a model called the Common Underlying Proficiency Model (CUP). This model proposes that in bilinguals there is a common underlying proficiency for both languages. Therefore, assuming sufficient exposure, the content skills learned in one language are transferable to the second language. Cummins divided linguistic competence into two categories, which he termed BICS and CALP:

a) BICS stands for Basic Interpersonal Communication Skills. This is the surface competence. It is composed of the visible features of language, which are very easy to measure, including pronunciation, vocabulary, grammar, and speaking. These language features are used in oral communication along with other non-verbal features, such as gestures, which help in the transmission of the oral message. Such communicative tasks are undemanding, according to Cummins, and can be easily attained two years after the arrival to the country. Minority children learn these skills easily, especially if they are in a classroom where support from the context aids understanding.

b) CALP refers to Cognitive Academic Language Proficiency. This relates to cognitive linguistic competence. This type of competence is revealed in the effective use of cognitive functions of language as a tool of thought. These language skills are decontextualized, and are, therefore, more demanding. They develop outside everyday situations. Good development of these skills depends on how well both languages are established. They take a 
longer time to develop. In fact, Cummins believes it takes five to seven years for a person to develop these skills in a second language.

Cummins's theories attempt to explain why children of minority groups who are taught in their weaker language (the second language, the majority language of the country) fail in achieving good academic skills in school. They are unable to develop sufficient competence in the second language to work in school, and at the same time, their competence in their first language is hindered because at school the second language is used exclusively.

These children attain a surface competence in the second language, which makes them appear very proficient, but unfortunately, they do not achieve the cognitive language skills necessary for academic work in school. As a result, many of these students have academic problems and drop out of school.

These cognitive factors are very important, but they are not the only ones that come into play in the language development of bilingual children. Hoffmann (1991) believes that factors such as motivation, attitudes toward the second language and its speakers, schooling, parental support, and expectations influence the acquisition of language. Hoffmann (1991) notes that human beings experience language, culture, and education in different ways. Some people may be affected by "cognitive or linguistic determinants" (p. 134). For others, language acquisition and education may be more strongly influenced by motivational or attitudinal factors. 
In Rose's life history these theories can be used to explain some of her experiences and her siblings' experiences with language at school.

\section{Bilingualism Across the Life-Span}

The ways immigrants in the United States use their native languages and the new country's language vary according to the changes in their lives. The nature of these changes determine whether or not they maintain the native language throughout life.

Bilingualism is not a phenomenon that involves only the acquisition of two or more languages. Once two languages are learned and used, bilingualism becomes a way of life, as in the case of Rose. The fact that a person learned two languages does not mean that that person's proficiency and use of these languages will remain constant throughout that person's life. According to Hyltenstam and Obler (1989), bilingual speakers' proficiencies and uses of their two languages vary throughout their life-spans because of changing circumstances and living conditions. The use of their languages has to adapt to these changes, and sometimes, one of the languages becomes more useful than the other. Hyltenstam and Obler (1989) call this a "spectacular" (p. 3) variation. They believe that a large number of factors surround the acquisition and use of each language, and that the interplay between them at various points in the individuals' lives is the key to determining the "linguistic status" (p. 3) of a person at any point in time. 
The changes in the proficiency and use of the bilinguals' languages determine the survival of minority languages.

\section{LANGUAGE MAINTENANCE OR LOSS, LANGUAGE SHIFT, AND LANGUAGE USE}

The constant contact of minority languages with the majority language produces changes in the uses and scope each language enjoys in the lives of its speakers. It is during this process of language use change that, depending on various factors, a native language can be maintained or lost.

Pedraza (1985) believes that in order to understand language maintenance or loss and language shift, it is necessary to understand how "language is used in everyday behavior" (p. 68). This means that in order to describe the issues involving the maintenance or loss of minority languages, one has to understand what occurs at the different social levels of the group involved.

According to Fishman (1972), the study of language maintenance and language shift is directly related to the relationship between change or stability in the patterns of use of the minority language and the majority language in different situations. These patterns, in turn, are related to "ongoing psychological or cultural processes in populations that utilize more than one speech variety for intra-group or inter-group purposes" (p. 76). This means that the different language varieties spoken by a group change. There are instances when one variety displaces the other among some members of the group. The reasons for these displacements, 
especially in certain interactions, have been studied by language researchers, and their conclusions are outlined below.

Factors Affecting Language Maintenance or Language Shift

Several researchers (Grosjean, 1982; Hoffmann, 1991; Hakuta, 1986; Fishman, 1975, 1972 \& 1991; Stevens, 1985; Bossard, 1945) have defined factors that influence the maintenance or loss of minority languages. These factors range from social to attitudinal. The following are some factors which are relevant for this study:

a) Social Aspects. There are several factors within this area. The first is the size of the group, which includes the number of people in the group and the group's growth rate. Constant immigration keeps the group growing, which at the same time, keeps the minority language alive. However, language shift is likely to occur more rapidly if the members of the group plan to stay long in the country. The longer a group has been in the country, the more likely it is that further generations will shift to the majority language.

Second, there may be a degree of isolation of the group from other groups. The more isolated the group is, the better the chance of maintaining the native language. Conversely, if there is enough contact with the majority group, the members of the minority group will need to develop ways to communicate with them, which will mean that they will have to learn the majority language.

The third social aspect is that the degree of contact the group has with the home country will influence the native language's 
maintenance. The more the contact, the higher the likelihood that the native language will be maintained. This contact could consist of frequent visits to the home country, visits from relatives and friends from the country of origin, and other types of contact.

Another social aspect that affects the survival of the native language is the degree of social mobility possessed by the members of the group. The occupations and professions each family member has determine the amount of contact with the majority group. The more contact there is, the more likely the majority language will be used, thus displacing the native language.

Maintenance of the native language is also influenced by the level of a person's activity inside or outside of the minority group. If a person is very active within the minority group, the person is more likely to maintain the language. The reverse is also true; the more active a person is inside the majority group, the more likely the person is to shift to the majority language.

The final factor to be considered in the social area is the geographic concentration of the members of the minority group. Some minority groups have established themselves in certain areas within cities or in the countryside. The more isolated and constrained they are, the more likely they are to maintain their native language and customs.

b) Attitudes. Individuals in minority groups develop attitudes towards the minority language and the majority language.

First, the degree of acceptance the members of the minority group have toward the native language determines its survival. At 
the same time, if the degree of acceptance of the majority language is higher than that of the minority language, language shift will occur. Sometimes minority group members believe that the majority language is better and worth learning. Learning the majority language then becomes a way of achieving acceptance. Brice Heath (1985) believes that when minority group members perceive that, for instance, standard English is the "right language" (p. 6), they are more likely to learn it. They perceive English as "both, a fundamental instrument and a required symbol of knowledge and character" (p. 6).

Child (cited in Hoffmann, 1991) in one of his studies identified three tendencies among Italian immigrants in New York regarding their attitudes toward their background and language. Some of the immigrants strongly identified with American culture and society, and rejected their heritage. Others were the opposite: they identified with their Italian background and rejected American culture. The third type did not think in terms of being either Italian or American. Instead, they considered themselves a mixture of both. Regarding language, Child found that most of his subjects were shifting from Italian-English bilingualism to monolingualism in English. The subjects who identified more with American society showed a more advanced degree of language shift than the other subjects. These results suggest that even though individuals may strongly identify with their ethnic background, language maintenance is not guaranteed. 
From another perspective, Fishman (1991) asserts that language is "symbolically linked to its culture" (p. 22). Language is the means by which people identify with their own group. Therefore, language shift also involves a shift in culture. The task of a bilingual, then, is to find a balance between these two cultural worlds.

In addition to the minority group's attitudes toward the minority and majority languages, their attitudes toward the two cultures must be considered. Cultural attitudes reveal how close people feel toward their native culture. The closer they feel, the more likely they are to maintain the customs, culture, and language. However, if the individuals are willing to identify with and assimilate to the majority culture, native language maintenance will suffer.

The fact that these tendencies regarding cultural attitudes seem to contradict Child's results, above, shows that the results of studies involving language maintenance and attitudes may be dramatically affected by the variables among different groups. Therefore, it is important to realize that variations in attitudes is often so great that each individual is unique.

Furthermore, Fishman (1972) found that not only do attitudes change from generation to generation, but they may also change within a single generation over time. He observed that some individuals from the first and second generations, who at first perceived the native language as ugly and grammarless, ultimately showed an emerging esteem towards the minority language, viewing it more positively and nostalgically. Younger second and third 
generation individuals viewed the native language with "less emotion" (p. 105), but they consistently registered higher levels of acceptance of the native language with the passage of time. These increasingly positive attitudes were, however, "unaccompanied by increased usage" (p. 105). This finding is important because, as it will be shown in Chapter IV, Rose has gone through a similar process as a younger second generation immigrant.

A final factor in the area of attitudes is the degree of acceptance the majority group has for the minority group, which affects the maintenance of both the native language and its culture. The less accepted the minority group is, the more likely its members are to assimilate and learn the majority language, and thereby, gain acceptance. The degree of acceptance by the majority group for the minority group also has to do with government policy towards the minority group and its language. Policies and laws adopted concerning the use or prohibition of minority languages in schools, in the workplace, and in official government documents affect the survival of minority languages.

Romaine (1989) and Hoffmann (1991) state that one of the most powerful factors in language maintenance or loss is education. The language used in the schooling of immigrant children determines the survival of their minority languages. School is the socializing factor for these children because it reflects the attitudes and expectations of the majority group toward the minority group. Whether immigrant children perceive their environment at school as 
friendly or hostile towards their native language and culture determines the maintenance or loss of a minority language.

If the minority group members have a very strong desire to assimilate, this may become the chief motivation for learning the majority language. Gardner and Lambert (1972) studied the motivational factors in language learning in Canada. They found that there are various types of motivation, which they grouped into two main divisions, instrumental and integrative. They believe that both forms of motivation are present in all language learners, but vary according to the age, experience, and social needs of the learners. In the case of minority language groups, integrative motivation, the desire to be accepted in the majority group, is the chief reason for learning the majority language. By learning the majority language, immigrants accept and become integrated into the mainstream culture and society. The language learners identify strongly with the members of the majority group and adopt aspects of their behavior, culture, and language.

c) Language Use. The different uses of a bilingual's languages and the proficiencies developed in each of them are the foundation for the healthy maintenance of native languages. The degree of use the minority language receives is crucial for its survival. Because this factor is so important in the study of Rose's language life history, a review of research on language use follows. 
Language Use

According to Hoffmann (1991), language is "not an abstract entity, but a tool employed for taking part in acts of communication" (p. 23). A bilingual combines the ability to use two languages in different situations as a means of communication, switching back and forth between languages according to the needs of the communication task. Mackey (1970) notes that bilingualism is not a "phenomenon of language, but of language use" (p. 554). This means that what counts in bilingualism is the manifestation of language, which shows a bilingual's linguistic system at work. Therefore, it is important to study the observable parts of language in order to determine the ways in which bilinguals use their languages.

Along these lines, Fishman (1975), in his research with Puerto Ricans in New York, found that language use, the choice of a language in communicative situations, is never random. Rather, it always follows a pattern. Fishman (1975) asserts that "'Proper' usage dictates that only one of the varieties will be chosen by particular classes of interlocutors on particular kinds of situations to discuss particular kinds of topics" (p. 583).

Research shows that bilingual speakers predetermine the patterns of use of their languages. In every speech event, the bilingual habitually assesses the situation, the person, the topic being addressed, and the function of the interaction, and then chooses the appropriate language. Bilingual speakers may feel, for example, that it is more appropriate to speak in one language with their mother, but to use the other language to talk about sports with friends. 
According to Fishman (1975), the factors involved in linking situation with language choice reflect deeper "spheres of activity in any society under consideration" (p. 585).

\section{Domains of Language Use}

Fishman $(1975,1972)$ terms these spheres of activity as "language domains" (p. 599). He defines them as "clusters of social situations typically constrained by a common set of behavior rules" (p. 599). These domains of language use apply to speakers of all languages whether monolingual or bilingual, and regulate the speakers' linguistic behavior, as well as enabling them to relate the language domains to socio-cultural norms and expectations. Bilingual speakers are aware of these domains, and use the language appropriate to each domain as dictated by the situation. Bilingual speakers first choose the appropriate language and then choose a suitable degree for formality. Fishman (1975) defines five basic language domains:

a) Family. This domain comprises spouse, children, siblings, father, mother, grandparents, uncles, cousins, and other members of the extended family, as applicable.

b) Friendship. Included are friends in the neighborhood, friends inside the group of origin, friends outside the group of origin, like friends at the workplace, and other types of friends.

c) Religion. This language domain relates to the language used in the group's religious practices, the religious ceremonies, and the language in which the people themselves pray. 
d) Employment. This domain involves the language spoken with the employer or supervisor, with work mates, and with other people within this area. This is a very important domain because a person spends the majority of the day at the workplace.

e) Education. This domain involves the language in which the person received or is receiving education. In the case of children, it involves the main language used with teachers, fellow students, and friends during their school days.

Other researchers, cited in Hoffmann (1991), before and after Fishman, have studied domains of language use. For example, Schmidt-Rohr mentions playground and street, school, church, literature, press, military, courts, and government and administration. Greenfield proposes home, beach, church, school, and workplace. Parsher cites family, friendship, neighborhood, transactions, education, government, and employment.

It seems that the domains identified by different researchers depend upon which societies they have studied. Therefore, in order to establish the domains of language use for a specific group of people, it is necessary to first study the group's social relations. For this study, Fishman's classification of language domains is used as a frame of reference because it is the most suitable for analyzing Rose's language use. Some additional domains are included in order to accommodate Rose's different spheres of interaction. 


\section{Configuration of Language Domains}

Hoffmann (1991) asserts that the configuration of a domain has three component factors, which trigger, in bilinguals, the use of either of their languages. The three components are described below.

a) The participants in a conversation. Within this factor, the speaker takes into account age, gender, socio-economic status, type of relation, and background, which the participants may or may not share.

b) The place where the interaction occurs. A certain language is used in a determined place or time. For example, bilinguals use one language to speak with their grandparents at home, and another language to talk with their friends at school.

c) The subject under discussion. The choice of language also depends on how competent the speaker feels to discuss a certain subject in a specific language. Usually, bilingual speakers have learned or developed certain skills in a determined language, so it is easier to talk or communicate in the particular language that is associated with that particular subject.

All the factors reviewed above come into play when speakers use their languages. It is not the language itself that dictates the use, but rather the social situations and the experiences the speakers have acquired from their environment.

In children, language development is closely linked to an increasing awareness of the environment. When children are young, language choice is usually determined by social and emotional 
factors. As they become older, other more complex factors come into place, such as the topic of conversation. As children grow, their competence in the two languages may vary. The less balanced they become, the more likely they are to show a preference for one language over the other. Once the children are older, language dominance emerges, which means one of the languages is more comfortable and, therefore, the most used by the children.

\section{Language Use and its Relationship to Language Shift}

As has been shown, the bilingual's language use is of extreme importance in the maintenance of minority languages. First generation immigrants have to attain a certain level of proficiency in the majority language in order to survive. It is their children who are caught in between two languages and cultures. The extent to which the domains of language use remain stable throughout the speakers' life guarantees the maintenance of the native language.

Unfortunately, for a number of reasons, this stability is not possible. The second generation of immigrants is usually pressured to learn the majority language. As time goes by, and they grow older, the interactions with members of the group of origin may vary; thus, the use of language varies too. Language domains that before were absolutely dominated by the minority language are gradually taken over by the majority language. Once the last and most stable domain, the family, is invaded by the dominant language, it is inevitable that language shift will occur. 
Language Maintenance and Language Shift Among Hispanics in the United States

Currently, Hispanic Americans are the fastest growing minority in the United States (Grenier, 1984; Hakuta, 1986; Grosjean, 1982). The common characteristic that identifies this group is their language, Spanish. After English, Spanish is the second most widely spoken language in the United States (Mirowsky and Ross, 1984).

These assertions, however, may be misleading because language use in everyday life is necessary in order to ensure a language's maintenance when it is in a contact situation, as is the case of Spanish in the United States. Hakuta and D'Andrea (1992) studied the language use of 308 Hispanic high school students in the United States in order to analyze how and where these students use English and Spanish. The researchers wanted to determine the degree of Spanish maintenance among the students.

The results of the study show that language shift to English is quickly occurring, due to rapid acquisition of English. The researchers found that the students do not resist the learning of English and that their choice of language is deeply affected by their peers and surrounding environment, rather than by their parents' and families' language choices.

The results of this and other studies suggest that Hispanic Americans are rapidly shifting from Spanish to English for communication. This is due mostly to the increasing interaction of Hispanics with the majority group. This shifting implies that this 
process of "Anglicization" (Grenier, 1984, p. 538) could be a threat to the conservation of the identity of the Hispanic population.

There are three major elements involved in language shift (Grenier, 1984):

The first element is that there are strong economic incentives. The shift to English may be seen as an improvement in the individuals' economic situation. Therefore, a language shift is viewed as a way of achieving better status in society and, therefore, better economic opportunities.

Secondly, before the shift to English occurs, the people in the minority group must learn and practice the language. This entails increasing their contacts with people that speak the majority language and developing new friendships and contacts in the majority group.

Finally, in language shift there is a psychological cost. Some people resist it because they fear their cultural identity will be damaged. The extent to which the people of the minority group want to change their cultural identity determines the level of language shift.

Grenier (1984) also mentions several additional factors that influence language shift. First, the speaker's age is one factor because the younger people are, the more exposure to the majority language they have. Consequently, they may be more willing to shift than other people would be. Secondly, the longer immigrants of the same group stay in the United States, the more likely language shift is to occur. However, if there is a constant flow of new immigrants, 
the minority language survives longer because such an influx tends to lengthen the period of language maintenance. Thirdly, gender is important. Men usually spend more time outside the home than women, and, therefore, they are more in contact with members of the majority group. Another factor influencing language shift is marriage. High levels of language shifting occur when minority group members marry outside the group of origin.

Finally, the linguistic composition of the neighborhood is also important. The larger the proportion of minority language group members in the neighborhood, the less contact its people have with majority group members, and the better chances are for maintaining the native language. 
CHAPTER III

\section{METHODS}

In order to understand the language choices faced by children from new immigrant families in the United States and how education, the family, and the community affect these choices, I carried out a case study of the language history of an American woman of Mexican descent. The examination of an individual's language life history can lead to a better understanding of bilingual language development, language use, the process of language shift, and of the role these play in the maintenance or loss of minority languages.

This chapter will describe how I gathered and analyzed the data. The procedures and techniques used were primarily qualitative: through interviewing, observing, and event/network analysis. The informant's language history was reconstructed as a testimony of the life of a person with two languages.

\section{QUALITATIVE RESEARCH}

Qualitative research has been gaining acceptance as a valid way to understand language issues. According to Johnson (1992), "qualitative approaches to research have gained a strong foothold in L2 research" (p. 33). Because a one-sided quantitative approach cannot account for all the variables involved in language, researchers 
are increasingly employing qualitative techniques to provide flexibility and a holistic view of the issues under inquiry.

\section{LIFE HISTORIES}

According to Dobbert (1982) the process of recording life histories has two steps. First, an informant is chosen and interviewed by the researcher. The informant talks about her past in as much detail as possible within the constraints of time. Second, the researcher analyzes the ways in which the informant's life history exemplifies the general cultural patterns under research. These steps were followed in the present language life history. The informant was encouraged to talk about her experiences, her bilingual upbringing, her reactions to her two languages (English and Spanish), and her use of them.

\section{SUBJECT}

Rose was selected as the subject for this study because of her background and her interest in exploring how her two languages, English and Spanish, have interacted and influenced her during different periods of her life. Rose is a 39-year-old American of Mexican descent, who was born and raised in Stockton, California. Her parents were natives from Guadalajara, Mexico. Rose's family came to the United States to further her father's medical studies and stayed. Rose has lived all her life in the United States, except for three years (2-5 years-old), when she lived in Mexico. Although she 
spoke Spanish at home and in her visits to Mexico, she was not encouraged to maintain her language. Her schooling and environment outside the home were English. She did not study Spanish formally until she took Spanish in foreign language classes in high school.

Presently, she lives in Portland and works at a clerical job in a Catholic organization. She is married and has two children, who attend a Spanish immersion program at a local public school. Rose wants her children to learn a second language since she realizes the increasing importance of being a bilingual in the United States, and the value of preserving their Mexican heritage through their children.

\section{GAINING ENTRY}

I work at the same organization as Rose does and had met her a year before the study began. Although our offices interact for certain projects and workshops, they are completely independent from each other.

My first encounter with Rose occurred when I began working with the organization almost two years ago. Rose showed interest in my background since I come from a Spanish-speaking Latin American country. Soon after we met, she told me her parents were from Mexico, and that she spoke some Spanish. After that, language became a recurring subject in some of our conversations, and I realized that she was very interested in the topic. Furthermore, Rose seemed reticent to speak Spanish with me even though I was 
speaking the language. This raised questions regarding the reasons behind that reticence. I asked if she would allow me to interview her and write her language history, and she agreed to be my informant.

Because I already knew my informant independently from the study, gaining entry and her confidence was easier than if I had not known her before. The interviews took place in quiet places, conducive to conversation, Rose's residence, my office at our workplace, and the library of a local university.

During the event/network analysis, other subjects observed were Rose's supervisors and the visitors to her office. Because I already knew her supervisors, they easily became accustomed to my presence during the analysis.

\section{PROCEDURES}

The research for this study progressed through two phases. The first phase involved the interviewing process, the transcription of the interviews, and an event/network analysis at Rose's workplace. The research methods for the interviews were based upon Spradley's (1979) procedures for performing ethnographic interviews. The methods for the event/network analysis were based upon Dobbert (1982) and similar to those followed by Crocetti (1993). The second phase of the study was the analysis and writing of Rose's language life history. 
Interviews and Observations

Eighteen hours of interviews were conducted with Rose over a six-month period. The interviews were tape recorded and later transcribed verbatim. I also kept field-notes of the interviews. After each interview, I wrote for about 15-20 minutes, analyzing the interview and the major themes covered. These notes, along with the transcriptions of the interviews, were used to prepare for further interviews. The interviews, the field notes, and other notes were used to write the language life history.

The place for each interview was agreed upon by Rose and me in advance, so we could arrange our schedules. Sometimes scheduling was a problem because of Rose's obligations and family situation. Rose was always extremely helpful and willing to accommodate her schedule, within her limits, to have the interviews. We always tried to choose quiet places where we would not be interrupted. Interviews at Rose's residence generally took place on weekends and when her children were out. Interviews at my office in our workplace were held during our lunch hour. In one instance, two consecutive interviews took place at the library of a local university because one of Rose's children was sick. We tried to have at least one interview per week, but sometimes because of conflicting schedules between Rose and me, vacation time, and other obligations, we had to skip one or two weeks in a row.

Upon request by the informant, one interview was carried out in Spanish. The informant wanted to try to use Spanish within the 
context of an interview, which she considered a challenge to her proficiency in the language.

The interviewing process was done based upon Spradley's (1979) Developmental Research Sequence (DRS) for ethnographic interviews, which is composed of twelve steps to follow in interviews with informants. These steps describe interview techniques and tell how to locate an informant, make ethnographic records, ask questions, and analyze the data.

In accordance with the directions of the DRS, the first interviews focused on descriptive questions, such as grand tour questions to elicit general themes for further interviews. Once the major themes were defined, a domain analysis was performed to discover cover terms to describe the informant's culture. Later, structural questions were asked to discover the components within the terms and perhaps new terms. Also, more descriptive questions were asked. When this phase was completed, taxonomies were defined and then confirmed with the informant through contrasting questions. Throughout the entire DRS process, combinations of the different types of questions were used in the interviews.

Questions and anecdotal material directly related to the informant's language development and language use were extracted from the transcripts and analyzed in order to discover the different themes that were emerging as a result of the interviewing process. This was done two times: after the first nine interviews and again after the second nine interviews. 
During several interviews that dealt directly with Rose's language use domains, questions from Gal (1979) were used. Rose was also asked to complete two charts having to do with language use domains (see Appendix A). These charts were structured as a result of previous interviews and listed the areas of past and present language use Rose had reported. To complete the chart, Rose marked whether she used English, Spanish, or both languages in each of the listed language domains. Her responses and descriptions while completing the charts constituted part of one of the interviews.

The importance of these two charts to her language history is that Rose was analyzing her language use based on a list of domains which directly emerged from the interviews. This list was not predetermined by me or based upon other researchers' lists. The reason I did not give her a list of language domains was because other people's language domains would not apply to Rose's unique use of English and Spanish, which was captured in these charts.

In addition, Rose was asked to read and respond to excerpts (see Appendix B) from Richard Rodriguez's book Hunger of Memory (1982) and Eva Hoffman's Lost in Translation (1989). These books were chosen because of the experiences their authors wrote about their lives with two languages. I chose several excerpts from different parts of the books that dealt with the writers' language experiences as they were growing up, the ways in which their perceptions of their two languages and cultures changed, and the changes they experienced with their languages throughout their lives. The purpose of this exercise was to elicit Rose's opinion about 
the writers' experiences and to see if she could relate her own experiences to theirs. Rose was given a week to read the excerpts. An interview followed; the results of which are a component of Rose's language life history and are reported in Chapter IV.

During the six-month period of interviews, I was attentive to any comments made by Rose, conversations between Rose and me outside the interviews, and anything else I considered relevant to the study. This material was recorded in the field notes. For example, Rose once commented that Hispanic Month was being celebrated, and was the topic of several newspaper articles. Her impressions of these articles and programs were recorded in the notes. Observations of Rose at her workplace were also recorded. For instance, I once happened to see Rose relating to some physically challenged visitors to her office. Because this interaction revealed characteristics of her personality, it was recorded in my notes.

\section{Event/Network Analysis}

The aim of doing an event/network analysis for this research was to define the social structures in operation in Rose's present life, and to determine how her social contacts could trigger the use of either English, Spanish, or both. According to Dobbert (1982), "In network analysis, the researcher studies the social process in a manner that forces that process to reveal clues about the underlying social structure" (p. 160). Dobbert states that a network analysis reveals the structural aspects of a social situation through the repetition of behavioral patterns that give form to the social entity. 
Fasold (1984) underscores the importance of event/network analysis because it allows the researcher to study the different choices individuals have within their own culture, and that, in turn, allows the culture's deeper structures to be revealed.

For this study, a network analysis was performed during an eight-hour work day at Rose's office, on what Rose termed a "typical day." Rose selected a day on which she felt she would not feel disrupted and on which her supervisors would not feel that the office work was being interrupted. Rose's supervisors were notified in advance of my presence on the particular date, and they agreed to participate in the analysis. The interactions during the analysis were recorded in a form (see Appendix $\mathrm{C}$ ). The results of the analysis are presented in Chapter IV.

Although in the original proposal for this study it was stated that an event/network analysis would be performed at Rose's home with her family, this could not be done for reasons of the informant's privacy. However, informal observations at her home during interviews gave me an idea of the interactions between Rose, her husband, and their children.

\section{ETHICAL CONSIDERATIONS}

The informant's identity was kept confidential at all times, and a pseudonym identifies her throughout this thesis. She gave pseudonyms to the people that she wished to remain anonymous. The informant's permission to use the material from the interviews, 
observations, and network analysis was obtained through a consent form.

Before the interviewing process began, I explained to the informant the purposes of the study, and that at any point during the study, she could request information not be used for the final language life history. As it turned out, the informant did not restrict any portion of the material.

\section{LIMITATIONS TO THIS STUDY}

Because this is a case study, it cannot be generalized to a larger group. This study analyzes one person's experiences. The informant's experiences are unique to her, and they do not necessarily apply to all immigrants coming to the United States.

The value of this study relies mainly in the testimony of the informant as an example of how an immigrant felt and experienced her life with two languages.

Another limitation is that eighteen hours of interviews may have only revealed parts of the informant's experiences. More interviews may have revealed other aspects not covered in this study.

Furthermore, because of the interview-based nature of this study, it was limited to the informant's self-reporting, which may or may not have told the whole story. Sometimes the informant said she could not remember things exactly. This may have affected the results of the study. 
Finally, event/network analyses were not done at her home or other social settings besides her workplace. Had these analyses been done, other details of her life may have emerged, which are not covered in this study. 


\section{CHAPTER IV}

\section{ROSE'S LANGUAGE LIFE HISTORY}

\section{INTRODUCTION}

This chapter presents Rose's language life history. In it, Rose narrates her life in her own words and describes the ways in which her Spanish and English influenced different parts of her life as she was growing up in Stockton, her family, friends, school, and jobs. She also describes the ways that her two languages influence her life at present.

Rose's language history is an example of the ways in which children who are born into immigrant families grow within the context of their families' native language and that of another language, the one spoken outside the home in the community to which the family has immigrated. In this chapter Rose recounts that she began using Spanish at a very early age in her childhood, but when starting school, she needed to use English. She also tells how English gradually became the dominant language in her life, and how the family's Spanish began to erode because of the influence of the English each family member brought into the home. These events had a very significant influence on Rose's language development and on her proficiency in Spanish. 
Rose's willingness to participate in this study was due to her hope of discovering the reasons for her present difficulty in using Spanish with ease and fluency. As we examine her life, different reasons for the erosion of her Spanish become discernible. First, although as a young child, Rose used Spanish most of the time, her neighborhood, her school, her brothers and sisters, and her community at large spoke English. This created a unique mixture of languages in her own home. Second, Rose's parents played a very important role in English becoming the language most used within the family. Rose's parents had seen their older children experiencing difficulties at school. They wanted their children to succeed in school, so they allowed them to use English freely at home. They themselves began to use English more than Spanish as time passed. At the end of her narrative, Rose says that at present she would like to use more Spanish, but she feels unable to because her proficiency in the language at this time, she feels, is inadequate.

Rose's language history has been divided into seven parts. Parts one to six are comprised of her narrative. Within the narrative, part one sets forth her general background while parts two through six specifically chronicle her language narrative. Her background has been separated from the rest of her language history in order to provide, in her background, a basic description of her life before detailing her language history. Thus, part one gives a frame of reference for the characteristics of her life.

In parts two to five, Rose presents her experiences with Spanish and English throughout her life. The division of these parts 
emerged from the interviewing process. Each section is entitled according to an important event or special characteristic of the particular period in Rose's life and contains anecdotal material. All these are in chronological order, except for part two.

Part six concludes her narrative as she responds to the language histories of two bilingual authors and relates her bilingual experience to theirs. Part seven completes Rose's language history by presenting the results of an event/network analysis conducted at her workplace.

Italics are used in quoting Rose's words throughout this language life history. Brackets are used to indicate words Rose has omitted in her narrative, and three periods are used to show Rose's pauses and false starts. In the other chapters of this study, quotation marks are used when quoting Rose.

\section{PART 1: ROSE'S BACKGROUND}

\section{Introduction}

In this section, Rose details experiences from her family life, her school life, typical celebrations at home, her activities, her trips to Mexico, her college life, and her life in Stockton. This background is presented in a chronological order. The various events that Rose describes address many different areas of her life experiences. This background information make possible a fuller understanding of Rose's language narrative in parts two through six since some areas 
of her background will be re-addressed later in the more specific language history.

\section{$\underline{\text { Rose is Born }}$}

On March 11, 1954, Rose was born in Stockton, California to Jose and Maria, the seventh in a family of eight children. Her parents were natives of Guadalajara, Mexico, and were living in the United States where Rose's father was a medical doctor. Two years after Rose was born, the family moved back to Mexico. Although the move seemed permanent, three years later the family was back in Stockton to stay. Here is Rose's account of her family's story and her first few years of life:

My dad was a medical student in Mexico and came to the United States for his internship and was planning to go back to Mexico, but they approached him, a doctor at the hospital that he was working in San Francisco, and told him that the San Joaquin Valley was in real need of a Spanish speaking doctor. He asked him if he was interested in the job. That was during the 40's.

Then, my mom came to the United States when they were first married, so my dad could do his residency up here in the United States. And then, because of pressures from his relatives, especially his father, they moved back to Mexico. They had the first child, the oldest brother, in the United States. When they moved back to Mexico, it seemed like a very permanent move because they built their house, and my dad started his practice down there. But, eventually, my mom just kept asking to move back to the United 
States, but she never explained why. She just said she felt more comfortable in the US. I think that she was unhappy. It seemed that finally it was some of her relatives, her uncle or something, who suggested to my dad to go back.

Rose does not remember the move to Mexico itself. She has an image of these marble floors where we played, at her home in Guadalajara on a very busy street where other relatives lived. Her house in Stockton (see Appendix D) was a long ranch-style, one-story house. What I most vividly remember is the pool on the back. In Stockton it was very warm, especially during the summer, and just being able to jump into refreshing water was wonderful. I remember feeling so lucky that I had a pool. Sometimes during the summer, we would have friends over to barbecue and pool parties. The house had a light blue type of decorative theme, with the living room being on the greens and blues. I would always remember right above the main couch in the living room, there were these two huge paintings of bullfight matadores.

\section{Stockton and Its Surroundings}

Stockton consisted of three parts: the north, the south, and downtown (see Appendix E). Rose's family lived in a new area in the northern part of Stockton. Her parents had their house built, one of the first in the neighborhood. Downtown Stockton had three main thoroughfares: El Dorado, Pacific, and Pershing avenues. Along the western end of Pershing Avenue were residential areas and shops. Rose's high school was located near El Dorado as was her father's 
medical office, so she often went to her father's office after school. Her grammar school was located near the south part of Stockton. Both her high school and grammar school were Catholic and co-ed.

Southeast Stockton was the poorest part of town and was associated with crime and violence. Also, a higher concentration of Mexicans lived there. The few times Rose was in this part of town, she remembers seeing the store signs in Spanish. Further southeast, there were agriculture areas where the migrant workers lived. Rose's father sometimes volunteered at a migrant workers' clinic, where most of the patients were Spanish-speaking. Whether at the clinic or in Rose's father's regular practice, the patients were Spanish-speaking people.

\section{Family Life}

Rose's family was large. Her father, Jose, was born and raised in Guadalajara, Mexico, one of nine children in an old family of Guadalajara that had lived in the area since Colonial times. Rose's mother, Maria, was the daughter of two French immigrants. Maria's father was an orchestra conductor. Maria herself was born in Colima, Mexico, and was raised speaking Spanish and French.

Rose remembers her family life very fondly. One of her most vivid memories is the smell of her home: The smell that I most associate with when I was growing up is the smell of beans cooking. My mom would always have a pot of beans on the stove. This always takes me back to growing up. 
Rose's family was composed of her mother and father and eight children. Her older brothers and sisters were Luis, Cecilia, Carlos, Joseph, Laura, and Maria Luisa. Her younger sister's name is Patricia. Coming from a large family, Rose had to share things: I shared a bedroom at one time with other three [of my] sisters. So there were four of us. It was a long, large room. So, gradually, each one of us moved out of the room. It is interesting that coming from a large family, you are always moving around. I did not have a space that I could claim as my own. I never really developed a kind of collection of trinkets or stuff. I remember a couple of friends would talk about their collections of frogs or pins, or little statues or dolls or something. But I just never developed any interest like that.

She describes her childhood as a typical and normal childhood with parents on whom she could fully depend and in whom she found security. They lived a normal life with none of the large problems experienced by other families she has seen. She had a close relationship with her three sisters, Laura, Maria Luisa and Patricia, who with Rose were the younger children. She remembers the other brothers and sisters, Luis, Cecilia, Carlos and Joseph, but more vaguely since the age difference was quite big. When she was in grammar school, her older brothers and sisters were either in high school or in college. So, she mostly remembers her interactions with her sisters at home. Rose, her three sisters, and other neighborhood children played hide and seek, jump rope, and other games. Rose liked to play in the empty fields and jump in the tall grass with her friends. 
Rose remembers waking up early on hot summer days, going to the kitchen, and finding her mother preparing breakfast. Rose would have breakfast and get ready to do her projects. Every summer Rose made a list of projects she wanted to accomplish during the summer. Typical projects included sewing and doing crafts, which she still enjoys. Rose would also work on her typewriting skills or learn a new sport.

\section{Rose's Parents}

Rose's father had his own practice. Every morning he left the house at six o'clock and went to Mass at the chapel in a Catholic hospital near his office. He would return home around six in the afternoon for dinner.

Rose's mother was an excellent cook. She always had three or four courses for every meal. To Rose, their food was normal food, but it always had a Mexican component to it. Her mother always put warm tortillas on the table (instead of bread), just as is the custom in Mexico. At least three times a week they had refried beans, but Rose's mother also always served meat because she wanted to be certain of providing adequate nutrition for her family and because meat was an essential part of the daily diet in Mexico. Other typical Mexican food they had was a type of corn soup called pozole and chayote, a vegetable similar to sweet potatoes that her mother cooked, peeled, and served in chunks. Very special Mexican foods, such as stuffed chiles and enchiladas were prepared only when the family entertained guests. Rose loved those meals. 
After dinner her father worked in his study or read, and her mother was always nearby. The children were free to do what they wanted, such as watching television, playing records, playing with neighborhood children, reading, but invariably at eight o'clock, they would be called to pray the rosary. This was a custom of Rose's family. Her parents were Catholics, and her father, especially, faithfully followed the teachings of the Church and the Pope, and instilled in his children the love of God and the importance of being Catholic. Catholicism was to Rose the most important aspect of Mexican culture that her parents retained and imparted to their children.

\section{$\underline{\text { Rules of Behavior at Home }}$}

Although all parents set up rules of behavior for their children, Rose felt that somehow her parents' rules were different from those of other families she knew. Rose and her siblings knew that they were not to speak out unless spoken to and that they were to know their place: I remember just feeling that there was a definite set of rules like not to speak out, knowing your place. I think I learned just to watch what I said. You know, edited remarks. You knew what you could not talk to my parents about. There was just definitely these regulations as far what you should or should not talk about.

Other rules of behavior related to friends and social activities: My parents laid down rules about what they expected about our behavior, and had a big say about who we should be friends with. 
But, to them it was important to know whose parents these friends had, rather than getting to know the friends. Also, in high school we had school dances, which my parents were against to, and actually they evolved a whole lot from my older brothers and sisters. To go anywhere they needed to bring along a younger brother or sister, and even just to go out, just informally with a friend. So, my parents were strict with the older ones. By the time they got to the younger ones, they were not quite so strict, but compared to what my friends got to do, they seemed pretty strict.

Rules applied at dinner time too. Rose comments: There was not too much talking going on at the table. There was definitely the thing that the kids should be quiet unless they are spoken to. Sometimes, a conversation got started about my dad's day, and if it had to do too much with something unpleasant medically, my mother would not want that to be discussed at the dinner table.

During her childhood Rose began to realize that there were differences between her family and other families. The rules around the house, the interaction of her parents with the children, the family activities, the food, and the language were some of the differences that she noticed: When I was a child I started developing friends in grammar school and the neighborhood, and I saw such a big contrast between their family situations and our family situation. I felt I had a happy home life. It was not that theirs were happier and mine was not. I noticed the differences when I started to see how other families lived and interacted, much more informally, you know; my family just seemed to be very formal. I remember one friend of my 
sister once walked in the house and said: "Hi, Doc! What's up!" And my dad got upset and told her he did not like being called that. To Rose's father, propriety and respect were very important.

Rose's father also felt that American society was too lax with its morals. He felt that in American society the moral fibers were just falling apart, and that they wished they had raised us in Mexico. My dad held Mexican culture up so highly because they saw the Mexican society or culture as being much more religious and faithful to the ten commandments or to living a rightful life, more spiritual. They saw Americans as more materialistic and not moral enough. They felt that Americans were too free and liberal, especially raising kids. They just thought, overall, that society was not strict enough with their children, so they did not want to be part of that. Rose adds that her mother would just prefer us in the house. And, maybe this was because she was not all that familiar or comfortable with American society, and my dad shared similar feelings.

At the time, Rose felt that her parents' picture of Mexico had been true when they were young, but that it was no longer accurate because Mexico had changed too: When we visited Mexico, and I would go out with my cousin's friends, I saw that they were able to do things that I was not allowed at home. For example, staying out later than midnight.

In the area of parent-child interaction, Rose remembers feeling that some of the American parents she knew were much more informal than her parents. Rose remembers the Burkes, who were her neighbors: The Burkes were really a memory while growing up. 
They were Irish, a very Irish family. They even had an Irish setter dog. They had six kids close in age to us. They would always come over, or we would always play outside all the neighborhood games with them, like hide and seek and all those things. Their relatives would come from Ireland, and they would have an Irish accent. I remember their interaction as a family. I remember it being very informal, lots of joking around, and teasing with the kids. Thus, as a child, Rose considered the Mexican life-style to be more formal while the American life-style she considered to be casual, characterized by humor, joking, and laughter, and this is also her current view.

Rose also remembers another couple, friends of her parents, who sometimes came to baby-sit. She remembers that couple as a totally American type. He worked for the railroad, and she was a homemaker. Rose remembers that he was the kind of person that would play with the kids and really kid around with them. And that was very different, a different approach. With my parents was just a very formal interaction.

In enforcing rules, Rose's parents generally took that attitude of "what I say goes. I do not have to explain it to you." I do not think they ever gave much of an explanation really [for the rules].

\section{Celebrations at Home}

At Rose's home, important celebrations were related to the Catholic religion. The most important celebrations were Christmas and Lent. For Rose, Christmas was celebrated like in any other Catholic home. Christmas would start on the night of December 24th, 
when the family went to Midnight Mass. Rose remembers how hard it was to stay awake until midnight. After returning from Mass, they went to bed. On the morning of the 25 th, the main focus was opening the gifts, and afterwards, in the afternoon they had a festive dinner. During the Christmas season, Rose's home was decorated. We would have lights in the outside, and a white tree was brought in. It would have all kinds of ornaments. Also, we would have a Nativity. During Christmas dinner they would have a roast or a turkey and a sweet potato casserole. The stuffing for the turkey would sometimes have a Mexican flavor to it, with a lot of raisins and nuts. Rose feels that their Christmas celebrations were much similar to those of Americans, except for Midnight Mass, which her parents observed because it reminded them of Mexico.

Lent was a period of change and renewal when the family members needed to give up something to show a change in their lives. Rose says her parents always tried to find something that the children could give up for Lent. Typically, they gave up candy, chocolate, or dessert during the six weeks before Easter. Rose jokes, it was always tied to food! Just before Easter the family went to church on Holy Thursday and Good Friday, and on Easter Day, they went to morning Mass. When they got home, the children always looked for their Easter baskets, which their mother had hidden around the house.

When Rose reached college age, the meaning of Lent changed in that she then gave up different things. You would have to find something, almost like New Year's Resolutions when you find things 
you would like to either improve on, for example, to maybe do something for somebody that is helpful, or do something to help out. Lent was then a time of giving up and a time for change.

Other times of celebration in Rose's family were birthdays, complete with party guests, cake, and presents. However, there was something even more special about birthdays. Rose's parents named each child after a Catholic Saint or a relative. In this way, her parents honored their relatives and the saints in the Catholic tradition.

Finally, there were celebrations related to Catholic sacraments; for example, in second grade Rose had her First Communion. She remembers this time as a very special thing that happened to her. The day of the ceremony I thought it was such a special time. I remember that we were a huge number of kids [in the church]. It just seemed like I was just part of something so neat. First, I went to Mass as part of the ceremony. We [the children] got to sit in the front, and when it came time to receive communion, our group was the first one to receive it. So, we would just file along and go up and receive the communion, one at the time. Then we just went back to our pew. So, that was really pretty much the extent of the ceremony. I remember standing besides this statue to have my picture taken, and then I just remember as I was filing up to receive Communion. It was like I was the only one there. I felt that special, even though I was in a group of 50 or something. I had a white dress. I remember it very well. It was short. I know in Mexico...I remember seeing pictures of my relatives in Mexico, and you know, they would 
be wearing long dresses. It seemed much more fancier than what I had. They would hold a candle, and their mom and dad would be standing next to them. It just seemed much more of a ceremony, almost like a wedding. That is the idea I got from the pictures. They had a veil. I think I just wore a little round, lace wreath on my head, and I did not hold any candles. [In Rose's First Communion] the boys wore a small suit. But, you know, when I think about the pictures of my relatives, ours were definitely nice clothes, a little bit nicer than Sunday clothes, and maybe just because they were all white, but it was not a really fancy set up like the one in Mexico. And with the boys, it was nothing particularly outstanding.

\section{Visits to Mexico}

Every two or three years, Rose's family made a short visit to Mexico that lasted several weeks to a month. For Rose, unlike American families who seemed to have summer vacations and regular weekend outings, her family was pretty much home based. The family considered one or two weeks at the beach to be a treat, but the visits to Mexico made some summer vacations really special.

For those visits all the family went to Guadalajara. The children were divided and sent to stay with different sets of relatives, according to the age of the family's children. The older brothers and sisters usually went with Rose's mother's relatives, while the younger ones stayed with Rose's father's relatives. Rose generally stayed with her Tia (aunt) Lourdes, whose daughter Carmen, nicknamed Quiquis, was Rose's age. 
Rose developed a close relationship with her cousin, Carmen. The days in Mexico passed slowly and happily. Both girls spent their time playing card games or tennis, and taking handicraft classes. Rose remembers taking a course with a woman down the street. Each one of us would take a loaf of white bread and mix it with glue, and you would make this type of craft project with flowers. The petals would be made out of this bread, and we would paint them. Such creative activities were very enjoyable to Rose.

Because Rose's father's family had been long established in Guadalajara, there were many relatives nearby. Tia Lourdes's house, where Rose stayed, was a big, old house located in an older neighborhood with houses that have been there forever. Rose remembers the tile and the hardwood floors in this house, which were so different from houses in the United States. The house had many antique furnishings, which lent it an air of richness. The house also had a large, open patio because of the heat and a spacious kitchen with a big stove. Rose still describes Mexico and its houses as revolving around the kitchen because it seemed that the kitchen was the center of the activity in the house.

During the visits to Mexico, Rose came in contact with things that were different from her environment in Stockton. First, she had to speak another language. Although she spoke Spanish in her home in Stockton, in Mexico she had to use it everywhere, all the time, and for different purposes. She felt she understood the language well in Mexico, but speaking it was a problem. Second, the food, the surroundings, and the air were very different in Mexico. She 
especially recalls the wonderful memories of the food. The food stands on the street, the market places, and the candy. In the market places there were things that were so unique that we wanted to buy them all. There was just a different smell and atmosphere to Mexico. Rose describes Mexico as having a rich texture type of feeling. Part of this feeling is the extended family of aunts, uncles, cousins, grandparents, and great-grandparents that characterizes Mexican families. During a typical day visiting the local market place she could see the colorful and tangible environment with bright pinks, yellows, oranges and red, and the customs. Also, in Mexico you see the ancientness and the old buildings, and the ruins and the pyramids, the ancient cultures. In Mexico, Rose says, one can see and touch this ancientness; whereas in the United States, one finds it only in books. Another difference in Mexico was religion, which is much more alive and part of the culture, where people live religion as part of their lives.

\section{High School and College}

Every time Rose returned to Stockton from a visit to Mexico, she felt happy to be back home, back with her friends. High school for her was normal and typical. In high school, Rose had a friend of Italian descent, Lori Girardi. Together they formed a group of friends that frequented drive-ins after school, went shopping, and visited with other friends. Rose also enjoyed doing things by herself, such as swimming and playing tennis. She joined the volleyball team, where she met a girl of Mexican descent, Michelle Muniz. 
Michelle had many relatives in the area, and they often hosted typical Mexican holiday celebrations. One Christmas, Michelle invited Rose to tamales after Midnight Mass. She remembers being surprised by the large number of people at the gathering. For Rose it was a revelation to see that there was something else to being Mexican.

Because in high school Rose began to be conscious of her environment, she also became more aware of her background and began to feel that there was something different about her upbringing. Stockton had a high concentration of Spanish-speaking people, especially in the south part of town, where many migrants and farm workers lived. The people in Stockton identified the migrants and farm workers as Spanish speakers with poor English skills, who were uneducated, poor, and unemployed. Furthermore, they were viewed as trouble makers because they were involved with drugs, alcohol, and crime. These negative images affected Rose because, although no one at school ever said anything to her, sometimes she thought, this group is not well regarded, and she did not want to be identified with them. At the same time, she realized that her parents and her relatives in Mexico, who were middle class and of European descent, were embracing Mexican culture. Her Mexican relatives were well-educated professionals, who had even come to the United States for their professional training. People in Mexico thought of them as Europeans, and in the United States people confused them with Europeans. Nevertheless, during those 
teenage years, Rose sometimes had the uncomfortable thought that she was different from other Americans.

After graduating from high school, Rose majored in business at Santa Clara College, near Stockton. College represented a change in her life. Like many other high school graduates in the United States, going to college meant achieving more independence and living outside the home, away from parents.

She enjoyed all her college classes, but especially the ones where the teachers were really dynamic. It is not that the subject matter stood out as something that I connected with, but it was more the teacher who motivated me.

Although away from home, Rose felt that there were still boundaries that I needed to operate in. Her father's overprotectiveness and strictness with the girls in the family did not apply in her case, since she had always been a shy, quiet person: I went to college and led a very, what I would call a not wild life at all. I always went to class and did what I was supposed to do.

\section{The Jesuit Volunteer Corps (JVC)}

During Rose's senior year at Santa Clara, she became more in touch with her spiritual life. In a meeting at the Newman Center on campus, a Jesuit from the Jesuit Volunteer Corps (JVC) asked the students to volunteer their services for one year for the less advantaged in society.

For Rose, it seemed a lifetime opportunity before jumping into a full-time job life style. When the Jesuit came to talk, it struck 
something in me connected to my growing spiritual life that I just thought it would be worthwhile to do something helpful. The funny part is that after I graduated, I did get a job with a department store in San Francisco as a buyer, but I decided in favor of the JVC, and did that instead for two years. One year I was in Seattle working at a parish as a Physical Education teacher and Youth Minister, and then, the second year I worked in Portland in the offices of JVC. I related very much with the values of JVC. The values of simple life-style were very anti-business, which was my degree, you know, the whole materialistic part of life. So, at the end of my experience, I was antagonistic about going back into the business world.

The Jesuit Volunteer Corps also gave Rose a new appreciation of her background. One of the values promoted by the JVC, the acceptance of others, gave Rose a new measure of self-awareness and acceptance. The JVC also encouraged going back to the roots of one's heritage, which furthered Rose's rediscovery of the importance of her Mexican background.

\section{Marriage and Present Life}

Rose's Family. Most of Rose's extended family now lives in California and Mexico. Before her father's death (last year), her parents lived in Mexico, but her mother now also lives in California with one of Rose's sisters. Rose still has relatives in Mexico, but she does not visit them frequently. Rose herself presently lives in Portland with her husband and their children. The two children, Rachel (11 years old) and Matthew (9 years old), both attend a 
Spanish Immersion program at a local public school. When choosing schools for their children, Rose was happy that she was able to place them into the immersion program because she realized how important bilingual abilities will be in the future, and how important it was for her family to maintain its heritage. Already her children can read whole chapters in books in Spanish, and they are quite proficient in the language for their age.

Through her children's school, Rose learned more about Hispanic culture and the countries in Latin America. This has given her a new perspective on the richness of her cultural heritage. She feels that living in Portland and having her children in the immersion program have caused her to experience a new, open environment. She says, I feel that the atmosphere...that I just notice that...while I was growing up I felt a real feeling of prejudice toward Mexicans. It seemed like now I am noticing more of an appreciation, kind of, of what they bring with them as far as their heritage. That has helped me not to be so defensive. As she continues her description of things she now perceives as more open, she adds, Language itself. It seems people now think it is a real opportunity to know two languages. It is very different how my feeling is towards Spanish than any other language or towards Mexico or any other country. I feel I can claim Mexico as my own, and I want to connect with it and the language. I feel this emerging, just really wanting to make that connection, feeling that would be a real value to us to connect to that part of our background, you know, my kids and I. 
Rose's Occupation. Rose works as a secretary in an office, where she divides her time between four bosses, who manage three different divisions in the organization. One of the divisions is involved with working with people with disabilities. I have frequently observed Rose's unique skills in relating to people. Once I happened to see her at our workplace coordinating some work for a group of disabled young people. She greeted them, helped them begin, and explained to them what she wanted them to do. Her love, care, and respect were evident as she talked with this group. Since it was nearly St. Valentine's Day, the group had bought a card for Rose, to show how much they appreciated her. When she received the card, she was moved and thanked them. Everybody in the group appeared happy and thankful for Rose's help and friendship.

Although she has a fast-paced schedule and many duties to perform, she always has time to talk with people. Her bosses appreciate these special skills that make Rose uniquely suited to her job.

The preceding section, ROSE'S BACKGROUND, has provided a general biographical account of Rose's life as a background against which to view the remainder of her life history. The following sections of her life history specifically address the issue of language in her life, her language development, and her language awareness as a speaker of two languages. 


\section{PART 2: FIRST MEMORIES OF LANGUAGE}

In this section, Rose recalls her earliest memories of speaking Spanish, memories that date back to her middle school years, between 10 to 11 years old in Mexico. This part, FIRST MEMORIES OF LANGUAGE, has been placed first in her language life history and is not in chronological order because these First Memories of Language that Rose narrates are very vividly present in her life. They in fact constitute a marker event in her life because it was at this period in her life that Rose realized that English and Spanish were two different languages, that her proficiency in the two languages differed, and that somehow, her ability to communicate in Spanish was changing with time. These are Rose's own words about her first memories of Spanish: I do not remember speaking Spanish. I think I do not know how far back I can remember. I do remember that I always felt uncomfortable with my language. It was interesting that I usually had to struggle with my Spanish. You know, I never felt that comfortable with it. My first memories of speaking Spanish were when I was visiting Mexico. It was just hard to speak Spanish. I could sit in a room with people and, you know, I could find out what was going on in the conversation, but I never felt comfortable. And, you would think I would be better towards the end of our vacation, but it just would not come. This was when I was middle school age. Ten to eleven years old.

When visiting Mexico, Rose spent the majority of her time with Carmen (Quiquis), her cousin. Although she had visited Mexico 
before her middle school years, it was not until this time in her life that she began to experience problems with her Spanish: I do not know if I remember the younger visits there well, but when I was older, when we were in a situation of mixed groups of boys and girls, then I would feel extremely uncomfortable. It could have been part my shyness and part of it the language, but I just do not remember ever feeling comfortable and fluent with my Spanish. There would be my cousin and a couple of her friends and distant cousins once in a while. We would go and have coke and french fries, and they would be busy talking about what was going on with their group of friends, there in Guadalajara. I would not tune it [the conversation] out; I would be right there listening and, you know, laughing when something funny was said, and paying attention, but not contributing much unless I was asked a question. In their questions they would be curious to know what life was like in the United States, but there would not be a lot of interacting. They would like to know the home rules, you know, how long you can stay out, do your parents let you do this or that, but I just do not remember all that much. It was not a lively conversation. My answers would be in broken Spanish, where I would be searching for a word in Spanish or maybe not using the right verb tense, you know, very short kind of answers. What happened to Rose's Spanish? What happened in her environment that hindered her learning of Spanish? When and how did she use English and Spanish? The following examination of Rose's experiences with Spanish and English seeks to answer these questions. 


\section{PART 3: A LISTENING CHILD}

\section{Introduction}

This part goes back and explores Rose's early childhood in Stockton, the time leading up to the marker event period described in the previous section, FIRST MEMORIES OF LANGUAGE. Here Rose narrates experiences growing up with English and Spanish within her family life, at school, and during her earlier visits to Mexico. She describes the language patterns of her family members and their different uses of the two languages. She also tells about learning to read and write in Spanish. The most significant finding in this section is that Rose characterizes herself as a listening child. According to Rose, this characteristic assisted her in learning and adjusting to new situations, many of which involved language. She used this trait constantly during her childhood, and even today, she feels she is still inherently a listening person.

As a child, Rose remembers being continually attentive to the world outside, ready to learn and hear new things: I was extremely reserved until I was able to communicate [in the language]. I feel like a strength of mine is that I am a good observer, and I can pick things up, and kind of put things together from observing. I am kind of a good detective (laughs), you know, kind of figuring out things by my own. I just feel like I just kind of always had my tuners up as far as...hmm...not necessarily at home, but outside the house because everything outside the house was new and different. [The outside 
world] tended to provide a lot of...kind of different...new experiences, and, you know, I was interested and tuning into hearing things around me.

Rose's brothers and sisters were good listeners also: I could imagine my brothers and sisters being similar to me in that we tend to try to be invisible in new situations until we felt we could handle it. We tended to be very quiet and not participate. It was just more silence until we could speak the language [English]. My brother and my mom said that the kids were hard workers in trying to get along and trying to understand and learn the language [English].

\section{$\underline{\text { Rose's Home }}$}

This characteristic of Rose and her siblings of being good listeners was directly related to the fact that they lived in two languages. At home, Rose heard Spanish, especially from her mother and the housekeepers, while her father combined both languages. The children spoke mostly English, but used Spanish in certain circumstances. The fact that English and Spanish were always part of Rose's home life, coupled with the characteristic of being a good listener, made her transition from Mexico to the United States easier: Our transition was smooth. We had each other in all our moves. It made it really easy to adjust. My mom thought that things were easier also because we spoke English and Spanish to each other. I do remember a lot that when we were young our games, like jacks and a lot of floor games. We would play with my sisters and brothers. 
These statements by Rose reveal that in her case, being a young child using two languages was not a struggle. She does not recall any difficulties or sharp contrasts between the environment at home and those outside of her home. Though Spanish was the predominant language at home, Rose was not forced to speak Spanish, but was free to use English at will. One of her memories is praying the rosary together with her family in the evenings: The family time would be saying the rosary together, and, you know, now that I think about it, the rosary would be sometimes in Spanish and sometimes in English because one time I remember we would be saying the rosary, the phone rang, and I ran to answer it, and I said: "Hail Mary!" I remember saying it in English. So, I must have been saying the prayers in English too.

The mixture of English and Spanish was always present at home. Her parents had different proficiencies in English; therefore, their use of either English or Spanish was affected by their own proficiency in the language. My dad was very proficient in English, even though he kept his Spanish accent, but he spoke Spanish and English in his job; whereas my mom did not really learn much English, so she still feels much more comfortable with Spanish, and has a pretty heavy accent and often people cannot understand her English.

Rose usually used more Spanish with her mother than with her father. I am trying to picture myself with the time period [her childhood]. Well, generally thinking about the past with my dad, I 
would put with my dad more English, but with my mom, I just think I would tend to think [I would use] a little bit more of Spanish.

Rose's memories of warm summer mornings reveal more about her language use with her mother. Rose would walk into the kitchen and see her mother. I would say hello to my mom and give her a kiss. I think she would ask me what I would like to have for breakfast. She always wanted us to eat a lot. I think she would use Spanish, but I would answer in English, but, I think, my bits and pieces of Spanish would get in my answers. When I think of my mom, most of the times it would be Spanish that she would be speaking. I can remember that when she was on the phone arranging appointments in Stockton, and I remember noticing that her English was very difficult for other people to understand. She would often have to repeat herself, and that was frustrating for her. And so, I can picture her feeling more relieved after talking on the phone and talking more freely in Spanish.

Rose's father, on the other hand, usually spoke a combination of English and Spanish. I think he would be more of a combination. Where, you know, my mom spoke mostly Spanish around us, my dad combined them. My mom has recently developed half-English/halfSpanish when I was college age. She, in one sentence would mix both. When my dad would get upset about something, he would use his Spanish.

Because at Rose's home the use of English and Spanish was combined for the benefit of the children, the use of Spanish varied. Rose's mother was essentially the only source of Spanish Rose had at 
home because her father and siblings usually spoke English. Thus, theirs was a household where the mixture of language was a matter of everyday life, and as Rose says, that was the way things were.

For a period of five years, two housekeepers that Rose's parents had brought from Mexico were another source of contact with Spanish at home: When I was very young, and we were moving back to Stockton from Mexico, my parents were able to find women from Mexico to help in the house. So, when we moved to this house when I was in kindergarten, they came with us. They were two sisters, Lencha y Maria, and they only spoke Spanish. They stayed with us for five years. I got Spanish from them. They would only speak Spanish, so I did not have any choice but to speak Spanish too. Rose does not have any specific memories of the sisters, only that they were present in the house, cleaning and cooking, with their white aprons, flowered dresses, and long, black braids. She does recall though that they spoke Spanish with her.

\section{Children of a Bilingual Home}

Being children of a bilingual home, Rose and her brothers and sisters developed different proficiencies in Spanish and English. Each of their experiences was unique. Rose reflects on her siblings' experiences with their languages, and on the current uses they give to them. Rose recalls, for example, that her older sister spoke more Spanish to her parents, that her older brothers and sisters were held back in school, and that some of her siblings have a Spanish accent to their English, even after many years of living in the United States. 
Rose drew a diagram of her family, which is included in Appendix F, while describing her siblings' proficiencies in Spanish. The following is her description:

The first to the sixth child were all exposed to schools in Mexico and the United States. And I know some of them were held back a year in the United States. But I do not know all the details. It took them sometimes a year to catch up because of the language. So, I think, maybe my parents seeing that the older ones were having a difficult time with school...initially really, because eventually everybody did fine and went through college...but, maybe initially it was a little bit of a struggle, so they wanted to help us and not burden us with the language.

It's interesting. Let me go through my brothers and sisters. The oldest is Luis, and that is the one who is now living in Mexico. He has his family there. Ceci or Cecilia is the next. With her husband after they were married--he is totally American and did not know any Spanish--but they moved to Mexico, so he could go to medical school there. So, she helped him through the school program without him knowing Spanish. So, I think the older ones, having been in school in Mexico, were very fluent and comfortable. Ceci and Luis were in high school when they came back to the United States. Luis moved back to Mexico after college because I remember him specifically giving the reason that he liked the lifestyle down there better. He seemed to be the romantic type. I do not know, Mexico seems to be more a place for the romantic because you socialize more. They both have a Spanish accent in their English. Ceci is very 
proficient in Spanish. You know, I think that she was around the house a lot. It seemed like my brothers, once they went to college-often their colleges were far--we did not see them because they did not come to visit very often. You know, the daughter goes to college close by, and she is often home. So, I have many more memories of her being around the house than my brothers. I think that she spoke in Spanish to my parents. Being older, she was in Mexico in a lot of her school years. She went to college in the United States. I just wonder if Spanish was a much more comfortable language for her or not. She spoke more Spanish than anybody else. I think to us [the younger sisters], she would speak English. I have memories of her talking to my parents in Spanish.

Then there is Carlos. I do not think he uses his Spanish much. He went into German. He spent a couple of years of college in Germany. He was not really around relatives much, and he works in Los Angeles. I just do not know about his needs for Spanish. He has not traveled to Mexico much at all. So, I think, he would be...would use more English. He has some accent to his English, interesting enough. He was fourteen when we came back from Mexico.

And then Joseph. He now uses Spanish for his job just in the last five years. He got this job with an international company where he uses his Spanish. He was hired to be the Spanish-speaking person. He is in business administration. When my family went back to Mexico, he was ten years old. He said he did not realize that English and Spanish were different languages. He told me once of a situation where he had walked to the little corner grocery store [in 
Guadalajara] and asked for something, and he ended up asking it in English, and the man did not understand and laughed at him. He did not even think of not knowing the language. It seemed that both languages were the same to him almost. The combination was just there. It surprised him and embarrassed him that he was not speaking Spanish as he was supposed to. He has also told me that when he was in college, he seemed to connect with the Latin American students. He is also on the shy side. I think his Spanish should be pretty good, and he also has a slight accent in his English, just as if you just met him and were speaking English with him, you would know that English was not his first language.

And then Laura. She did use it [Spanish] in her job. She worked for an airline. She works in Los Angeles and there would be a lot of people flying, and she would help with the translations. But, I noticed when I was in Mexico with her recently, she did not feel comfortable with Spanish either, but it was definitely better than mine. On a scale of 1 to 10 , she would be a 6 .

Mary Louise or Maria Luisa. She ended up being a Spanish teacher until she started having kids. She is very proficient in Spanish, and she does not have any accent to her English.

Finally, Patty. She was three-years old when we came back from Mexico. She is proficient in Spanish. She was the director of a Spanish speaking social services agency for a couple of years.

When comparing the Spanish proficiencies of all the children, Rose feels that her brothers and sisters attained a better grasp of 
Spanish than she did, and that they are more able to use it in their everyday lives than she is.

\section{Kindergarten and Grammar School}

In all the moves the family made, the children spoke to each other in Spanish and in English. Rose's parents did not discourage this practice. Moreover, they themselves mixed both languages in order to facilitate their children's adjustment to the United States and to school. I never was asked to or required to use Spanish [at home]. I think my parents wanted us to succeed in school, and we needed just to use English. That was probably their thinking, and I do not remember my parents ever being afraid that we would lose our Spanish. And there were, for instance, Masses in Spanish [in Catholic churches] that were going on at the Cathedral [in Stockton], but it was never brought up to go to those. So, I think, my parents were also struggling to make it through American society, and I do not think they had much freedom or space to think about helping us with the language. I think they just wanted us to succeed in the American school system. It was their first priority. I think, you know, just that for survival in our society, it is better to transform, so you can succeed.

Rose remembers very little of kindergarten and her first years in grammar school, but she does recall that she did not have difficulties progressing in her school work: When I was two we moved to Mexico. So, I was in Mexico from two to five. Gosh! That is the time when kids really start talking, and I know that Spanish 
was definitely the language in which I was spoken to. I do not really remember, and I cannot even remember kindergarten being difficult because of the language. I remember some of the play-time situations, how we played with the dolls and in the playground. In kindergarten everybody is learning the alphabet or the colors. It is like everybody is at the same level. I do not remember having problems talking with the other kids or teachers or being singled out. And, I remember I had a good neighborhood friend that I would go to school with that $I$ do not recall that language was a struggle. Everything seemed pretty normal.

\section{Learning to Read and Write in Spanish}

Rose was never formally taught Spanish at home. She does not remember her parents telling stories or teaching her children's songs in Spanish. She learned the language by simply picking it up from her parents. They spoke to her in Spanish, and she responded. Rose taught herself to read Spanish: You know, we would have these bookshelves around the house, from where I would take books. I have always been told that I read a lot when I was young, but I do not remember much of what I read. I think that it was only in my dad's library that there were books in Spanish. But there were no children's books. He had medical books, lots of Catholic books, and some of my mom's cookbooks. Also, there would be letters from my relatives to my parents that I would pick up now and then. I would read letters from relatives, and I do remember writing. Yeah, I remember writing letters to my cousin. I think I always wrote the 
letters in English, because I knew my cousin was studying English, and I remember receiving her letters in Spanish.

There must have been just enough material just laying around or the letters from my cousin for me just to pick up enough of it, so that it seemed familiar. For instance, like a grocery list. My mom must have written it in Spanish, you know, just little things like that that were just enough that without her sitting down and formally teaching me. She would just do it with letters I would just pick up in the grocery list. She would just go over it with me. And, I do not remember anything else. I think you learn to read a language by how the letters sound, which I did in English. Then, I think, you can sound out some Spanish words. I can really adapt. I think I kind of developed this skill of just deducting by myself the solution or the answer to things. I feel that that skill is really strong in me. I think that being in such a large family where it was not just that one on one, you kind of just learn to think by yourself.

$I$ do not remember any stories told to me by my parents or my sisters or brothers. When I grew older and heard recently about passing on family stories, I always thought that it was a great idea that my family should have done. I remember that my son had an assignment about writing down a family folk tale, that the parents have heard in their childhood. I really could not remember anything. I remember too, when I was younger, and some of my cousins that were older and married and had kids, and I do not remember now, but I remember singing a couple of the little nursery rhymes that I thought were so cute, for example, that one about "The 
Three Little Pigs, Los Tres Cochinitos." I just remember singing along with the kids. They sounded so much cuter in Spanish.

\section{PART 4: DIFFERENTIATING ENGLISH AND SPANISH}

\section{Introduction}

In this part Rose talks about her teenage years, when she realized that English and Spanish were two different languages. Rose describes some high school experiences, and her feelings about Spanish, as it gradually became more difficult for her, and English became her dominant language.

\section{Teenage Years and Family Trips to Mexico}

Rose did not realize the complexity of the Spanish language when she was a child. It was only during her later visits to Mexico that she began to realize this complexity and clearly distinguish English from Spanish. It was not until I went down to Mexico that it seemed like a different language. At home, the combination of English and Spanish was just part of home.

Throughout her childhood and teenage years, the Spanish at home was familiar and comfortable: The Spanish that was spoken at home was so familiar...you know...I guess I knew my parents' vocabulary so well, and my replies were little phrases, or I could talk in English...that I think that when I went to Mexico...and maybe it was more when I was on my own too...there were experiences that I had to kind of depend on my own mastery of the language that I did 
not find it appropriate. I was very comfortable with my parents' Spanish because their vocabulary was very familiar and the interaction was the same.

As Rose became older, and her communication needs became more sophisticated, she began experiencing difficulties with Spanish. These difficulties were most pronounced during her visits to Mexico: I do not know, maybe in Mexico things got difficult and different. I know that I stayed a whole summer when I was ten, but I have more memories of my uncomfortness more when I was a teenager. When we were younger, we pretty much hung around with my cousins and their house. We would take, for example, crafts and manuals classes that, you know, were not a problem. That does not bring memories. When I was in social situations with cousins and friends was when I felt, as I grew older and lost more of my Spanish, that I became more clumsy. I understood that that was a different language.

\section{High School Years}

According to Rose, as time went by her Spanish proficiency dropped. She spoke more and more English at home until she was speaking only English with her brothers and sisters. In fact, her siblings began to make fun of her Spanish. This made Rose feel more inadequate with her language: With my brothers and sisters, definitely English, to the point that there was this running joke of how poor my Spanish was, or at least, that was the feeling I got. They would make fun of my Spanish. Maybe the older ones joked 
around with the younger ones, because they were going also through a lot, so they would pick on us. I do not remember comments from anybody outside the family or relatives about my Spanish. I just know that I did struggle trying to master my Spanish. Some of the hesitancy comes from the joking around of brothers and sisters, you know, about my accent, and then, I began to speak consciously. I just did not know the language very well.

Rose was not the only one who felt she was joked about because of her language. Rose says that her brother, Joseph, remembers being teased by relatives in Mexico. My brother said he did get kidded a lot by the other Mexican relatives, just about how "these kids that have just moved from the United States that sound Americans, but, you know, you are really Mexicans, why are you sounding American?"

Eventually, in Rose's late school years, the visits to Mexico became the only contact she had with Spanish. She remembers that those were the only times that she spoke only Spanish, and it was a struggle: With relatives in Mexico, gosh! I would have to say Spanish, especially with my cousin. I remember though that, you know, she would speak some English, and she would like to practice her English with me, but actually the time was very, very little. Once, when I brought a [an American] friend to Guadalajara, I think, my relatives were forced to speak English. I remember being surprised at how much English they knew that I did not know, and they would not want to practice it with me. I think they realized that with us living in the United States, especially my aunts and 
uncles, they wanted us not to forget our Spanish. Although, I could just picture them, not directly and maybe one relative, who was pretty direct, might have even said something in my visits about how I did not know my language. This relative was an aunt whose house I would stay in. I cannot remember a specific situation, but it would be a small comment here and there. And I think, my relatives had this negative impression of the United States as far as life style and values, and so, us not speaking Spanish very well, they connected us more with the negative influence of the United States rather than our holding to the Mexican life style.

The increasing difficulties Rose was experiencing in speaking Spanish, the more limited contact with the language, and the relatives' perception that the United States was a negative influence, all seemed to accelerate the decline of Rose's Spanish proficiency. According to Rose, her Spanish level was not adequate to carry on more complicated and technical conversations, neither was it easy to express her emotions through Spanish. Sometimes I think that when a conversation would have gotten too technical, you know, sometimes my relatives' conversations, or when we went to Church, in the homilies, it was a combination that I could not hear every word very clearly or, for example, the Gospel readings were not completely clear to me. But, I could understand the topic of the conversation, but the speaking part was the difficult one. I was always able to understand ninety five percent of the time. There were some times that I would have loved to have a dictionary to make sure of the meaning of a word, but it was just the talking.... 


\section{Rose's High School Environment}

Rose went to a Catholic high school in Stockton. All her classes were in English, as were her interactions with friends and teachers. Rose never considered mentioning her Spanish background or language abilities at her school, and neither her teachers nor friends ever made reference to it. I never remember being singled out as Hispanic, and I would not mention either that I was Hispanic or my parents spoke Spanish. My teachers never made a reference of me speaking Spanish. There was never a situation like that. I think most of the people of Mexican descent were in the [public] school system. I think, the migrants who would have a language problem were in public schools near their neighborhood. The Catholic schools did not have that problem because of their location. We were not in contact with them.

I sure did not bring into any of my conversations or into school any of the Spanish, you know, that I heard at home. There was never an opportunity to. So, it was just at home that we would hear it, and then, going to school it was only English. There was just no other Spanish-speaking people or opportunities around us to speak Spanish.

Although most of the people at her school were not of Spanishspeaking origin, a few students were, and Rose recalls that they sometimes caused trouble and said profanities. She did not want to associate with them or talk with them: There were a couple of kids in my class that, by their accent, you know, they were from Spanish- 
speaking households. I did not really think of starting a conversation or using some Spanish with them. When one used some profanity in Spanish, other kids would come up to me and ask me: "Do you know what that means?" It would happen if it was said around us, and at least one of my friends would turn to me asking if I knew what that meant, and I always felt offended because I did not know any of those words. I could not even guess what they meant. I just felt embarrassed. I would immediately say: "I never speak or have ever heard those before." But then, I would also feel embarrassed, thinking: "Is it my Mexican showing?" But that thinking was when I was in high school. It is just that it [Spanish] was not around my environment at all, except in the house. And in Stockton, it was spoken only downtown and on the south, yeah, from downtown and to the south [where the migrant workers lived].

\section{Learning Spanish in High School}

Also in high school, Rose took Spanish as part of her foreign language requirement. She remembers that the classes were very basic, and that was one of the reasons for taking them: I do not remember my motivation, but I think it was because I thought it was going to be easy.

The classes actually were very easy for her because she had been using Spanish since she was young, and she could relate to things in the class that reminded her of Mexico. A lot of the words created images in my mind about things I have been exposed to in Mexico, and it was a nice comfortable feeling. I guess at that point I 
was not aware of what the treasure was to know the language of my parents or really wanted to grasp it again. I do not think I felt like that, otherwise, I would have continued taking classes through college. It was not until after college that that type of thinking started surfacing.

In Spanish class, Rose relied on her language intuitions rather than using the grammar rules being taught, which shows the extent to which Rose had internalized Spanish during her childhood. However, she still says, I would have benefited doing more memory work with the verbs and really also grasping the language from the grammatical point of view, rather than just how it sounds. I remember relying for tests and all things for the class on how it sounds as being the right way rather than relying on rules, grammar, or using that type of reasoning. We reviewed all the grammar and the verb tenses. I never applied myself to memorize a lot of them. I remember thinking: "Well, I can recall just what sounds right." You know, which way the verb goes by the way it sounds instead of thinking through the rules. That caused a lot of problems. You know, sometimes my memory would not do the things right [laughs]. I would mess up in the verb tenses sometimes. Other things that came easy to me were the masculines and feminines. I do not recall memorizing them, pretty much...just remembering how I used them before, and like the articles that you do not know by rules, like "el dia." [the day]. You have to remember that "dia" [day] is masculine. But, I did not have any problem. I already had it. 
Because the Spanish courses were very easy and never went very far, they did not actually contribute to her proficiency in the language.

Rose also did not experience difficulty when she began writing in class: It was not until the Spanish classes at high school that I started writing in Spanish, but, for some reason, the accents were familiar to me, and I did not have problems writing in the classes. I do not recall problems.

\section{PART 5: NEW CHALLENGES, NEW REALIZATIONS}

\section{Introduction}

In this section Rose talks about her college years, job experiences, and present life. Rose narrates how a term in Mexico in her senior year at her college and a volunteer job experience helped her realize the richness of her background and the Spanish language. In her present life, she shares some recent experiences with Spanish at her workplace and with her family, especially when her father died last year. She makes interesting points about the ways in which she differentiates native and non-native proficiency in Spanish, and the various areas in which Spanish has influenced her English. An important finding in this section is how Rose, after realizing in her teenage years that English and Spanish were different languages, starts rediscovering her Mexican background. This is a new realization for her. Also, a very important anecdote in this section is when she starts working with a senior citizen center and tries to use 
her Spanish in her job. This becomes a challenge to her proficiency in the language. Rose reflects in this part about her background, her two languages, and the traces her languages have left in her life.

\section{College Years}

Rose's college years were spent in a private Catholic college, studying business administration. Her first few years of college were uneventful. However, it is interesting to note that at the time Rose was applying to colleges, the quota system for American universities had just been initiated. Consequently, when Rose was completing college applications, she checked her background as Mexican American for the first time, mostly, she says, because she had heard that she would have a better chance of being admitted to the college. Initially I might have checked "white," but then...for a combination of reasons, I remember hearing that Hispanics would be given kind of a priority because of quotas or whatever. I am sure I thought about that when filling forms, and also, then the choice was Hispanic because of my background.

Before this time, however, Rose had checked "white" in most instances: I would think that in high school, then you have the first forms to fill in, like for jobs. I remember, I can almost picture choosing white. Maybe, towards the end of high school and for my college application, I checked Hispanic. Now for sure I would check Hispanic, you know, just for the reason that that is my background a hundred percent. 
As time went by, Rose's contact with Spanish diminished even more since she was away from home. Moreover, she did not take any language courses in college, and all her friends were Englishspeaking.

A Term in Mexico. In Rose's college, study abroad programs were offered to undergraduates during their junior year. Rose and her friend, Lori, wanted to go to Italy, but, at the last moment, Rose decided not to go because she felt that a year was too long and that it would be too expensive for her parents to afford. Instead, Rose and another friend, Polly, went for a term to a university in Puebla, Mexico, where Rose took courses in English on Mexican history and literature. She lived in an apartment with four other girls, and the five of them spent every weekend traveling. This was Rose's first opportunity to see a different type of Mexico, and it constituted a major turning point in her life, as she describes here: We attended classes there at the University of the Americas, and we had a choice to take the classes either in English or Spanish. I think I took them all in English [laughs]. We did a lot of traveling. They had just fourday weeks of school, and then, during the three-day weekends, we would make trips.

That term in Mexico just introduced me to a lot of Mexico that I was not aware of, the village part of Mexico. When I previously had gone to Mexico, it would have been to Guadalajara to visit relatives, and I never really knew much of the rest of Mexico, but while I was there studying, we were able to take a lot of trips outside since school itself was in a very little town. So, it was just fun exploring 
the little kind of restaurants, all the little chapels and churches scattered all over, and the small towns. A couple of us took a trip to Yucatan. It was very beautiful and different from large cities. It was interesting that when I was staying there, I ran across a lot of travelers that would be down there for an extended period of time just to get to know the country. They would just be in awe with Mexico, with the people, and it made me start to think about those things through other people's appreciation. I think I began to see what was there, and what I was not really aware of. This realization changed Rose's perceptions about herself, Mexico, and her background. During these weekend trips, Rose served as the Spanish interpreter for her companions, to help them buy things in restaurants or in the market places. However, with her friends, Rose used only English.

For the most part, Rose's Spanish was seldom used during college. Her visits to her relatives were scarcer, and she felt uncomfortable with Spanish when going out in groups. English gradually took over almost all the domains of language in her life.

\section{A New Perspective with the Jesuit Volunteer Corps}

As discussed previously, after graduating from college, Rose joined the JVC for two years. Working with the JVC, Rose witnessed a spirit of acceptance of others and an emphasis on the value of one's cultural roots, both of which complemented the changes that she had been experiencing regarding her Mexican origin. Nevertheless, although she realized the treasure her background was, she did not 
seek to increase her Spanish proficiency. Her friends, her work, and her social environment were completely in English.

\section{An El Salvadorian Guest}

When Rose finished her time with the JVC, she married another volunteer, and they lived in Portland. Soon after they married, they sponsored a mother and her children from El Salvador. This was a very interesting experience for Rose because she used her Spanish all the time while the family was in her home. They stayed with them almost three months: Ten or twelve years ago...this was before kids...our church had sponsored a family, a mom and her two little kids. They were a "Sanctuary" family. They stayed all the summer with us, and we only spoke Spanish. The kids were really cute. They were one and three years old. They were from El Salvador. The "Sanctuary" families are families from other countries that are at risk, that cannot go back to their country. Churches sponsor them, either finding them places to live or providing financial support for them. The mom and the two kids stayed with us. They did not speak English because they have not been in the United States too long.

I do not remember very well, but it was a very pleasant and enjoyable time. I was trying to teach her a little bit of English, but she did not have much energy to be learning the language. So, I remember showing her what would be some words in English that she could use, but mostly we would talk Spanish. 
Job Experiences with Spanish

Rose also began to look for jobs soon after she was married. One job that she found working in a Senior Citizen Center in Hillsboro, clearly stands out in her memory. It was a center for elderly Hispanics. This job was a difficult experience for Rose, partially because she had to use Spanish. Rose says, After the JVC, I was working just part-time jobs. I was not really focused on a career very much. Initially I did temporary, Kelly-type jobs... and I am trying to think how I got connected...how I ended up working for a period of time...for one year. There was a senior center in Hillsboro for Spanish speaking elderly people, and they were looking for a nutritionist, which sounded interesting to me, so I applied and, surprisingly, got the job. As it turns out to be, the director was a volunteer and suddenly left. So, I was kind was running the whole center and using my Spanish a lot, basically because the people that were there spoke Spanish, and it was very stressful in that I did not feel all that comfortable with my Spanish, and just the job in itself was much more than I felt qualified to do. Even though it was a small senior center, they provided meals, and social activities for the senior citizens.

Rose describes the job at the senior center as a big immersion in the Spanish language. She did not feel that her command of the language was adequate and that made her feel uncomfortable with the situation: The Spanish Senior Citizen Center was a big immersion in the Spanish language. Now, I actually spoke both [English and Spanish] there, but Spanish was a large part of it. I would say the 
majority in Spanish, and it was just so...the feeling then was...it is hard to clearly give reasons...was overall an uncomfortable time. I often felt as not having a good grasp of the language. For instance, there was one cook there that came to me and said that one of the men there approached her in a very uncomfortable way. So, as director, I needed to talk with him about that. And, I remember feeling totally inadequate with, first of all, the whole subject area [laughs], but I needed to use Spanish because he only spoke Spanish. My message to him was that at the center we wanted people to feel comfortable, and that some things were not appropriate. And, I guess he understood what I said [laughs].

The Senior Center experience was a setback in Rose's use of Spanish, as she says here: Overall, the job itself I was attempting to do just felt overwhelming to me. So, it was not just the Spanish that I felt uncomfortable with...that would have been one thing...but there were just a lot of factors why I was feeling so uncomfortable. There was nobody kind of helping me to walk through it, so I was trying to do it all by my own, and not coming with previous experience with things like that. So, I think that where I was initially excited to get into an area where I could start using my Spanish again, but, I think, 1 took a step backwards, and I felt like I did not know Spanish as well as I thought I did. I think I walked away unfortunately with that attitude.

Another job experience where Rose had to use her Spanish was at a university hospital in Portland where she was sometimes asked to translate for the Spanish-speaking patients. When I worked at the 
university hospital, it seemed that there I was asked to translate a few times for patients, and that felt a little bit tricky. I felt reluctant of the terminology that was needed, the medical terminology. Like one time I was asked to go to a patient's room where a doctor was... I needed to translate the doctor's questions to the patient. It was information that the patient was being given before they left the hospital. And, I got through it, but a lot was kind of pointing [laughs], when I did not know what to say. One thing, I think it was, she just had a baby, and she was not supposed to have sex for a certain period of time. I did not know how to say it. It was kind of embarrassing. So, in my work experience I have had chances to use Spanish, but in most of these occasions, they asked more than what I really knew.

In her present job, Rose has almost no contact with Spanish. She feels she does have opportunities to use her Spanish, but she does not take advantage of them. I can kick myself for having so many opportunities to improve and practice my Spanish, you know, even here at work with other people that speak Spanish. In my work presently I only use English. My supervisor, Hilda, sometimes would bring up phrases in Spanish, but in general, I would say we use English. With co-workers here...I know quite a few [who speak Spanish]: Alejandro, you, Rosa, Frank Fromherz, Leroy Creel. I run into people that speak Spanish, and again, I just speak English.

Oh! And there was a supervisor, Fr. Dan. He left about a year ago, and he worked with the deaf, but somehow he was connected with the Spanish community, too. He would say Mass in Spanish, and 
on the phone he would have some conversations in Spanish. I thought, "Wow, he has a great grasp of the language, great accent, great phrases." And I just automatically compared my Spanish to his, and I thought, "I feel too embarrassed to speak my Spanish." I remember his Spanish, his accent was so "ranchero," you know, real kind of dramatic type of Spanish, clipped, full of phrases, different from my parents' Spanish.

Rose has occasionally used her Spanish at work. Recently, she translated a letter for her supervisor, and that experience was very positive for her. I found that the letter that I recently translated for Sr. Linda was surprisingly easy even though there were some corrections, but her letter, you know, she writes often very simple. She was a second grade teacher, and sometimes the way she writes is as if she was writing to a kid, and I think that for the purpose of the letter, she wrote very simple, too, because of the people it was going to, and she knew it was going to be translated, so she wrote simple.

Rose spoke on the phone with the man to whom the letter was sent, and although Rose knew he spoke Spanish, she did not attempt to use it. Oh! The man called, and he had not gotten the letter yet. And he spoke English. It was a broken English, but he could understand just fine. And I told him we had just written to him in Spanish, that I had translated a letter for Sr. Linda, but I found myself thinking throughout the conversation, "I am talking English to him. Should I talk Spanish?" But, he seemed to be answering my questions in English. I did not force the issue, so I continued in English. 


\section{Rose's Father Dies}

Rose recently lost her father. She went to Mexico to help her mother and see her father before he died. Her experiences during this difficult time shed more light on her current use of her two languages. Rose recounts: It was very difficult, both because when I got there my dad was in the hospital and died later. And there were relatives constantly coming to see how he was doing. It was extremely difficult because of the emotional stuff going on, and then, even though I was there for three weeks, I just felt that my Spanish was not...it was really hard to speak it, and even practicing as time went on. I think because a lot of what I was trying to say was at the emotional level too, you know, feelings and stuff, and that is really hard to do. Like I would...you know...there was usually another sister. I was there for the full three weeks and my other four sisters would come and go for a period of time each. So, often when we were at home, the phone would be ringing, and we would have, not an argument, but I would always insist that my sister answer the phone, because it was so difficult for me. You know, a relative would call and ask how my dad was doing, and I would just kind of...I would feel like a little two-year old with such basic statements that I said. That was really hard. Whereas, a year ago, last January, my dad had an extensive surgery, and I was there for a whole week. And, I felt that by the end of the week, I felt really good with my Spanish. I think because of all the emotional stuff going on, my Spanish was getting twisted up. 
In a call for example, I would say simple things like: "Bueno, quien es? Soy Rose." [Hello, who is this? This is Rose]. And the other person would say: "Chulita, como esta tu papa ahora." [Dear, how is your dad?]. And I would say: "Lo mismo, no ha cambiado." [The same, he has not changed]. And then: "Como esta tu mama?" [How is your mother?]. And I would say: "Bien, tia." [Fine, aunt]. That is all I could say as far as use, plus it would be hard to know what to say too, you know, even in English, not to alarm anybody. My dad's condition did not change much from day to day. He was basically in a coma most of the time, and the doctors just never had much new to report. They were just waiting to see if he could come out of it, and he never did.

For Rose that time was uncomfortable. Her father was very ill, and she needed to accompany her mother and talk with her relatives, whom she had not seen for a long time. It was awkward in that we have not seen a lot of these relatives for a long time, so it was in a way like a regular visit, you know, catching up with their news, but you know, you would just like to be kind of focusing only in your dad. Although the relatives came just to distract us, we would just feel uncomfortable with that. We would feel this is not a time to socialize and kind of chat around, even if it was in Spanish.

Several times Rose tried to talk with the doctors in Spanish, and although she could get her message across, she often found herself using English:

It was interesting. When he [the doctor] would give his reports...he was a doctor from Mexico, but he had had a lot of his 
training in the United States...but he would definitely talk to my mom and me in Spanish. But, when I would try to ask a question that I had, and would start in Spanish, he would say: "You can go ahead and say it in English [Rose laughs]." And then I would ask my question in English, and he would answer in English. But all the nurses, who were really nice, all would speak Spanish.

While Rose's father was in the hospital, one of his sisters, who is a nun, came and stayed with him until the end. This was a special experience for Rose, not only because she got to see this aunt, but because the aunt led the family prayers in Spanish. My dad had the cutest little sister, my aunt. She is right now in her 90's. She is a nun, and much shorter than me. She would be just there a large part of the day. She is a Carmelite nun that came to Guadalajara far from outside of Mexico City, which is 5 or 6 hours away. It was like her mission to be there with her brother, and she would constantly be praying. So, we would join in praying with her. The prayers were all in Spanish. We would all be around my dad's bed. I was able to join with the rosary, Our Lord's Prayer and the Hail Mary's. The other prayers, some of them were repetitious prayers that I would finally catch on to, and I would understand them, but I was not that familiar with them. And even initially, before the hospital experience, I do know I could say I remembered then very smoothly, and you pray them so many times that you memorize them. But, they were familiar prayers that were somewhere in my memory and just came back. 
Visit to Mother

After the death of Rose's father, her mother moved to California, where Rose recently went to visit her. For the purposes of this study, Rose monitored her language use with her mother and found that she uses Spanish with her only to clearly make certain points or to talk about very familiar topics. In Rose's words. I found myself speaking some phrases in Spanish, kind of short or mechanical, like asking something that I wanted or asking her if she needed something around meal time. She spoke fifty percent-fifty percent English and Spanish, maybe a little more English. And, I now and then I would speak a Spanish phrase. I feel that my language is now ninety percent English and ten percent Spanish at the most. I would never think of starting a conversation in Spanish. I would think that that would be a little too difficult for me, but some phrases seem just to jump out without me thinking about them. It is not like I would have rehearsed them in my mind, to make sure I knew them, they just came out naturally. I would use Spanish with my mom just to make a point I really wanted to get across, and I wanted to make sure she heard me. Other times would be answering a question that she was asking in Spanish. I think both of those reasons would bring out my Spanish. I am pretty good at understanding her Spanish. I never felt like I did not understand. Sometimes, though, I hear words here and there that I have to look up in the dictionary, but not with my parents.

However, Rose did feel very uncomfortable with the Spanish when an aunt telephoned from Mexico during the visit. An aunt 
from Mexico called when I was there, and I found myself feeling uncomfortable, as my sister was talking to her, I thought that it would be difficult for me to carry on a conversation in Spanish. I just...it is just that social type of phrases and all that I think $I$ do not do very well.

During the visit to her mother, Rose also wrote a letter to her aunt who is a nun. While writing, she found that she could not easily express herself in Spanish, and that it was difficult to find the correct phrases that are used in writing letters. But recently, I have written letters to my aunt, when she went back to her convent, and so, I was writing a letter to her, and my mom and my sister were with me. I was writing in the backyard, and I had to constantly be asking them for phrases to use. I would say a thought that I wanted to write, but I did not know if it was appropriate or the polite way of saying things, or sometimes there would be sentimentality involved, and that made things more difficult.

\section{Rose's Everyday Life and Spanish}

In her everyday life Rose has no significant contact with Spanish at all. At work she speaks only English; in addition, her neighbors, her family, and her acquaintances mostly speak English. Her mother and siblings, with whom she might otherwise speak Spanish, live either in California or Mexico, so she does not have regular contact with them. Also, although Rose's children are in the Spanish immersion program, she does not practice Spanish. 
The following are Rose's comments concerning her use of Spanish at present, which she made while completing a chart on language use (see Appendix A): Let's see. With my mom, both [English and Spanish]. But, of anybody, she would be the one I would speak the most comfortable in Spanish with. Then with my brothers and sisters, English.

With my daughter and son, I speak ninety nine percent in English. I try to, you know, using Spanish, but they are the ones who bring it up more than I do. I just think I am so busy with all the running of the house that I do not think of bringing up Spanish a lot more. For example, they would bring their homework with the page of instructions in Spanish, so then, I would be forced to speak Spanish. And I feel comfortable with it. I would see we speak one percent of Spanish, and it could be more or we could try to increase.

With the kids' teachers, well, that is another, where, you know, theoretically, I should try just to speak Spanish with the Spanish teachers. And I know I should be speaking Spanish in front of my kids to their teachers, you know, like after school, but because I know they are rushed, and there would be one or two things, I am not quite sure how to say them. Then I would talk half and half with them, but I know it should be Spanish. There is potential in that area. And, with the principal at school, I only speak English. I do not know if she knows any Spanish.

With Hispanic parents. Well, just recently there was a Hispanic parent that was waiting with me to talk with the teacher in a parentteacher conference time. And she was explaining how they have just 
moved here. I think they have just moved here from Mexico, and she knew English pretty well. I told her that my parents were from Mexico, but we spoke English. You know, I see other parents of the kids that are in the program that are just learning Spanish, and they would practice Spanish with anybody that they can, that they run across, and I admire them for that. They are really working hard in learning the language. It seems that Rose's opportunities to speak Spanish come sporadically, or when she visits Mexico or is around her relatives. Even with them, she is using more and more English.

\section{Spanish in Other Significant Areas of Rose's Life}

Prayer Life. Because Rose's parents were strong Catholics, praying has always been very important in her life. As said before, some of the family time was spent praying the rosary, and Rose's father was a devout Catholic, who attended Mass regularly and closely followed the teachings of the Church and the Pope. Being in this environment, Rose developed her own spirituality even as a child. Her first contact with praying was through her parents, and this was carried out in Spanish. As Rose grew older, English gradually replaced Spanish in this area of her life. Presently, her prayers are carried out only in English. When the situation requires praying in Spanish, she is able to remember the formal, repetitious prayers in Spanish, but they are not the ones that have the deepest meaning for her. Rose recalls, My parents would use Spanish. Like when we would say the Rosary at home, it would primarily be in Spanish. But, when we attended Mass at our parish, Presentation, 
they would use English all the time in the responses they would say out loud, since our parish was English-speaking, mostly with Anglos. My first prayers must have been the Rosary that was said at home, and that was before I even started kindergarten. So those were definitely in Spanish. So it must have been in Spanish, and then comes first grade, all the other rote prayers we learned to say were primarily in English. I remember mainly using English in my prayers. In Mexico, prayers would come out automatically in the Mass. Well, not that automatically, but there would be verses and prayers that sounded so familiar that I just remembered them.

In Stockton, we went to Mass every Sunday. There were Spanish-speaking Masses going on in Stockton as I was growing up, but we never went to them. So I guess, just the familiarity of it was just nice. And generally, to me the English seems much more varied than the Spanish-speaking Mass, which seems much more rote. But when I pray, I use English.

Now in Spanish, verbally with all the prayers that are said out loud, I would, I could actually go along with them. It seems that I could remember all the responses to the prayers pretty well. I could follow the Mass very easily. But with praying to myself, silently, it would be in English. But at Mass, I could respond in Spanish. And for comfortness, I guess I would prefer English, but the Spanish... it brings a lot of memories for some reason. When $I$ would be going to Mass when my dad was in the hospital, we would be going everyday. $I$ was surprised at a lot of the prayers that $I$ would remember, and not just the Lord's Prayer and Hail Mary's, but the prayers that are 
said just in Mass. And I remembered them, and I was not quite sure where I remembered them from. It was just from my visits to Mexico, I guess.

Rose's Children's Schooling in Spanish and Its Effects on the Family. Rose has two children, Rachel and Matthew; both attend a Spanish immersion program at a local school. Rose wanted them to be at the school because she realizes how important knowing two languages will be in the future in the United States, and she did not want her children to lose the language of their heritage. Having lived with two languages herself, she also understands the personal benefits involved. Rose is pleased with her children's school and says she has learned a lot about Latin America through her children. The experience of having her children in the immersion program has been very important to Rose. It has also been very pleasing to Rose's parents, as Rose points out here. Rachel has been in it for four years, and they [Rose's parents] were very excited about it. You know, I think that they [Rose's parents] seemed they were trying to get established in the United States. I think that they would have liked us wanting to reconnect to either the relatives in Mexico or the language. It was interesting, they casually...I was wondering if they were going to ask if it was a Catholic school. And they never did, so you know, it was enough a reason not to put them in a Catholic school in order for them to learn Spanish.

Some time ago, Rose took her children to visit their grandparents in Mexico, and they were delighted that Rachel and Matthew were learning Spanish. The children have not been in the 
immersion program long enough to actually hold a conversation; nevertheless, their grandparents were very pleased. Rose says, $I$ took them [the children] to Mexico to visit my parents. That was two or three years ago. So, they [the children] really had not taken so much Spanish, and my parents would try to talk to them in Spanish and try to tell how much they really knew. They [Rose's parents] were very happy. Primarily, it seems that the kids were learning their Spanish through songs, so they would sit with them and sing their songs together.

It was important, pleasing, and meaningful to Rose's parents that their grandchildren were learning Spanish. This may signify that, even though they could not do the same for their own children, they are happy that their grandchildren are learning Spanish and learning about their background.

Another significant event that occurred in connection with her children's school was that Rose joined a Spanish conversation group. The school offered conversation groups for the parents of the students in the immersion program, and although Rose no longer attends the group, it was a positive experience for her while she did. Rose explains, Two years ago, when Rachel started kindergarten in the immersion program, they [the school] would have small groups of parents meeting to learn Spanish. And the group that I was in was an intermediate with parents that already knew a bit of Spanish. It was kind of a conversational thing. I was the only Hispanic parent there and the rest were Americans. I felt very much a master of the language compared to them [laughs]. You see, it all depends who you 
are around with [laughs], but when we got to reviewing the verbs ...then it was different [laughs].

\section{Rose's Perceptions of her Spanish}

Textbook Spanish vs. Natural Spanish. Rose feels that her Spanish is textbook Spanish rather than the natural Spanish used by her parents and other native Spanish-speakers. She feels that the difference is a significant one, I feel I talk more like a textbook type of Spanish, what you would hear of people learning the language versus the natives. When I think of "textbook Spanish," I think of the beginning level of Spanish where you have questions and answers, for example: "Vas a la biblioteca? Si, voy a la biblioteca." [Do you go to the library? Yes, I go to the library]. Things like that, that are very simple. My vocabulary, I know, is not very extensive. $I$ just use the simple kind of basic words.

You know, the phrases that people use with friends, the ones that in a way naturalize the language and are used so automatically. The phrases and the intonation I think are more emotional or emphatic. I think I do not have that. Things like "hijole," the slang I never learned. It [her Spanish] does not seem really authentic. It just seems that I am translating word for word from English. It does not have the flow of a native Spanish-speaking person, and it is interesting, for instance, the Spanish I have heard from my parents is so different from the people I hear talking in Spanish around me in the United States. It is more...from the migrant worker type.... I do not know, the migrants' Spanish seems more expressive in just 
the phrases they use. Where I feel my parents just said what it needed to be said, so they got their point across. There was not much more emotional content. My parents' Spanish was in a way simple because I can just feel I could understand it well. There were not too many words that I could not understand, but they spoke Spanish often in the same areas, so there was vocabulary that belonged to that area. For instance, my mom tended to speak more in Spanish when it dealt with meals or food, so to me, that Spanish was very understandable, not complex. They did not use much slang at all. So in a way, that is a kind of a textbook Spanish because it was so straight forward, but it was natural. They had the right accents.

\section{Spanish Influences in Rose's English. Another factor in Rose's} language development is the way in which Spanish has influenced her English syntax although, when speaking, her accent is that of a native speaker of Standard American English. Several times during our interviews Rose mentioned that since, as a child, she mostly spoke Spanish, she did not learn certain English phrases at home. Instead, she learned them outside the house, or she substituted direct translations from Spanish of the phrases used by her parents. Rose comments, ...often my English, I have realized often is inaccurate. I think some of it comes from the Spanish we spoke. Where people say different things than I. There is a way that is American, like the jokes, the phrases that are just so much used in the United States, the phrases that I would never see my parents using. For example, people would say "turn out the lights." I would 
say "shut off the lights." And, "get down from the car" is not usually said in the United States. We [in the United States] say "get out of the car," and in Mexico is "bajate del carro." And I find myself doing a literal translation rather than what is usually said here in the United States. There are just a few phrases that I say literally from Spanish, and they are not the way Americans would say that. I make mistakes with them because of translating,

According to Rose, these are expressions that children learn at home from their parents, but since her parents did not speak English, she had to learn them outside the home: I think, it is because I did not grow up with them [the phrases], and so, whenever I would hear them once or twice outside the house, and I would try to remember them and repeat them, and I would get them wrong. I am always mixing up those phrases. I get some words mixed up or use a different word with them. Especially the American expressions that the typical child would be hearing constantly at home, and, you know, and he would be able to easily retrieve them, and I often turn them around.

Even now, Rose uses these Spanish-influenced expressions in her every day life, which shows how internalized they were in her early language development, I still have them. They are part of my vocabulary. I use them constantly, and I do not know why I keep wanting to use them too, when I should not, but right now, none comes to mind. I still have stayed with them.

Rose's Feelings about English and Spanish. Rose feels that English is now the most comfortable language for her, and the one 
she prefers. However, the sound of Spanish is still special to Rose. She explains, I guess, just that English is easier to use, and I can use it with much more ease for myself in describing; expressing is easier. But, just to my ear? Gosh! I love how Spanish sounds. Adjectives and descriptions tend to be much...for instance, things that have been translated right next to each other, like Christmas Carols or something like that; they just...they lose a lot often in the translation back and forth.

Although Rose's reflections reveal the conflicting feelings about her language and background that she has so often experienced throughout her life, she still likes the sounds of Spanish because of their connection with her childhood.

Parts one to five presented Rose's language narrative. Rose narrated her life in her own words, and described the ways in which her life with two languages was. She told experiences and anecdotes while she was growing up with her family in Stockton, her friends, her job experiences, and the changes she experienced in her perspectives regarding her two languages and her Mexican background. In part six Rose tells her reactions to two readings. She reveals new details of her life and her two languages. Part six is another important component of Rose's language life history.

PART 6: REACTIONS TO RODRIGUEZ'S AND HOFFMAN'S READINGS

Objective of the Task

As part of the language life history interviews, excerpts (see Appendix B) from Hunger of Memory by Richard Rodriguez (1982) 
and Lost in Translation by Eva Hoffman (1989) were given to Rose. The objective was to obtain Rose's reactions to the readings and to see if she could identify with the experiences narrated by the authors.

These books were chosen because they were language life histories of the authors. In these books they recounted their life experiences with two languages. Because their experiences were similar to those of Rose, it was appropriate to ask her to read some excerpts and comment on them. Her reactions were useful material for her language history.

The excerpts were chosen from various parts of each book. All the excerpts dealt with the writers' experiences with their two languages. The excerpts were pieced together and given to Rose for her to read. She was given a week to read the excerpts and extract the points that she would like to comment on. Her comments were tape recorded in an interview, and the results are reported below.

$\underline{\text { Results }}$

Rose identifies more with certain statements by Richard Rodriguez than she does with Eva Hoffman's account. Rose states, $I$ highlighted points actually in both of the readings. Although it seems that I highlighted more in the Rodriguez one. This really struck me as far as things I can identify with. Boy! They were just really interesting. I think that my life was not all that similar to Richard's upbringing, but there were still some points I would like to comment. 
Her comments reveal some interesting experiences she had while growing up. In her reflections below, she comments on both the differences and similarities that she found while comparing her experiences with those of the authors.

The first difference is that whereas Richard Rodriguez writes about a sharp change of languages between the time when Spanish was permitted in his home and the time when his parents forbade its use and insisted that only English be used, Rose did not notice any such change in her house. Rose felt free to speak either English or Spanish in her home, so she did not experience the stress that Rodriguez felt when changing languages. This is important to note because it explains her easy adaptation to English when she was a child. Rose says, My experiences were not similar in that I did not feel the real ...the big change that he felt in his home life when his parents spoke Spanish to him, and then they were forced to speak English. You know, that seemed a real strong part of his life, which I did not experience. I think my parents generally felt free to speak Spanish or English, and my mom spoke generally more Spanish. That seemed to be really what she felt more comfortable with. There was not a turning point where we really needed to consciously speak English. I did not feel my home life had taken a real turn or change like Richard's had.

Another difference that I noticed was when he would come home and there would be this just kind of "we excited rejoined our voice in celebration of sounds." And I could not really picture our family as when we were home being excited to speak Spanish. It 
just seemed like we brought English home, and it was not a big deal. When my dad used to come back home, it was more individual, but it seems that when kids are really young is when they go running to their parents, you know, and maybe I can just remember when we were older. It was just, you know, going up to my dad to say hello, but it would just be a hello, and give him a kiss, and that was about it. At that point he would talk to us in Spanish. His hello's would be in Spanish to my mom, but it seems to me that they would be much more low key that Rodriguez's "excited celebration of sounds." In those instances my father would call me by my nickname, and with simple things like "como estas?" [how are you?] or "como fue tu dia?" [how was your day?]. He always called me like that at home. It was like a term of endearment, and he would go like this [Rose grabs her cheek, imitating her father]. Those were probably the things that I saw as very different to my experience.

Rose also notes several similarities, which were very interesting. Among them is her feeling that Spanish is a soothing language. She identifies it with the soft, endearing terms that her mother spoke at bedtime. This is one of Rose's fondest memories of Spanish. She says, I am going to read the sentences [in Rodriguez's book] and then maybe explain: "Conveyed through those sounds was the pleasing, soothing, consoling reminder of being at home." More what I picked up here was I agree that hearing my parents speaking Spanish was kind of a soothing thing. My mom would say good night to me in Spanish, a lot of the loving type of endearment phrases were in Spanish. I think a lot of the kind of fond memories I would 
tie to when Spanish was spoken. Terms like "mi linda," you know, things that would be spoken throughout the day in regular conversations. There seemed like there were times that I would remember Spanish more being spoken like this. A lot of the pleasant vague memories that I have would be when my parents would be comfortable themselves saying something in a positive or endearing way would be in Spanish.

Next, Rose identifies herself as a listening child, just like Rodriguez; for Rose this is a very strong statement. When she was younger, she always wanted to hear everything. As noted before in her language account, she feels that being a good listener is one of her strongest traits, one that assisted her in developing her language skills: Then, another phrase: "I was a listening child." And, boy! I could really connect with that. I just feel like I just kind of always had my tuners up as far as...hmmm...and not necessarily at home, but outside the house, because everything outside was new and different. I guess, that is kind of a general feeling I had, and was not until I read his account that I thought that was true. I guess home life was different enough, what he calls it here "public life" that, you know, I was just... and maybe that is so with kids in general, when they leave the home, but not necessarily with the listening part. I think that it tended to provide a lot of new experiences, and I was always interested and tuning into hearing things around me.

Rose, being a listening child, could distinguish the tones of Spanish from English. Like Rodriguez, Rose felt that Spanish was a softer language. This reveals part of her attitudes toward the 
language. He [Rodriguez] mentioned here that he even felt that Spanish was softer and that people speaking English were kind of louder and more authoritative, and I am sensitive to people that have this kind of loud and booming type of voice. I wonder if that came from being so different.... The home atmosphere, and the phrases were often different as far as expressions and idioms. I learned a lot of them outside home.

Another aspect of Rose's attitudes towards Spanish concerns the way she felt, as a child, about her parents' accent. Like other children exposed to two languages, who feel embarrassed when their parents talk with an accent, Rose felt that her parents' accent attracted attention to them. This made her feel different from other people, as she relates here: When listening to my mom, for instance, trying to talk on the phone where she would often have to repeat herself and in public, and I just remember noticing that my parents talked a lot different from other grown-ups, and I think there was a kind of...I don't know... embarrassment... but just really kind of noticing differences and with me being more in the shy side, that made me more uncomfortable. It kind of drew more attention to my family, when $I$ would prefer to kind of hide or melt into the environment. For example, I can picture very clear my mom talking on the phone and having to repeat, say the address several times because they could not understand her, and I just felt kind of embarrassed thinking: "What are those people going to think on the other end." You know, it was not ever: "Oh, gosh can they just do a better job of understanding her?" It was more of the negative 
impression they would have. I would think: "Why my mom could not say that better?"

Another interesting comment Rose made in response to Rodriguez's account concerns her ability in Spanish and English. In Spanish she feels she cannot express everything; she is afraid of making mistakes. In English, especially when she was younger, she was afraid of not knowing a word or expression because she had not been exposed to it since her parents were not native English speakers. In relation to these feelings, Rose tells the following story, beginning with an explanation of how Rodriguez's account brought her own experience to mind: This is a very small one: "I couldn't say, I wouldn't say." Where Richard was talking about how in school the teacher would talk about words in a sentence and, kind like in an exercise she would be doing with the kids, reminded me of an experience that stuck with me, and I never understood why. I remember, we would be taking turns reading out loud, and I did not mind doing that because I was sure I knew all the words and their pronunciation. I never thought twice about it, but once I ran across, or somebody else was reading, and there was this line that used "vs., versus." And I just remember panicking, you know, thinking: "Gosh, if I had been reading that, I would not have know what to say. This is just terrible." I felt very conscious that I could make a mistake, and $I$ remember feeling like maybe there are other types of expressions or whatever abbreviations in English that I do not know about. I attributed that to me being reared in Spanish. 
Later in life, Rose realized that all children have experienced that type of problem while learning to read. She has seen it in her own children. Everyone encounters new words and abbreviations, but at that time, Rose says, she thought that she was the only one to experience that phenomenon, and that it was due to her being a bilingual in English and Spanish.

As mentioned previously in Rose's narrative, Spanish became more and more complicated for her as time went by, and her confidence in Spanish diminished when she began experiencing communication problems. Thus, she identifies herself with Rodriguez's experience of being a "victim of a disabling confusion" (Rodriguez, 1982, p. 28). This confusion resulted, Rodriguez says, from the fact that as he grew more fluent in English, he could no longer speak Spanish with confidence. He was able to understand spoken Spanish, but could not pronounce it. A "powerful guilt" (Rodriguez, 1982, p. 28) blocked him from speaking Spanish freely. Rose feels that this was her own experience, which is very important in her perception of her language ability, both in English and Spanish. She says, I just found that very interesting. I know that I have some kind of block that I cannot figure out. I can understand Spanish, but to speak it is so difficult. I can mentally think about the words to say, but when I start pronouncing them, as Rodriguez says: "everything I said seemed to me horribly Anglicized." That is probably one of the blocks for me. It is like knowing I speak a terrible Spanish, when I should speak [it] better. I am embarrassed with the level, with the outcome. I can understand better than I can 
speak. I have an accent. I feel I have to have a good accent because my parents are from Mexico, and having had spoken and listened [to it] at home as a child. Also, I think that my brothers and sisters can speak so much better.

At this point, Rose also mentions how her accent in Spanish was perceived by other Spanish speakers, especially her own family and relatives in Mexico. Their perceptions made it more difficult for her to develop confidence in her Spanish as time went by. Again, she identifies with Rodriguez's experience when relatives criticized him for not being fluent in Spanish. He [Rodriguez] also spoke about how other people that spoke Spanish would kind of tease him that he did not know "su propio idioma" [his own language]. And I think from my relatives, too, in Mexico, when going visiting, struck like a familiar bell. You know, I could just picture them, not directly, and maybe one relative who was pretty direct, might have even said something about it in my visits how I did not know my language...it would be just a small comment here and there. Something like "que lastima!" [what a pity!] that my language could not be as good as it should.

Although Rose relates more to Rodriguez's experiences, she also identifies with two points made by Eva Hoffman (1989) in Lost in Translation. The first is how Eva learned new words and expressions once she arrived in Canada and started going to school. The second was how Hoffman could not use the word "I" when writing in English. Both were experiences that reminded Rose of her own experience with language. I could identify with this: "Everyday I learned new 
words, new expression that would come up in school exercises and conversations." And I think I have mentioned this before, that it seemed like there was a lot of new spoken English that I could not understand that I did not hear at home. Then she seems to talk that "when I write in English I am unable to use the word I." And it came up recently too. I noticed it before, for instance, when I am in my RENEW group there is a lot of faith sharing where you ideally share some of your experiences with others in the group, and I noticed in those, too, that I was using "you" rather than "I." It was interesting to read it from her too. I would depersonalize my experience. I would try to remove it just a little bit from myself by using the word "you." For example, when we were talking about neighborhoods and trying to be hospitable, when I was talking about my own neighborhood, I would say, "When there is a family that you do not know very well, and it is hard to find a common ground with them, then it is easy for you to just ignore them, you do not have to deal with them." And "you" just comes out rather than saying "my neighborhood"....

In these two readings Rose has found a lot in common with her experience as a bilingual. She says, It was just beautiful. Boy! It was wonderful. Everybody should read them to see how immigrants feel when, you know, you are just put into a new situation. 
PART 7: RESULTS OF THE EVENT/NETWORK ANALYSIS

\section{Introduction}

As stated in Chapter III, an event/network analysis was performed in an attempt to discover the different contacts Rose has at her workplace and in order to analyze what circumstances trigger her use of English, Spanish, or both languages.

According to Dobbert (1982), an event/network analysis is designed to discover the structure of social situations in "an ongoing set of interactions that is observable by any uninvolved outside viewer" (p. 157). This structure can be observed through repeated behavioral patterns which give form to the social entity. In looking at the structure of social situations, an event/network analysis has two goals, first, discovering the social structure's skeleton and, second, interpreting the acts and behaviors that are within this skeleton. The purpose of an event/network analysis is "to define social structure through looking at it in operation" (Dobbert, 1982, p. $160)$.

For the event/network analysis in this study, Rose's workplace was chosen as the place to gather further information about her language use. For reasons of informant privacy, an event/network analysis was not performed with her family.

For the analysis, I followed the procedure used by Crocetti (1993). On a form (see Appendix C), I recorded all the interactions that took place in Rose's office during an eight-hour work day. Information on the form included the interaction number, the nature 
of the address, the key (serious, emotional, etc.), the participants, the message form (Spanish or English), the topic of the conversation, the equality of the interaction, the territory, and other details of the interaction. In designing the form, I took into account details used in Crocetti's (1993) network analysis and Saville-Troike's (1989) communication events components.

Equality in an interaction was defined in terms of the status of each participant. For example, if Rose interacted with one of her bosses, this interaction was considered unequal because Rose's bosses are higher in rank than she. If an interaction was with a co-worker, this was considered an equal exchange because Rose and her coworkers are equal in rank. Interactions during phone calls and with visitors were regarded as equal, unless there was a clue in the interaction that revealed the other person's status to be higher than Rose's.

Saville-Troike (1989), in analyzing communication events, identifies several components of communication. Among them are genre, topic, purpose, function, setting, key, participants, message form, message content, act sequence, and rules of interaction.

Although this classification was actually designed to record communication events, I decided that some of these components were relevant to this study. Therefore, included on the form were key, participants, topic and, most important of all, message form, which was subdivided into English and Spanish. In addition, whenever no interaction was taking place I took notes separately 
from the form, describing the setting and the work each participant was doing.

Rose was asked to choose the best time to have the network analysis done, and she chose a Friday since she considered it less disruptive for the office and her bosses and, at the same time, she defined it as a typical day of work. Rose herself informed her four bosses of the analysis, and they seemed to be delighted and very interested in participating in it.

The participants in the interactions were coded in the following way:

Rose was coded as $\mathrm{R}$, her bosses as B1, B2, B3, and B4 (a number was assigned to each boss according to the order in which they arrived at the office), her co-workers as $\mathrm{CW}$ (numbers were also given to them in order of succession), visitors as $\mathrm{V}$, callers on the phone as $\mathrm{CP}$, a priest as $\mathrm{PR}$, and other participants, not specifically identifiable, as OP.

As in Crocetti's (1993) Master's thesis, the possibilities for the nature of the address or interactions were question/answer, questions, small talk, gossiping, recommending, responding, explaining, advising, information exchange, thanking, comforting, directing, clarifying, promising, requesting, complementing, advising, joking, retelling, reminding, requesting assistance, rebuking, reprimanding, informing, prescribing, instructing, and teasing.

The day the analysis took place, Rose and I met at Rose's office, a large area shared with two of her bosses. As can be seen in the diagram in Appendix G, Rose sits in the middle between B1 and B4. 
There are several file cabinets along the back wall, and along the left wall there are several bookcases and a large printer. According to Rose, B1, who works with the deaf and physically challenged, likes to give the office a home like environment, so there is also a wicker sofa with pink and blue cushions on the left side of the room, as well as plants and flowers in different places in the office. B2 and B3 share an office, which is in an inside room, more separated form the rest of the office. I sat in the far right corner of the room, an unobtrusive place where I was able to see Rose, her bosses, and any person who came through the door.

The network analysis began at about nine o'clock in the morning when Rose arrived at her office. Rose told B1 that I would be present all day. B1 then greeted me, expressing her pleasure at having me in the office that day, and asked some quick questions about the nature of the analysis to be done. As soon as I sat in the corner, everyone went about their jobs and tried not to notice me.

\section{Results}

The results of the network analysis showed that Rose's network at her workplace is composed of her four bosses, co-workers, callers on the phone, and other participants (see Figure 1). All the interactions were carried out in English. Any exchange of speech, either originating from Rose or directed to Rose, was considered an interaction. If a third person (or more) participated in the conversation, it was still considered the same interaction, but whenever the topic was changed or a new participant initiated 
ROSE'S WORKPLACE SOCIAL NETWORK

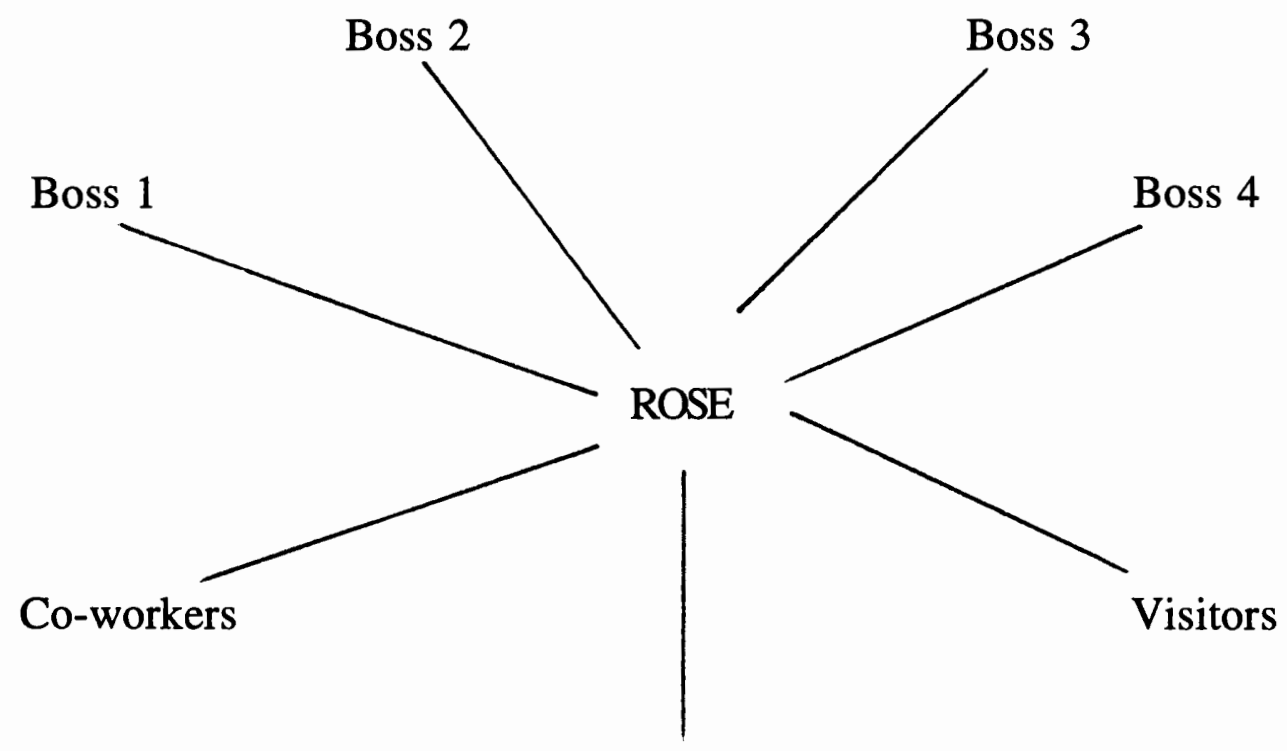

Callers on the phone

Figure 1. Rose's Workplace Social Network 
speech toward Rose, it was considered a new interaction. During the eight-hour period of the analysis, sixty-two interactions were recorded. Of these sixty-two interactions, fifteen were phone calls that Rose received or made. There were thirty-eight interactions with her bosses, seven interactions with other co-workers, and two interactions with a stranger.

The interactions between Rose and her bosses were varied. They included questions, questions and answers, informing, requesting information, instructing, commenting, clarifying, responding, complimenting, greeting, and small talk. The topics were usually related to the office and the office budget, which they were working on that day. The small talk focused on plans for the weekend, the upcoming Valentine's Day, and things that had happened during the week. Most of the interactions were unequal in nature, except for the small talk and joking. Most of them also took place in Rose's territory, here defined as the space she occupies at her desk and the space around it. Rose's bosses often entered her territory, and Rose sometimes went into their territories (their offices or working spaces).

Rose's interactions with people on the telephone were questions, questions and answers, information exchange, informing, requesting assistance, and explaining. The key of the interactions was usually serious, and they were all in English. The interactions were equal, and the territory was Rose's.

The seven interactions with co-workers were generally questions and answers, requesting, requesting assistance, small talk, 
and greeting. The message form was always English. The usual participants were co-workers that Rose happened to meet in the copy room, and the interactions were always equal.

In addition to the interactions recorded during the day, Rose and two of her bosses (B1 and B2) attended Mass at noon, and I went along with them. Because it was impossible to take notes during the Mass, I wrote notes later. The Mass, which related to Lent, took about forty-five minutes, and was carried out in English.

After Mass, Rose and I bought lunch and returned to Rose's office, where B1, B2, and B4 joined us for lunch. During lunch, which took about forty-five minutes, the topic of conversation was movies at the beginning, and later, Rose's bosses were interested in knowing more details about this study. The conversation was in English.

During the day, there were also periods when no interaction took place, when Rose and her bosses were working silently without talking. These periods of time ranged from five minutes to fifty minutes, interrupted only by an occasional phone call.

\section{Conclusions}

In conclusion, the network analysis showed that Rose's interactions at her office are carried out entirely in English. She has reported that she seldom has the opportunity to speak Spanish at her job. Although some employees do speak the language, Rose prefers to speak English with them. During this network analysis, none of these employees came to the office. In informal observations, Rose's use of only English at her workplace was confirmed. Informal 
observations also confirm that Rose uses English when interacting with the physically challenged people, who obtain assistance at her office.

Because it was impossible to conduct a network analysis in Rose's home, I have relied on Rose's reports of her language use and on my informal observations, in order to draw conclusions concerning her language use at home. English is the language that is always used in Rose's home, except in instances when Rose helps her children with their homework in Spanish, or when she reads stories to them in Spanish.

Finally, this network analysis supports the conclusion suggested by her language life history, namely that Rose's predominant language is English, and that her use of Spanish has been decreasing over the years primarily due to changes in her environment. Gradually, English has replaced Spanish in areas where Spanish was formerly predominantly used, for example, in her family circle. As a child and a teenager, mostly Spanish was used in her home by her parents, especially her mother. The continuous visits to Mexico also made Rose use her Spanish. As the years went by, and Rose got married and had her own family, English took the place of Spanish in this area. Even the visits to Mexico have decreased, and when she does visit, she uses more English each time. Nowadays, Rose's environment is predominantly English, and she uses Spanish very infrequently. 


\section{CHAPTER V}

\section{ANALYSIS AND CONCLUSIONS}

\section{INTRODUCTION}

The purpose of this case study was to present the language life history of an American woman of Mexican descent. Rose narrated her life experiences of growing up while learning and using two languages. She described her perceptions of Spanish and English, her perceptions of her own background, and her changing attitudes toward Spanish and Mexican culture. Her language life history revealed how she went through various stages of bilingual language development, how she learned the majority language, English, and how, in the end, this became her dominant language. Her story is a testimony of the life of an immigrant and of her struggles with two languages and two cultures throughout her life.

\section{STATEMENT OF THE HYPOTHESES FOR THIS STUDY}

During the interviewing and analysis processes of this study, a series of hypotheses was formulated based on the data being collected both in the interviews and from the theoretical research regarding bilingual development, language use, language shift, and 
language maintenance or loss. The following is a listing of the hypotheses formulated during this study and an explanation of the way they relate to Rose's language life history.

Hypothesis \#1

Language use changes throughout the life-span of a bilingual and varies according to the person being addressed, the situation, the place, and the particular period in the life of the bilingual.

This hypothesis was generated by examining Rose's narrative because it showed that throughout her life, her uses of English and Spanish have been in constant change. The different uses that she assigned to English and Spanish were directly influenced by the situation in which she was involved, whether it was with her family, in school, with her friends, or in Mexico. In her life, these situations varied, and thus, her choice of language varied.

\section{Hypothesis \#2}

Language use may be accounted for in terms of the social interaction that the bilingual and the bilingual's family have with the surrounding environment.

Rose's changing language use is an example of this hypothesis. Her bilingual development and the ways in which she used English and Spanish were always influenced by her social environment. For instance, as pointed out before, Rose grew up in a neighborhood where hers was the only family that spoke Spanish. This 
environment fostered the use of English. Had Rose's family lived in an area of Stockton where there were more Spanish-speakers, she would probably have been able to develop very different uses for her Spanish and English.

Hypothesis \#3:

Changes in language use may be accounted for in terms of the family's motivation to learn English as a way of fully merging into the majority community.

The formulation of this hypothesis is related to Rose's explicit statement that her parents' and her own desire to assimilate fostered the use of English within the family circle. The family's motivation to merge into the majority community in Stockton was strong enough to give up their Spanish in favor of English. Rose's parents' concerns about their children's success in school in the United States was another strong motivation for learning English. They realized the importance of education for the future success of their children within American society.

Hypothesis \#4

The changes in language use are directly related to the process of language shift, and thus to the issues of language maintenance and language loss.

Throughout the narrative of Rose's life, this hypothesis was suggested. Her language life history shows that the changes in her use of Spanish and English caused English to gradually supersede 
Spanish, and ultimately resulted in her language shift to English. The result was the loss of Spanish, not only in the uses Rose assigned to it, but also in her proficiency in the language. This leads to the conclusion that the number of uses for and the level of proficiency in a minority language determines its survival within the minority group.

\section{Hypothesis \#5}

The bilingual development of a minority child is directly affected by social forces in the child's environment.

Rose's life history has shown the ways in which her family, friends, school, and neighborhood influenced her bilingual development. Rose used Spanish and English in different situations, and the uses of her languages were always linked to her social environment.

\section{ANALYSIS OF ROSE'S LANGUAGE HISTORY}

A key result from examining Rose's language life history is an understanding of her process of language shift. This process took place because of the changes in her use of English and Spanish throughout her life. Consequently, as she became older, Spanish replaced English in almost all domains. Through a language domain analysis, her language shift can be understood. This confirms Pedraza's (1985) assertion that in order to understand language shift 
and language maintenance or loss, it is necessary to understand how language is used in everyday behavior.

The following language domain analysis is divided into three chronological parts, covering three periods of Rose's life history: childhood, adolescence, and adulthood. In each part, the major language domains that emerged from her language history are analyzed to determine how Rose's uses of Spanish and English changed. The domains enumerated here are based upon Fishman (1975), with adaptations to suit Rose's particular language domains. These domains are: family, school, friends and neighborhood, Mexico, and religion. Later in Rose's life, the school domain is replaced with the workplace domain. Table I summarizes the domains and Rose's language use. Along with the language domain analysis, relevant points of Rose's bilingual development and of the language patterns within her family are discussed because these factors also affected her language use and language shift.

\section{Early Years}

Family. As mentioned in the review of the literature, the first challenge immigrants to the United States face is a new language and, with it, a new culture different from their own.

The immigrant's original language now is in constant contact and must coexist with the new language spoken by the majority group. Within the family circle, each member develops a different proficiency in the new language and individual ways of using it. The 


\section{TABLE I}

ROSE'S LANGUAGE USE AT DIFFERENT PERIODS

OF HER LIFE

\section{Domain of Lan}

\section{Family}

father

mother

siblings

housekeepers

School

teachers

classmates

friends

Friends \& Neighborhood

friends

adult neighbors

Mexico

cousin

relatives

cousin's friends

$\underline{\text { Religion }}$

prayers at home

Church in Stockton

Church in Mexico

Religious Ed. classes
Spanish

English

Both

XX

XX

XX

XX

XX

$\mathrm{XX}$

$X X$

$\mathrm{XX}$

$\mathrm{XX}$

$\mathrm{XX}$

$\mathrm{XX}$

$\mathrm{XX}$

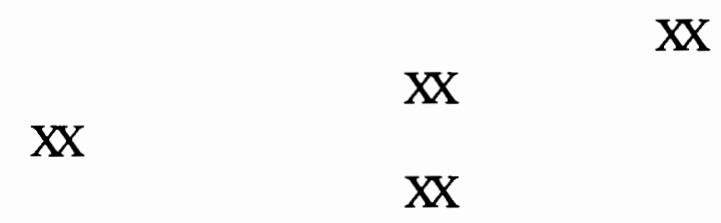

TEENAGE AND COLLEGE YEARS

Family

father

mother

siblings

School

teachers

classmates

friends
XX

$\mathrm{XX}$

XX

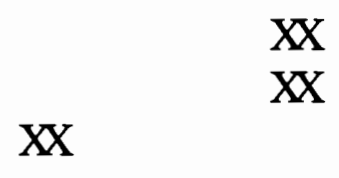

XX

$X X$

XX 
TABLE I (continued)

ROSE'S LANGUAGE USE AT DIFFERENT PERIODS

OF HER LIFE

Domain of Language Use Spanish English Both

Friends \& Neighborhood

friends

adult neighbors

$\underline{\text { Mexico }}$

cousin

relatives

cousin's friends

$\underline{\text { Religion }}$

prayers at home

Church in Stockton

Church in Mexico

Religious Ed. classes

personal prayers
$X X$

$\mathrm{XX}$

$\mathrm{XX}$

$X X$

$\mathrm{XX}$

$\begin{array}{ll}\mathrm{XX} & \mathrm{XX} \\ & \mathrm{XX} \\ & \mathrm{XX}\end{array}$

ADULT LIFE

Family

mother

siblings

husband

children

Workplace

supervisors

work mates

Friends \& Neighborhood neighbors

Mexico

$$
\text { relatives }
$$

Religion

Church

personal prayers
XX

$X X$

$X X$

$\mathrm{XX}$

$X X$

$\mathrm{XX}$

XX

XX 
father, the mother, and the children now need to develop new communication skills to use in their social network.

In Rose's family the sudden coexistence of two languages occurred when the family returned to Stockton for good when Rose was five years old. There, her father started his practice, her mother worked at home, and the children went to school. The language patterns of Rose's family were similar to the ones discussed by Grosjean (1982) and Bossard (1945). Rose's father was very proficient in English. He used it in high levels of proficiency in his profession as a doctor. At home, he used Spanish, especially with his wife. With his children, he used a mixture of both languages. Rose's mother was more secluded, since she spent most of the time at the house. Her contacts were limited to acquaintances and friends of her husband; thus, her dominant language was Spanish, which she used with Rose and the other children.

Rose's brothers and sisters had various levels of proficiency in English and Spanish, as evidenced by their use of these languages. Although all of the children brought English home from school, their friends, and their neighbors, the older children still used more Spanish than the younger children. This was because they had been exposed to Spanish for a longer time than the younger siblings had before they arrived in the United States. The older brothers and sisters had also been to school in Mexico. In the United States, they experienced some trouble with English at school. The younger children, on the other hand, did not have problems with English. Rather, because they had not had enough exposure to Spanish, except 
at home, their proficiency and use of this language decreased while their proficiency in and use of English increased. These circumstances closely resemble the patterns that Fishman (1972) describes, namely, that the older children are more retentive of the minority language in contrast with the younger children, who are less retentive. In younger children, then, language shift occurs at a faster pace, and they may, therefore, become agents who accelerate the rate of language shift within the family and the minority community at large.

Rose was one of the youngest in her family. She was never forced to speak Spanish at home. Although there was always a mixture of both languages present in her family environment, Rose reports very distinctive uses of each language within the family. She clearly remembers that, as a child, she always spoke English to her brothers and sisters, half English and half Spanish with her father, and mostly Spanish with her mother. When the family had housekeepers, she always spoke Spanish to them. These facts reveal that Rose, as a young child, was aware of when and with whom she used either English or Spanish. Rose's choice of language depending on the person being addressed supports Hoffmann's (1991) assertion that young bilingual children differentiate their two languages early in life.

Both Rose's family's habit of mixing English and Spanish and the fact that her parents did not require Spanish to be spoken at home helped Rose not to feel a sharp contrast between the language spoken at home and the language spoken at school, in the 
neighborhood, and with her friends. Rose reported that her parents clearly wanted her and her siblings to succeed in school and in American society. Therefore, they did not want to "burden" the children with learning Spanish. This statement shows that parental attitudes and expectations deeply influence the development of both the native language and the majority language. Rose's parents believed it was worth sacrificing their language for the sake of the children's easy adaptation to school and to American society. These attitudes of Rose's parents toward English and Spanish confirm what Grosjean (1982) and other researchers have mentioned that the immigrant's own attitudes toward the majority and the minority languages determine the degree of the minority language's maintenance within the family circle.

School. Another important factor in Rose's language shift was her schooling. As Hoffmann (1991) and Romaine (1989) assert, school is one of the major factors in language shift since children spend most of their day in school with their teachers and friends. If immigrant children are taught only in the majority language, it is very likely that that language will become their dominant language in the future because it has become their tool for learning and relating to their environment.

Rose attended a private school where English was the only language of instruction. When Rose began her schooling in kindergarten, she did not experience language problems. Rather, her English developed at the same pace as it did for the native-speaking children in her classroom. Rose reports that they were all at the 
same level, learning the colors and the names of things. Rose's smooth linguistic transition to school clearly contrasts with the problems experienced by her older brothers and sisters, who were held back a year in school in order to attain the linguistic competence to perform the academic tasks required. These contrasting experiences of Rose and her older siblings illustrate Cummins's $(1979,1980)$ theories regarding language proficiency and cognitive skills. According to Cummins, language proficiency has two dimensions, superficial competence which corresponds to speaking and listening skills, and a cognitive-academic competence which uses language as a tool for cognitive functioning. It is clear that Rose's siblings had developed surface proficiency of English because they were able to easily communicate in English, but when new academic skills were required in school, the older children had to be held back in order to catch up with their native-speaking classmates. This reveals that the English proficiency of the older children was not developed enough to perform academic work at the level of English speakers. Rose, however, did not have that problem because, being younger when she moved to the United States, she had more time to attain the necessary level of language proficiency.

Although the older brothers and sisters had these language problems, they were able to overcome their language obstacles and develop enough proficiency to graduate from high school and go on to college. This shows that, as Hoffmann (1991) points out, the development of Cummins's two types of language proficiency is just a part of language learning. The factors of motivation and a positive 
attitude are also extremely important in the academic success of second language learners. In Rose's family these two other factors were also met. The children were hard workers and very dedicated in school, which helped to minimize their language problems in the United States. In addition, Rose's parents' expectations and support of their children's education played a key role in the successful schooling of the older brothers and sisters. Allowing their children to freely speak whichever language felt more comfortable was very important in not hindering the children's academic performance at school.

Friends and Neighborhood. Another factor to be taken into consideration in Rose's language shift to English is her social environment. In addition to home and school, her social environment was composed of her friends and acquaintances in her neighborhood. Rose's childhood friends were "completely American," as she narrated in her language life history, and spoke only English. This domain of her life was very important because, as Hakuta and D'Andrea (1992) found in their research with Mexican-American high school students, peers are a key influence on the language choices made by immigrant children. In fact, Hakuta and D'Andrea (1992) found that peers' choice of language was even more important than the family members' choice of language.

Rose did not have contact with other Hispanic children. She reported being acquainted with some in school, but she never interacted with them. 
The Stockton neighborhood in which Rose grew up also influenced her language development. Rose's parents were middle class, educated Mexicans. They did not belong to the migrant/farm worker class of Hispanics in Stockton and, in fact, chose to live in a middle-class neighborhood in the northern part of Stockton, far away from the concentration of Mexican migrants in the southern part of town. The dominant language in Rose's neighborhood was English, so Rose and her siblings needed English in order to communicate and play with the children in the neighborhood. This spurred Rose to further develop her English.

Rose's physical distance from the migrant Mexican workers and their neighborhood was evident in her narrative. She explained that she visited that part of town only occasionally while her father made his rounds. Rose recalled seeing advertisements and signs in Spanish, but she had no friends or acquaintances in the Hispanic neighborhood. If Rose's family had lived in the Hispanic neighborhood, Rose's Spanish development would undoubtedly have been different. Grosjean (1982) asserts that the geographic concentration of the members of the minority group is very important in the maintenance of the minority language. The higher the concentration, the more likely the language is to be maintained. On the other hand, if some members of the minority group move to a neighborhood dominated by people from the majority group (as Rose's family did), contact with the minority group decreases, and so does the use of the native language. Consequently, use of the majority language increases, and the majority language begins taking 
over domains which formerly belonged solely to the minority language. Another facet of geographic concentration is isolation. Grosjean (1982) points out that the degree of isolation the minority group has in relation to the majority group determines the level of minority language maintenance. The more isolated the minority group is, the more likely the minority language is to survive. In Rose's case, her family was the only Spanish-speaking family in the neighborhood, so they needed to use English to interact and socialize with their neighbors. They could not isolate themselves from the majority group.

Mexico. Rose's vacations in Mexico throughout her childhood never created a problem in the area of language. Her Spanish proficiency was always good enough to communicate with her relatives and with her cousin, Quiquis. This indicates that while her Spanish proficiency was good, at the same time, the Spanish she needed to use was simple and very similar to the Spanish she used at home in Stockton. This domain of language use is very important in order to understand what later happened to Rose's Spanish.

Religion. In this domain there was an interesting mixture in Rose's childhood. The Mass services and other religious ceremonies in the family's parish were held in English since there were no other Spanish speakers in the neighborhood. Rose's parents prayed in English in those services, but at home they used Spanish for their personal prayers. Most of the family prayers, especially the rosary, were also in Spanish. Thus, Rose did learn her prayers in Spanish, but since parish Masses and her religious education classes at school 
were all in English, she used mainly English in her religious life. In this domain then, both languages were competing for precedence.

\section{$\underline{\text { Rose's Teenage Years and College Years }}$}

Family. Rose's family environment did not change much during her teenage years. She continued to use a mixture of English and Spanish at home although she used English more frequently than before, even with her mother. Rose perfectly understood her parents' Spanish, but she replied in English most of the time. According to Grosjean (1982), this is not uncommon in immigrant families, where the parents speak the minority language, and the children speak the dominant language even to their parents. In Rose's case, her Spanish met the needs of the home environment, and she could resort to English any time she could not express herself in Spanish.

It was during this adolescent period of her life that Rose felt some embarrassment about her Mexican ancestry. Having become acutely aware of language differences, Rose sometimes felt that her parents' accent attracted the attention of other people, and that she did not like that. This is an example of how immigrant children want to be unnoticed, a tendency noted by Bossard (1945) in his study of the personality of bilinguals. Bossard (1945) found that in response to feeling different from other people in society, bilinguals often develop protective devices so as not to be noticed by others. Rose shared some of these feelings. She wanted not to be noticed; she did 
not want to be considered different; she wanted to be completely assimilated.

School. In the school environment, Rose also realized that her background was different. Although at her school she was never singled out as a Hispanic, she did feel self-conscious at times. For example, she told of an instance when she was 11 or 12 years old, and the teacher was making the students read out loud. As another student was reading, Rose saw the abbreviation "vs." and panicked because she felt she would never have known the meaning of that abbreviation. She attributed this lack of knowledge to the fact that she was raised in another language. This example demonstrates that Rose, as a teenager, grew more and more self-conscious of her background and her bilingual upbringing, even though, prior to that time, it had not caused her to feel ashamed or uncomfortable. In her high school, Rose also took Spanish classes. This did not prove to be a factor that improved her language proficiency or increased her desire to use Spanish, however. The classes were very simple, and Rose's Spanish did not benefit from them. In these classes though, Rose wrote and read in Spanish for the first time. Up to that point in her life, she had used Spanish only orally, as is common in immigrant families. Often, the children are proficient in the minority language, but can only speak it and understand it. They do not have the opportunity to write or read the language. This is another factor in the maintenance and loss of minority languages, as Fase, Jaespaert and Kroon (1992) point out. They observe that the maintenance or loss of a minority language depends not only on its 
use by the minority community, but also on the proficiency the individuals in the community develop in the language. Within this proficiency, there are several skills, including speaking, listening comprehension, reading, and writing. If some of these skills are not adequately developed, the proficiency level of the speaker decreases. This decrease, in turn, will directly affect the survival of the minority language.

Friends and Neighborhood. During Rose's teenage years, she became more aware of herself and her surroundings, and the differences in her upbringing began to be more obvious to her than they had been before. Like any other teenager in the United States, Rose began to see her group of peers as more and more important, and she began going out with friends and going to parties. During these activities, she realized that her parents' expectations of her were different from the expectations her friends' parents had of them. Her parents enforced rules that were consistent with Mexican society. For example, the authority of her father was not to be questioned. As Cabrera (1963) noted in his thesis about the contrasts between Mexican and American cultures, unquestionable respect for authority is a characteristic of Mexican culture. Within the family, the father is the head and the authority figure, who must be obeyed. In American society, on the other hand, questioning parental decisions is more acceptable, due to American culture's stress on democracy, which is shown even within the family circle. Rose sometimes found difficult the fact that she was not allowed to question some of her father's decisions, and she attributed this 
strictness to a Mexican way of parenting. The differences between what she saw at home and what she saw in the outside society evoked conflicting feelings in Rose.

Rose's neighborhood in Stockton did not change; neither did her use of English with her neighbors change. In the society at large in Stockton, Rose began to perceive that there were some negative feelings towards Mexican migrants. She formed these perceptions based on people's comments, television, and newspapers, which depicted the migrants as poor, uneducated, and prone to violence. These negative images made Rose feel uncomfortable with her background at times. Although she never took pains to hide her background, she did not promote it, either. This also affected her language. At that point, using Spanish was not a priority, and she used English more and more. By her own account, Rose wanted to assimilate. This again relates to Bossard's (1945) study of bilinguals in which he asserts that minority children want to assimilate; they do not want to be considered different. Grosjean (1982) and Hoffmann (1991) also maintain that the environment where bilinguals grow up is of extreme importance in their willingness to assimilate. In addition, the messages immigrants receive from their environment drastically influence the maintenance or loss of the minority language (Grosjean, 1982). In Rose's case, her environment in Stockton did not foster her Spanish language development. Furthermore, Rose's own desire to assimilate helped her learn English. 
Mexico. Rose's bilingual development, as she reported, was smooth until she became a teenager. During these years, a disturbing event occurred. During a visit to relatives in Mexico, Rose realized that she could not communicate effectively and fluently in Spanish. For the first time in her life, Rose found herself stumbling over words, being conscious of her accent, and not being able to use verbs and other words correctly. She did not experience any of these troubles with English, which leads to the conclusion that Rose's bilingualism is subtractive in nature (Hoffmann, 1991; Allard and Landry, 1992). This means that her second language, English, was acquired at the expense of her first language, Spanish. As Rose grew older, her environment gradually became dominated by English. By her teenage years, her home was the only place where she spoke any Spanish, and that was almost exclusively with her mother. Because her everyday contact with Spanish occurred in such a limited domain, her development in the language was also limited to the communication needs within the home.

When Rose visited Mexico the summer she was ten or eleven years old, she realized for the first time that her Spanish was not sufficient to fulfill her communication needs. As was discussed earlier, the older a person gets, the more complex the demands of communication become. In other words, the demands on the use of language are more sophisticated (Hoffmann, 1991). This is exactly. what happened in Rose's case. With her relatives, especially with her cousin and her cousin's group of friends, the linguistic demands became more difficult to meet and, in fact, exceeded the limits of her 
Spanish proficiency. This was frustrating for Rose and made her feel slightly isolated from her cousin's group of friends.

It was not until she traveled to Mexico in college and later began her work with the Jesuit Volunteer Corps that Rose reevaluated her background and, along with that, her minority language, Spanish. She began to realize how important and rich her background was, and how much a part of her life it was. To her disappointment, however, her Spanish language development did not improve with this realization. Her dominant language continued to be English, and her life was absolutely surrounded by English. Her situation was similar to Child's (cited in Hoffmann, 1991) study of Italian immigrants. The majority of Child's subjects experienced some degree of language shift from Italian-English bilingualism to English monolingualism even if they strongly identified with Italian culture. Although Rose regained appreciation of her background, her language proficiency and use of Spanish did not increase. This supports the idea that appreciation of or positive attitudes about the minority language cannot replace loss of proficiency or loss of domains of use in the minority language.

Religion. There were not major changes in this domain. Rose mostly used English in Masses, prayers, and religious education classes at school; even inside the home, her prayers were in English, except for few memorized prayers in Spanish. When visiting Mexico, Rose could understand the prayers, but it was difficult to understand the homilies. This reveals her shrinking proficiency in Spanish. 


\section{$\underline{\text { Adult Life }}$}

Family. Major changes occurred in this area. Rose got married and formed her own family. As time went by, Rose's bilingual proficiency changed further when compared to her childhood. English has become her dominant language, and her uses of Spanish are limited to visits to relatives in Mexico (which have become less frequent with time), some contact with her parents in Spanish, and occasionally helping her children with Spanish homework. In essence, English has superseded Spanish in all domains, even in the most intimate one, the family. Rose's current life is carried out completely in English. She uses English with her husband, her children, her brothers and sisters, and her mother.

A significant point, however, is that Rose's children attend a Spanish immersion program at a public school in Portland. Rose has come to realize the importance of knowing a second language. Interestingly, not only have the children benefited from attending the program, but Rose's awareness of the richness of her Mexican background has also been enhanced, and she has learned a great deal about the Spanish-speaking world. Because of her new knowledge, Rose has come to recognize that the environment is more open toward Spanish and Spanish-speakers than she had previously believed. The fact that her children are in the immersion program is also pleasing to Rose's own parents, who like the idea of their grandchildren learning their language. 
Workplace. As Rose began her adult life, the workplace domain was added while the domain of school was dropped out since her schooling was complete.

Rose's job at the Senior Citizen Center, where she worked for a year, demanded daily use of Spanish, and her job at the University Hospital, where she worked briefly, required occasional use of Spanish. At both jobs, the experiences with Spanish proved challenging, due to her proficiency in Spanish, which was not adequately developed to fulfill these more complex communication needs (Hoffmann, 1991).

At her current job, Rose does not have any contact with Spanish. The only exception to this is an occasional visitor or caller on the phone, and those contacts continue to be challenging, again due to limited development in her Spanish proficiency. English is the only language she speaks with supervisors, co-workers, and visitors, as the results of the event/network analysis verify. English has always dominated the workplace domain of Rose's life.

Friends and Neighborhood. Rose uses only English with all her friends at present. In her neighborhood, there are only English speakers. Therefore, her contacts in her social environment are completely carried out in English. In the city where she lives, the Hispanic community is relatively small, and Rose is not involved with it at all.

Mexico. This domain of Rose's life is almost non-existent at present. Except for a few contacts with her parents when they lived in Guadalajara, Rose has traveled to Mexico only twice in the last few 
years. The last trip she made was when her father died. This last experience was frustrating for Rose at times because her Spanish proficiency was not developed enough to handle the delicate situations that she had to deal with during her father's illness. Mexico is the last domain where Spanish dominates, but since this domain is gradually decreasing, Rose's contact with Spanish is also disappearing.

After Rose's father's death, her mother moved to California to live with one of Rose's sisters. Rose visits her occasionally, but as she narrated at the end of her language history, she uses mostly English with her. Rose still has relatives in Mexico, but traveling has become more difficult now that she has a family. This reaffirms the importance of preserving ties with the home country (Grosjean, 1982) in order to maintain the minority language. The more ties, the more likely opportunities there are for the minority language to be used. Because this domain is so limited in Rose's case, it cannot be a way of increasing Rose's Spanish use.

Religion. This area is completely dominated by English at present. Rose's prayer life, Masses, and religious ceremonies are carried out entirely in English. She is still able to recall some memorized Spanish prayers, but they do not have the significance that her prayers and spiritual life in English have.

\section{CONCLUSIONS}

This section reports general conclusions drawn from the various aspects of Rose's language development and language shift, 
and an explanation of their relation to the issues of language maintenance and loss. These conclusions are also based on the theoretical considerations raised in Chapter II.

1. The effectiveness of Rose's language shift was predictable by examining her life and observing the way English gradually took the place of Spanish. In her childhood, Spanish was used at home, but not in other domains. The process of language shift in Rose's case, then, is understandable because her Spanish had very limited uses, and she did not develop the proficiency necessary to use her Spanish in more complex, sophisticated areas, such as in a job.

As Fase, Jaespaert, and Kroon (1992) note, in order to maintain a language, it is necessary to maintain both its uses and an adequate proficiency. Once there is a significant reduction in both the speaker's uses of a language and the speaker's proficiency in the language, the process of language shift begins. At this point, it is possible that the speaker could lose the minority language, which would then be replaced with the majority language.

Before kindergarten, Rose's life began with only one domain that was strictly English, namely, her neighborhood. The other domains, including her family, were dominated wholly or almost wholly by Spanish. As time went by and she went to school, began making friends and interacting in English with her siblings, she began using English more. Ultimately, English completely replaced Spanish in her adult life, except for one domain, Mexico. As Fishman (1972) asserts, domain analysis proves very helpful in analyzing language maintenance or loss. 
The analysis of Rose's language use domains determines that Rose lost her Spanish because the number of her Spanish language domains gradually decreased. Her Spanish proficiency dropped, and she shifted to English as her dominant language. If other immigrant people experience language shift processes similar to those of Rose and her family, it is easy to understand why the maintenance rate of minority languages in the United States is so low.

2. Within each of Rose's language domains, she used one or the other of her languages depending on the person being addressed, the topic, and the place where the interaction took place. This is observable in her family circle when, as a child, Rose knew she needed to use Spanish with her mother and the housekeepers, English with her siblings, and a mixture of both with her father. As an adult, she still uses Spanish with her mother whenever she needs to clarify a point. As Hoffmann (1991) states, the use of any of a bilingual's languages is determined by the addressee, the topic, and the place. This relates to language maintenance and loss in the sense that, if there are few addressees, topics, or places where the minority language is used, gradually the minority language will be lost. In Rose's adult life, her last domain of Spanish is Mexico, but since her Spanish proficiency has decreased, even there she uses more English. English is gaining entrance to this last Spanish domain.

3. Another very important aspect of Rose's language shift is the social forces that were involved in fostering this shift. When Rose was in high school, she perceived negative attitudes on the part of people in Stockton toward Spanish-speakers. Thus, the message 
she received from society was that knowing English was more important than knowing Spanish. All this contributed to her lack of motivation to learn more Spanish. Her change to English was a requirement in order to adapt to and succeed in American society. As reported in Rose's language history, her parents and her schooling also played crucial roles in not fostering her learning of Spanish.

Rose and her family wanted to assimilate into the society at large. This integrative motivation of theirs (Gardner and Lambert, 1972) was the chief force for them to learn English. Integrative motivation and the assimilative power of the United States are not the only factors that contribute to language shift. As indicated by Grenier (1984) in his study of language shift among Hispanics, there are three other elements in this process: economic incentives, use of English, and the psychological cost of shift. In Rose and her family each of these elements was present. First, in terms of economics, Rose's family was a middle-class Mexican family, who wanted to stay within their own class. In order to maintain their status in American society, they needed to learn English and to assimilate. Secondly, the neighborhood Rose's parents chose to live in and school they selected for the children revealed the desire to learn and use more English. Finally, the psychological cost of language shift was also present, especially, it seems, for Rose's father. Although it seems that Rose's father felt a strong identification with Mexican culture, he did not force it on his children. This ultimately cost him the Mexican identity of his children because Rose grew up considering herself not a Mexican, but an American with Mexican roots. Her weak 
identification with Mexican culture encouraged her assimilation and her language shift. For Rose there was also a psychological cost. While growing up, she felt different from other people in her school, neighborhood, and city. She assimilated, but even today, it seems she feels confused. She feels she cannot fully identify with her Mexican background, which is evident in her reluctance to speak Spanish and, at the same time, she does not feel totally American because she still has ties to her Mexican origins. These ties are her relatives in Mexico, her mother in California, and the traces that Spanish has left in her English, as she stated in her language life history.

4. Social expectations were another factor in Rose's bilingual development and shift to English; she learned the majority language because, as a child from a linguistic minority, that was expected from her. The social pressures received from her school, family, and friends were factors that played an important role in her English language learning. Skutnabb-Kangas (1984) accounts for the bilingual development of children by pointing out that the social factors involved in the language learning of majority children are different from those involved in the language learning of minority children. Minority children such as Rose receive pressure to learn the majority language and to assimilate. On the other hand, majority children learning a minority language do not experience this pressure because their language learning is a choice rather than an obligation. Learning the language is not crucial for the children's future. This is the case with Rose's children. They are learning 
Spanish through an immersion program, where Spanish is viewed as a foreign language, important only for educational and career reasons. The status of Spanish is much different in the case of Rose's children than it was in her case.

5. A paradox arises when Rose's language life history is compared with her children's experiences. In fact, Rose's children's educational situation is exactly opposite from Rose's situation when she was a child in school. Rose's children are considered majority group members because they are native English speakers. Through their Spanish immersion program, they are considered to be learning a foreign language. However, when Rose was young, she was considered an immigrant, member of a linguistic minority, who needed to learn English in order to succeed in American society. Rose's children's situation is privileged and is supported by their society, which currently views learning a foreign language as beneficial. Rose's situation as a child was viewed as a disadvantage. Society did not support her bilingualism and knowledge of a language other than English. This ambivalence is pointed out by Ruiz (1987), who argues that, in the United States, minority languages are "discriminated against" (p. 11) while foreign languages are seen as "formal subjects" (p. 11) to be taught. According to Ruiz, American society believes that minority languages should not be preserved because they are considered divisive. Foreign language study is acceptable as long as it remains a "foreign language" (Ruiz, 1987, p. 11). These are the reasons that Rose's children will possibly be able to maintain their Spanish, because their language learning is 
supported; and also, these are the reasons that Rose could not preserve her minority language. Her language was seen as an obstacle to her assimilation into American society.

6. As described previously, the patterns of language use in Rose's family are similar to those described by Grosjean (1982) and Bossard (1945). It is interesting to examine these patterns in terms of generations. As Hoffmann (1991) points out, by the fourth generation of immigrants, the original minority language typically disappears. Rose belongs to the second generation. She uses both languages, but clearly shows a preference for the majority language. This can be explained in light of the fact that she is one of the youngest children in the family. Her older brothers and sisters tend to use the minority language more than she does. Although Rose has recently acquired a stronger appreciation for her minority language and background, this has not increased its use. This phenomenon was accounted for by Fishman (1972) when he asserts that younger second generation immigrants do not have strong negative feelings about their minority language. However, though they may appreciate it, they do not use it.

The patterns observed by Grosjean (1982) and Bossard (1945), as mentioned above, also describe the third generation of immigrants. Rose's children, who constitute the third generation, seem to follow this pattern in that they are native speakers of the majority language, which is also their dominant language. However, because they attend the Spanish immersion program, their use of the minority language is significantly higher than would usually be 
predicted by the patterns mentioned above. This is important to note because it demonstrates the ways that outside factors can affect the usual patterns of language shift within society.

7. It is important to analyze Rose's support of her children's learning of Spanish. Rose believes that by learning Spanish, her children will have an important tool for the future and, at the same time, they will have a better appreciation of their own background. This relates to Hansen's (1938) theory concerning the third generation immigrant. According to him, third generation immigrants usually go back to their roots and reclaim them. This is somewhat paradoxical because the first generation came to the United States to live, the second generation was native-born and wanted to assimilate as quickly as possible; then, the third generation looks back and tries to regain its lost roots. In a sense, that is what Rose is helping her children to do. Although Rose belongs to the second generation of immigrants, she appreciates the importance and richness of her background and minority language. She wishes to transfer this feeling to her children, so that they can maintain some of the characteristics of their background, one of the most important being the Spanish language.

8. Rose stated in her language history that she prefers and feels more comfortable with English. That is her language, and she also feels close to American culture. She appreciates her Mexican background, but her Spanish proficiency is not as good as she wished.

Although Rose terms the Spanish she knows now "textbook" Spanish, which, to her, is not natural and does not have the right 
accents and phrases, the legacy of Spanish in her life is present in her English language. As she reported, she uses phrases in English that are direct translations from Spanish and which are traces of her upbringing. There are also other traces: Rose's brothers' and sisters' slight Spanish accents in their English, the fond memories of her parents speaking Spanish, especially the terms of endearment, prayers, the soothing sensations she experienced then and, especially, her capacity as a listening person, always alert to the world outside.

9. Rose's language life history is a reminder that the phenomenon of bilingualism is constantly changing. Hyltenstam and Obler (1989) refer to the changes in the linguistic behavior of bilinguals as "spectacular" (p. 3). According to these researchers, bilingualism is never static because the uses speakers assign to their languages are constantly changing and being adjusted to the different circumstances and conditions in the bilinguals' lives. During this process, the bilinguals' languages change in terms of their usefulness, in terms of the domains they occupy in the bilinguals' lives, and in terms of the proficiency that bilinguals ultimately attain in each of their languages. This was certainly the case for Rose. As discussed in the previous analysis in this chapter, throughout Rose's life, her acquisition and use of English and Spanish varied according to the situation in which she found herself. The interplay of both languages has marked and will continue to influence Rose's life. Bilingualism is a life-long process that never ends. 


\section{ROSE'S COMMENTS ON HER LANGUAGE LIFE HISTORY}

After reading her language life history, Rose expressed satisfaction with it. She considers this study "immensely valuable" for her, for her children, and for her family. The experience of bringing back memories of her life through the interviews was very important to her. Before this study took place, she had her background "pushed aside and hidden." This study helped her to "rediscover" her past and see her background in a new, positive light.

Through the experience of this study, she also became aware of some issues of culture and language that she had not considered before. This reflection process was important to her because, in her everyday life, she does not have time to think about her past and the significance it has for her and her family.

This experience has also reaffirmed her decision to support her children's learning of Spanish. She feels that, through this study, she has regained pride in her background, and she wants to pass this heritage on to her children.

\section{IMPLICATIONS FOR LANGUAGE EDUCATORS}

Rose's language life history uncovers several issues relevant to language educators, discussed below.

1. The narrative of Rose's language life history sheds light on how children from newly arrived immigrant families face the challenge of learning a new language, how this process is played out, and how different factors influence the process. This account may 
help a teacher to understand the life situations of children in her classroom.

2. Rose and her family exemplify the way that two languages coexist in the lives of each member of the family. For a language teacher, this is an important perspective in understanding how children and adults use language.

3. By reading about Rose's experiences, a language teacher may be able to more effectively help students in similar situations. Having seen the perspective of the language learner through Rose, the teacher may be able to better recognize the struggles of immigrant children. Ideally, the teacher would better meet the needs of these students by developing teaching techniques that are uniquely suitable for this important group of students.

4. From Rose's story, teachers may gain insight into the process of language shift and its implications for the maintenance and loss of minority languages. Teachers could then define their own beliefs about the importance of maintaining minority languages and about the importance of teaching the majority language. They could also determine how useful and significant it is to maintain bilingualism among immigrant children.

5. Teachers may gain a new appreciation for minority languages and the important role they play in the lives of immigrant students and their families.

6. If teachers find a student similar to Rose, they may be more sympathetic toward the student, and may have a greater appreciation for the student's situation. Those teachers might also 
encourage the student to rediscover his or her background and language by promoting its learning.

\section{A FINAL THOUGHT}

Rose's language life history has lead to some very significant insights into bilingual development, language patterns among immigrant families, language use, language shift, and the relationship of these to the issues of language maintenance or loss.

However, Rose's history is not meaningful only because of its implications to these issues. Her life experiences with her languages are a living testimony of the immigrant experience in the United States. Life histories such as Rose's are valuable documents on how immigrants live and develop their lives in a new country. As Hakuta (1986) says, the bilinguals' languages leave their traces in the social, psychological, and linguistic experiences of their speakers. That is why he termed bilingualism "the mirror of language" (p. 4).

Rose has allowed us to enter into her mirror of language. Her life, her experiences, her Spanish, her English, her family, Stockton, Guadalajara, and the Senior Citizens Center were the memories of a rich linguistic past, which is the most important result of this study. 


\section{REFERENCES}

Allard, R. and Landry, R. (1992). Ethnolinguistic vitality and language maintenance and loss. In Fase, W., K. Jaespaert and S. Kroon, (Eds.), Maintenance and loss of minority languages. Amsterdam: John Benjamins Publishing Co., 170-195.

Barker, G.C. (1972). Social functions of language in a Mexican community. Tucson: The University of Arizona Press.

Brice Heath, Shirley (1985). Language policies. Patterns of retention and maintenance. In Walker, C. (Ed.), Mexican Americans in comparative perspective. Washington D.C.: The Urban Institute Press, 257-282.

Bossard, J. (1945). The bilingual as a person. American Sociological Review, 10/6, 699-709.

Cabrera, Y.A. (1963). A study of Americans and Mexican Americans culture values and their significance in education. Published Dissertation, University of Colorado, Boulder.

Clyne, M. (1992). Linguistic and sociolinguistic aspects of language contact, maintenance and loss. In Fase, W., K. Jaespaert and S. Kroon, (Eds.), Maintenance and loss of minority languages. Amsterdam: John Benjamins Publishing Co., 17-36.

Crocetti, G. (1993). Second language use in the workplace: A case study of a dental hygienist. Unpublished Master's Thesis, Portland State University, Portland.

Cummins, J. (1979). Cognitive/academic language proficiency, linguistic interdependence, the optimal age question and some other matters. Working Papers on Bilingualism. 19, 197-205. 
(1980). The cross-lingual dimensions of language proficiency: Implications for bilingual education and the optimal age issue. TESOL Quarterly, 14, 175-187.

Dobbert, M.L. (1982). Ethnographic research. Theory and application for modern schools and societies. New York: Praeger Publishers.

Fase, W., K. Jaespaert and S. Kroon (1992). Maintenance and loss of minority languages. Amsterdam: John Benjamins Publishing Co.

Fasold, R. (1984). The sociolinguistics of Society. London: Basil Blackwell.

Fishman, J. (1965). Who speaks what language to whom and when? La Linguistique, 2, 670-680.

(1972). Language maintenance and language shift as a field of inquiry. Revisited. In Fishman, J. (Ed.), Language in sociocultural change. Stanford: Stanford University Press, $76-134$.

(1975). The relationship between micro- and macrosociolinguistics in the study of who speaks what language to whom and when. In Fishman, J. (Ed.), Bilingualism in the barrio. Bloomington: Indiana University, 583-604.

(1991). Reversing language shift. Theoretical and empirical foundations of assistance to threatened languages. Clevedon: Multilingual Matters.

Gal, S. (1979). Language shift: Social determinants of linguistic change in bilingual Austria. New York: Academic Press.

Gardner, R.C. and W.E. Lambert (1972). Attitudes and motivation in second language learning. New York: Newbury House.

Grenier, G. (1984). Shifts to English as usual language by Americans of Spanish tongue. Social Science Quarterly. $65 / 2, \quad 537-550$. 
Grosjean, F. (1982). Life with two languages: An introduction to bilingualism. Cambridge: Harvard University Press.

Hakuta, K. (1986). Mirror of language. New York: Basic Books, Inc.

Hakuta, K. and D. D'Andrea (1992). Some properties of bilingual maintenance and loss in Mexican American background high school students. Applied Linguistics, 13/1, 72-100.

Halliday, M.A.K. (1970). The users and uses of language. In Fishman, J. (Ed.), Readings in the sociology of language. The Hague: Mouton \& Co., 139-169.

Hansen, M.L. (1938). The problem of the third generation immigrant. Rock Island: Augustana Historical Society.

Hoffmann, C. (1991). An introduction to bilingualism. London: Longman.

Hoffman, E. (1989). Lost in translation. New York: Penguin Books.

Hyltenstam, K. and L.K. Obler (1989). Bilingualism across the lifespan. In Hyltenstam, K. and L.K. Obler (Eds.), Bilingualism across the life-span: Aspects of acquisition, maturity and loss. Cambridge: Cambridge University Press, 1-12.

Johnson, D. (1992). Approaches to research in second language learning. New York: Longman.

Mackey, W.F. (1970). The description of bilingualism. In Fishman, J. (Ed.), Readings in the sociology of language. The Hague: Mouton \& Co., 554-584.

Mirowsky, J. and C. Ross (1984). Language networks and social status among Mexican Americans. Social Science Quarterly, $65 / 2, \quad 551-564$. 
Pedraza, P. (1985). Language maintenance among New York Puerto Ricans. In Elias-Olivares, L. (Ed.), Spanish language use and public life in the United States. New York: Mouton Publishers, 59-70.

Rodriguez, R. (1982). Hunger of memory. The education of Richard Rodriguez. New York: Bantam Books.

Romaine, S. (1989). Bilingualism. Oxford: Basil Blackwell.

Ruiz, R. (1987). Foreign language study and bilingual education in the United States. (Paper presented at the annual meeting of the American Educational Research Association, Washington, D.C., April 20, 1987).

Saville-Troike, M. (1989). The ethnography of communication. London: Basil Blackwell.

Skutnabb-Kangas, T. (1984). Bilingualism or not. Clevedon: Multilingual Matters.

Spradley, J. (1979). The ethnographic interview. New York: Holt Rinenhart and Winston.

Stevens, G. (1985). Nativity, intermarriage and mother tongue. American Sociological Review, 50/1, 74-83. 
APPENDIX A

LANGUAGE USE CHARTS 
LANGUAGE USE---IN THE PAST

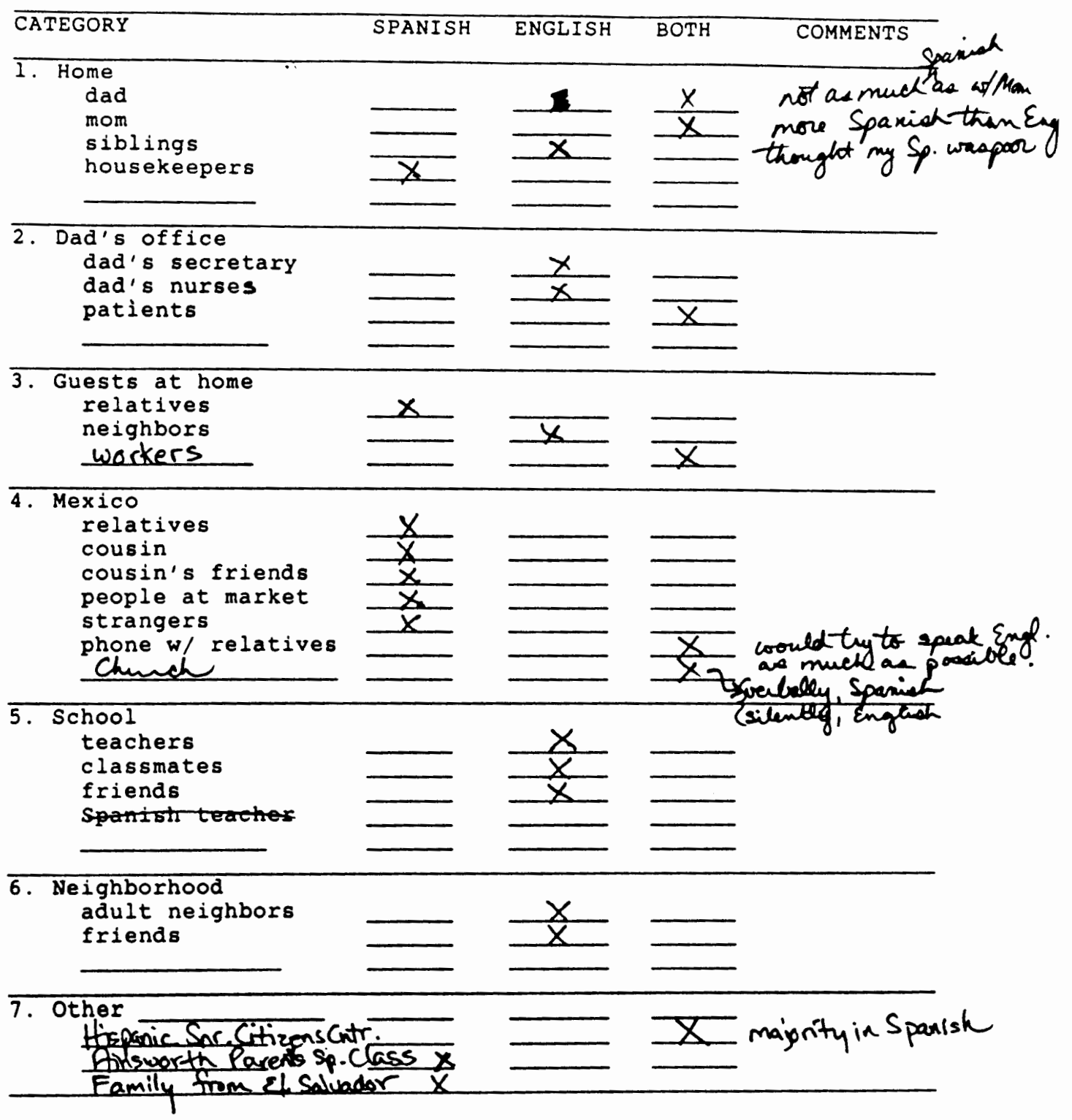


LANGUAGE USE---AT PRESENT

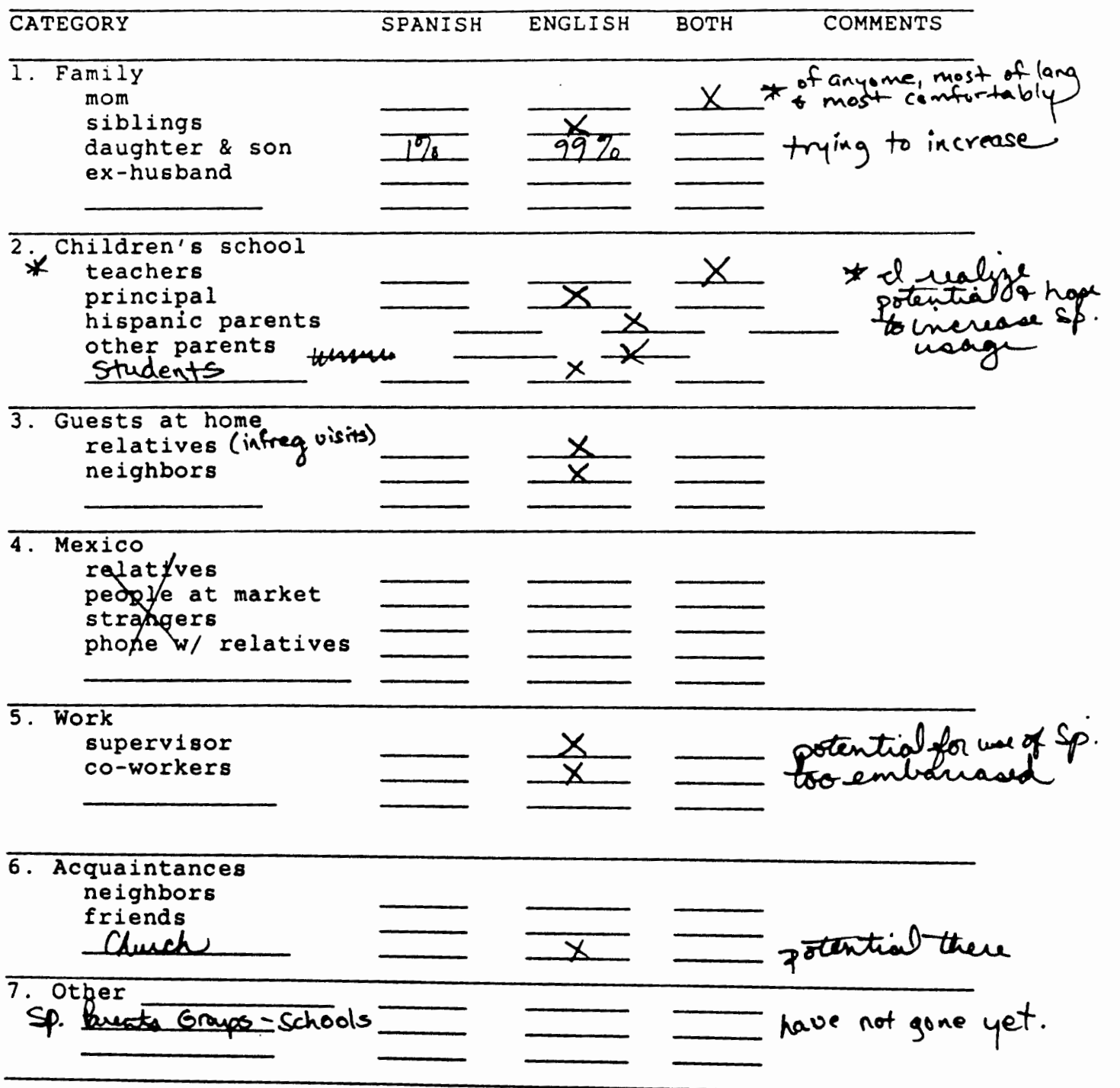


APPENDIX B

RODRIGUEZ'S AND HOFFMAN'S READINGS 


\section{HUNGER OF MEMORY}

\section{By Richard Rodriguez}

In public, my father and mother spoke a hacitant, accented, nox always orammatical English. And they would have to strain-their bodies tense-to auch the ense of what was rapidly said by los gringas. At boose they pooke Spanish. The language of their Mecican pase sounded in counterpoint to the English of public society. The words would corre quickly, with

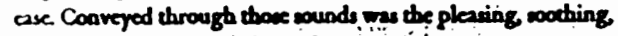
consoling reminder of being it home

$\checkmark$ During those years when I was first conscious of bearing my mocher and father addresod me only in Spanish; in Spapi- is ish I learned to reply. By coatriste, English (ingles), rarely beard in the house, was the language I came to asociate with gringos. I learned my firs words of English overhearing my parenes speak to strangers. At five years of age, I tinew just enough English for my mocher to crust we on arands wo wores one block away. No more.

$\because V$ I was a listening child cencful io bear the very different $\because$ sounds of Spanish and English Wide-yod with bearing, Id lisen to sounds more than wonds. Firse tiece were Englieb

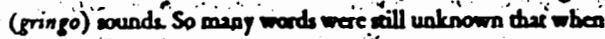

the butcher or the lady at the drugroore said something to me

Exotic polysyllabic sounds would bloom in the midse of their sentences. Ofien, the speecb of people in public seemed to me very loud, booming with confidence. The man behind the councer would literally ask, What can I do for your But by being so firm and so cleas, the sound of his voice said that he was a grimgo; he belonged in public socity.

$\checkmark$ When I was a boy, things were different. The aceent of 10 s gringos was never pleasing nor was is hard to hear. Crowds at Safeway or at bus rope would be noisy with sound. And I would be forced to edge away from ite chirping chanter above me.
I was unable to hear my own sounds, but I knew very well ihat I spoke English poorly. Mi words could noe serech far "enough to form complete thoighte. And the words I did speat I didn't know well enough to make into distina sounds (Lis teners would usually lower their heads, bettic to hear what I was orying to say.) But it was one thing for me to speak English with difficultr. It was more troubling for me to bear my parents - ppest in public: their high-whining yowels and guttural con - sooints; their sentences that got stuck with 'ch' and 'ab' sounds the confused syntax; the hairaing thytho of ounds oo differcit

from the way gringos spoke. I'd notice, moreover, that my parents' voices were softer than those of gringos we'd meet.

$\checkmark$ But then there was Spanish 'Espeatid: my family's language. Espentol: the language that aremed to me a private language. rd hor arangers on the radio and in the Mecican' Catholic

church across town speaking in Spanish, but I couldn't really believe that Spanish was a public language, like English. Spanish speakers, rather, seemed related to me, for I sensed that we shared - through our language - the experience of fecling apan from los gringos. It was thus a ghetto Spanish that I heard and I spoke Like those whose lives are bound by a barrio, I was reminded by Spanish of my separateness from los otros, los gringos in power. But more intensely than for most barrio children-because I did not live in a barrio-Spanish seemed co me the language of bocke (Mout days it was only at home that I'd bear it) It became the langrage of joyful return.

A family mecober would sey something to me and I would forl myself specially recognized. My parents would ay some thing to me and I would foel combraced by the sounds of their words Those sounds said: I am speaking wish case in Spanish. I am addressing you in words I newer we wiets los gringos. recognize you es somecone special, close, like wo one omeside. You belong wish is in the fowily.

$$
\text { (Ricerdo.) }
$$

\% Acte

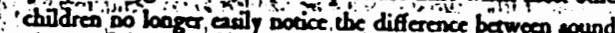

is urecred at bowe and worde apoken in public I had a different experience I lived in a world magically compounded of sounds I remained a child longer than most; I lingered wo tong, poived at ithe edge of language-ofter frighienod by the sounds of la 15 gringos, delighted by the sounds of Spanish at boum. I abared

i) with my family a language that was sartlingly different from

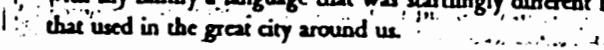


many nights when my father would come back from

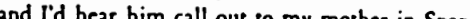
ounding relieved. In Spanish, he'd sound light and free notes be never could manage in English. Some nighes I'd jurnp up just at hearing his voice. With mis hermenos I would corne running into the room where he was with my mocher. Our laughing (so deep was the pleasurel) became screaming. Like others who know the pain of public alienation, we trassformed the knowledge of our public xparateness and made it consoling -the reminder of intimacy. Excited we joined our woices in a celettration of sounds We are speating now the way ue neurer speak ont in public. We are alone-logether, roices sounded, surrounded to tell me. Some nightes, no one sectoed willing to loosen the bold sounds had on us At dinner, we invented new words: (Ours sounded Spanish, but made sense only wo ixs) We pieced rogether new words by taking, ay, an English vert and giving it Spanish ondingz.My mother's instructions :

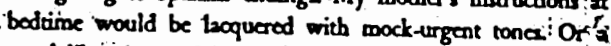
word like si would become in added measure of fecling. Tangua aplored the odguing words copocially the tat rowels. And we bappily soundod this

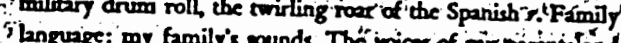

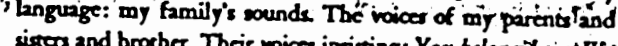
siscers and brocher. Thair wices insisting: You bxiong here: We are fomily members. Related. Spaciel is one another. Iiscent Voices singing and sighing, rising strining, then surging wing with plasure that burst syllables into fragmeatio of Lughtr. At times it secmod there was mendy quidt only when'? froen anocher room, the riselling whispers of in parens fiffod

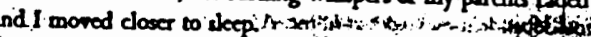

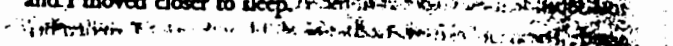


$\checkmark$ Because I wrongly imagined that English was intrinsically 2 public language and Spanish an intrinsically private one I casily noted the difference between classroom language and the languagt of home At schooh, words were directed to a general audience of listences ('Boys and girls') Words were maningfully ordered. And the point was not selfexprossion alone but to make oneedf underrood by many ochers. The eacher quizzed: :Boys and girls why do we use that word in this quead. Boys and girls why do we use thas word in this the sentence change its meaning if the words were differenty arranged? And waserit there a better way of aying much the

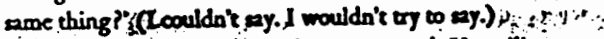

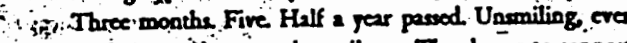
watchful, in teactiers noted my silence. They began wo connect my, behavio with, the diffoult progres - wy older sista and

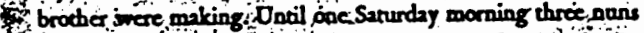

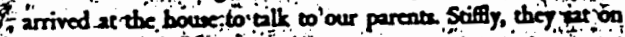

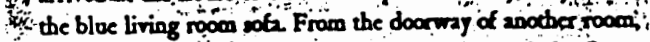
spying the visitions. I noced the incongruiry - the clash nof two worlds the ficos and voices of achool intruding upos the famit-

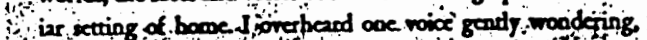

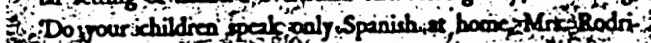

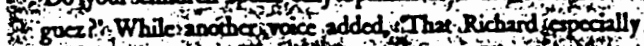

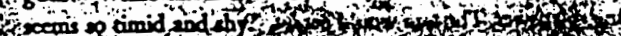

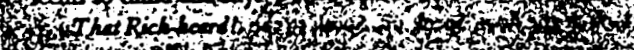

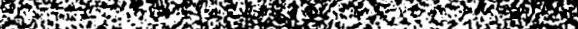
(1)
Anse 121

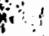

$\therefore$ With great act the visitors continued, Is it possible for you and your husband to encourage your children to practice their English when they are home?" Of course, my parenes complied. What would they not do for their children's well-being? And how could they have questioned the Church's authority which those women represented? In as instant, they agreed to give up the language (the sounds) that had revealed and accentuated aur family's closeness. The moment after the visitors left the change was observed. 'Ahore, speak to us en ingles;' my father change was coserved. Ahore,

$\checkmark$ At firs, it seemed a kind of game After dinner cach nighe the family gathered to practice 'our' English. (It was still then inglts, a language forcign to us, so we felt drawn es stragers to it) Laghing, we would ory to define words we could not pronounce We played with strange Englich, sounds, ofren over. anglicizing our pronumciations And we fillod the smiling gaps of oer sentence with tamiliar Spanish munde But that was cheating sametody shouted. Everyone laughed In -scbool oneanwbils, like my brocker and sirter, I was roquirod to attend a daily tutaring exsion. I needed a fult year of special atiention 1 alo needed my techers to kop my atrention from stringing

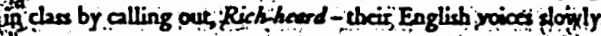

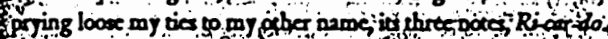

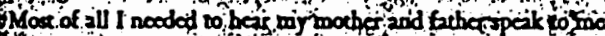
in a moment of ecriouspes in broken -nuddenly heritbraking - English. The senc was ineviable: Ope, Stunday maning I antered the kircheq where iny parenos were alling in Spanish

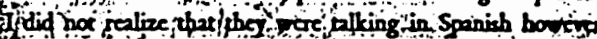

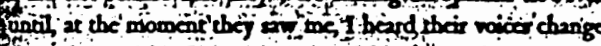

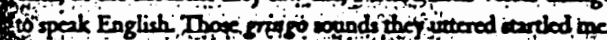

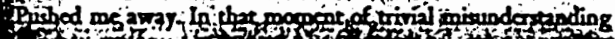

and profound insighe I fele my throat twisted by unsounded and profound ight I a d the room. But I had no place to escape to with Spanish. (The spell was broken.) My brocher and sisters were speaking English in anocher part of the house. 


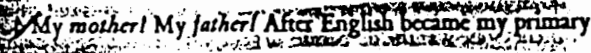

language, I no longer knew what words to use in addressing my parents. The old Spanish words (those tender accents of sound) I had used earlicr-mamd and papd-I couldn't use anymore. They would have been too painful reminders of how much had changed in my life. On the other hand, the words heard neighborhood kids call their parents seemed equally unsatisfactory. Mother and Fasher; Ma, Papa, Pa, Dad, Pop (how I hated the all-American sound of that last word especially) all these terms I felt were unsuitable, not really terms of address for my parents. As a resulk, I never used them at home. Whenever I'd speak to my parents, I would ory to get cheir antention with eye contact alone. In public conversations, I'd refer to 'my parents' or 'my mother and father.'

The silence at home, however, was finally more than a literal silence. Fewer words passed between parent and child, but more profound was the silence that resuleed from my inattenvion to sounds. At about the time I no longer bothered to listen with care to the wounds of English in ipublic; I grew careless about listening to the sounds family members made when they spoke. Most of the time I heard sorneone speaking ar home and didn't distinguish his sounds from the words poople uttered in public. I didn't even pay much atuention to my parents' accented

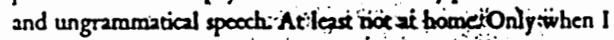
was with them in publici would I grow alent to their socents Though even then, their sounds crused thelles and les concern. For I was increasingiy confident of my own public iden-

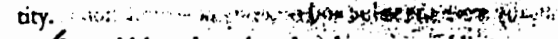

$\checkmark$ I would have been happier abour son public mocoes bad I - not socnetimas realled what is had bocodike eirliä, when my

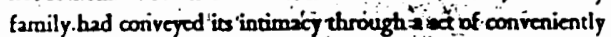

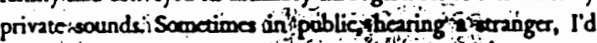

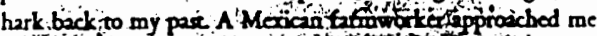

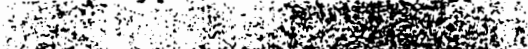

downewn to ask directions to momewhere " $" H i j i t o . .$. ?" he said. And his voice summoned deep longing. Another time, standing beside my mother in the visiting room of a Cormelite convent, before the dense screen which rendered the nuns shadowy figures I heard several Spanish-speaking nuns - their busy, singsong overlapping voices-assure us that yes, yes, we were remembered, all our family was remembered in their prayers. (Their voices echoed faraway family sounds) Anocher day, 2 dark-faced old woman - her band light on my shoulder - stead ied berself against me as she boarded a bus She murmured something I couldn't quite comprehend Her Spanish voice came near, like the face of a never-before-seen relative in the instant before I was. kissed. Her voice, like so many of the Spanish voices I'd hear in publis realled the golden age of my youth. Hearing Spanish them, I continued to be a careful, if ad, listener to sounds Hearing a Spanish-speaking family walking behind me, I rurned to look. I rmiled for an instant, before toy glance found the Hispanic-looking. faces of strangers in: the acrowd going by dims intity

I grew up victim to a disabling confusion. As I grew fuent \% in English, I no longer could speak Spanish with confidence I continued to understand spoken Spanish. And in high echool, 1 loarned bow to read and write Spanish. But for many years I could not pronourice it A powerful guilt blocked my spoken words; an essential glue was missing whenever I'd try to connect words to form sentences. I would be unable to break a barrier of sound, to speak freely. I would speak, or try to speak Spanich, and I would manage to utter halting, hiccuping sound that betrayed my uncase

$\checkmark$ When relatives and Spanish-speaking friends of my parents ame to the house; my brocher and sisters soemed reticent to use: Spanish, but at lost chey managed to any a few neceseary. words before being crcusod, I pever managed so gracefully.yl. was cursed with guilc Each time I'd hear myself addressed in Span ish, I would be unable to respond with any success I'd know. the words, I wanted to say, but I couldn't manage to say them. I would ory to speak, but everything I said soemed to me hor-: ribly anglicized. My mouth, would not form the,words right My jaw would tremble After a phrase or two, Id cough up a

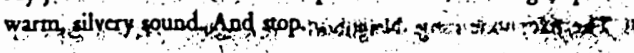


af betrayal by-learning English $\mathrm{But}$ betrayal agains w wom? Noc against visitors to the house cactly. No, I felt thas l had betrayed my immediate family. I knew that my parcinsibad encouraged me to learn English I knew that I had nurped to English only with angry reluctance. But once I spoke English with case, I came to feel guilty. (This guilt defied logic) If fhe that I had shatered the intimate bond that had once peld the Eamily close This original sin against my family told of

$\checkmark$ It surprised my listeners to hear me. They'd lower their heads, betier to grasp what I was trying to say. They would repeat their questions in gentle, affectionatc voices. But by then I would answer in English. No, no, they would say, we want you to speak to us in Spanish. ('. . e en español:) But 1 couldn't do it. Pocho then they called me. Sometimes playfully, téasingly, using the tender diminutive-mi pochito. Sometimes not so playfully, mockingly, Pocho. (A Spanish dictionary defines that word as an adjeccive meaning 'colorless' or 'bland.' But I heard it as a noun, naming the Mexican-American who, in becoming an American, forgets his native society.) "(Pacho!' the lady in the Mexican food store murtered, shaking her head. I looked up to the counter where red and green peppers were srung like Christraas tree lights and saw the frowning face of the stranger. My mother laughed somewhere behind me. (She aid that her children didn't want to practice 'our Spanish' after they started going to xhool) My mocher's smiling voice made me suspect that the lady who facod me was not really angry at ine. But, searching ber tace, I couldn't find the bint of a smile.

$\checkmark$ Embarrassed, my parents would regularly need to aplain their children's inability to spesk flowing Spanish during those

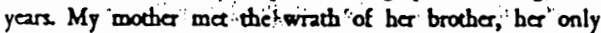
brocher, when be caine up from Mexioo one summer with his family. He sw his nieces and nephews for the very furs ime. After listening to me, he looked away and said what a disgrace it was that I couldn't spesk Spenish, 'sa proprio idioma' He made that remark io my möther: I notiod, howeve, that he

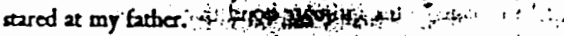

Tremember that man now, but seek no revenge in this telling. I recount such incidents only because they suggest the feree power Spanish had for many people I met at home; the,way Spanish was assoxiated with closeness. Most of those people who called me a pocho could have spoken English to me. Bur they would not. They seemed to chink that Spanish was the only language we could use, that Spanish alone permitted our, close association. (Such persons are vulnerable ajways to the gheto mectant and the politician who have learned the, yalue of speaking their clients' family language to gain immediate trust) For my part, I felt that I had somehow committed a: in 
J-, Nunean ur memukr

were never as raucous with sound as past times had been when we had had 'private' Spanish to use. (Our English-sounding house was never to be as noisy as our Spanish-speaking house had been.) Intimate moments were usually soft moments of sound. My mother was in the dining room while I did my homework nearby. And she looked over at me. Smiled. Said something - her words said noching very importane. But her voice sounded to tell me (We are rogether) I was her son. (Richard!)

Intimacy thus continued at home; intimacy was nox stilled by English. It is true that I would never forget the great change of my life, the diminished occasions of intimacy. But there would also be times whien I sensed the deepert truth abour language and inciomacy: Insimery is nol creased by a porcicour language; is is sreated by inimeses. The ged a particule life was noe lingriscic but social if after becoming a secestol

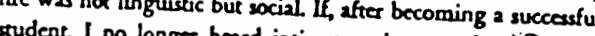
student, Ino longer beard intimate roices as often zis I had carlic, it was noc bocause Ispoke English is the chan Spanich It was bocause I used public language for most of the day. I moved acily at last a citiren in a 
APPENDIX C

INTERACTION FORM 
No. of Interaction:

Nature of the Address:

Key: (serlous, emotional):

Participants:

Message form:

Spanish

English

Top1c :

Equal1ty:

Equad

Unequal

Territory:

Deta118 of the Interaotion: 
APPENDIX D

ROSES HOUSE IN STOCKTON 

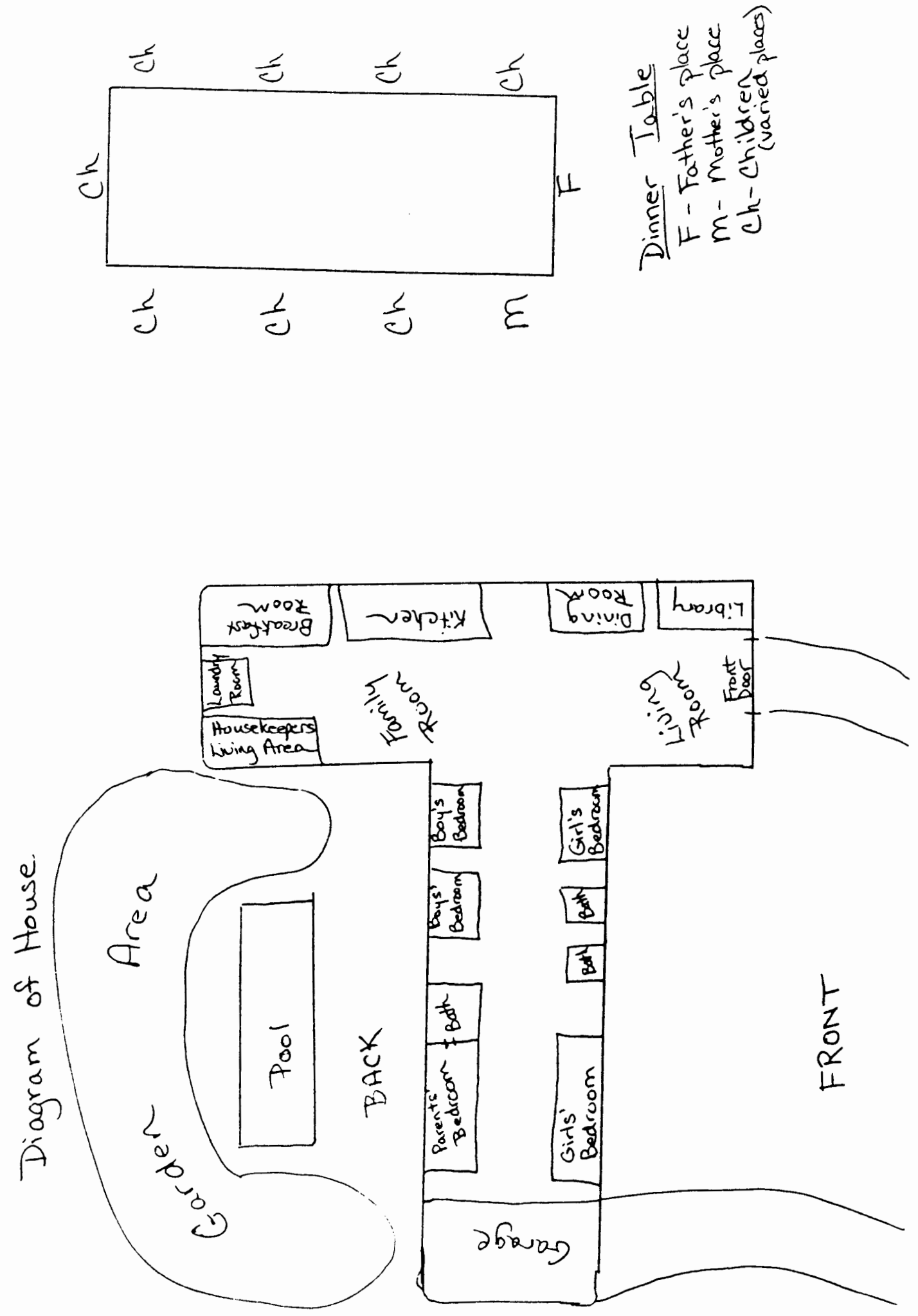
APPENDIX E

MAP OF STOCKTON 


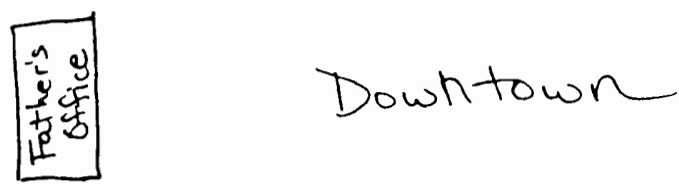

年
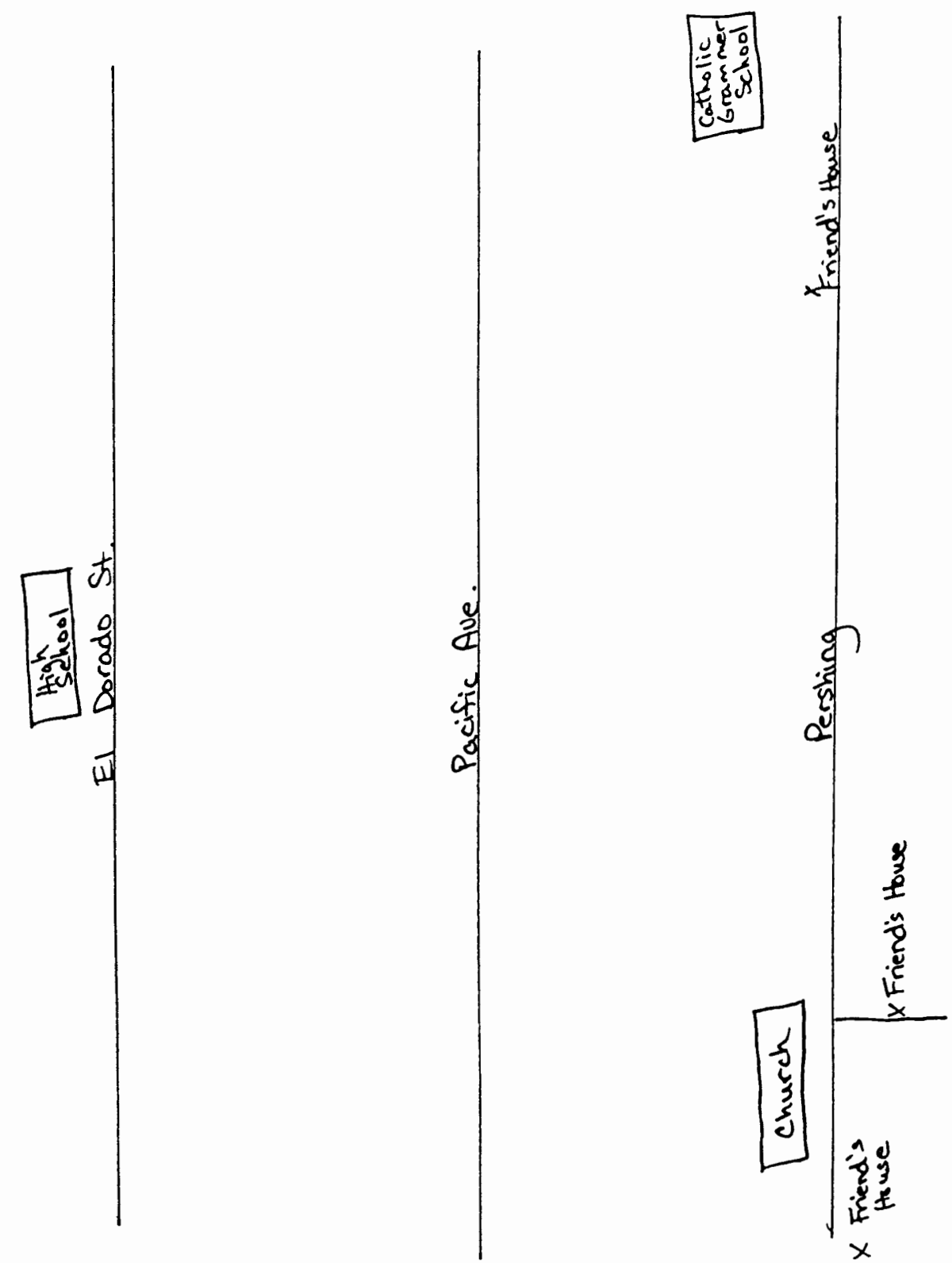

圆 


\section{APPENDIX F}

ROSE'S FAMILY TREE 


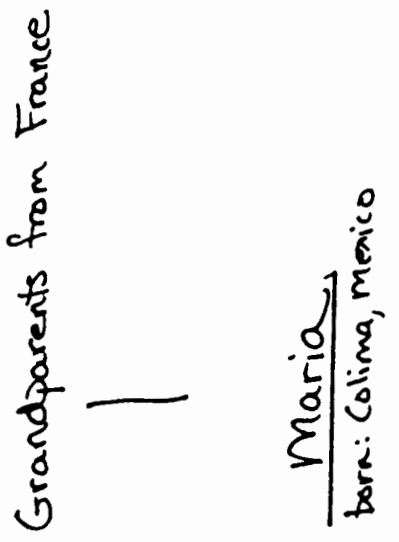

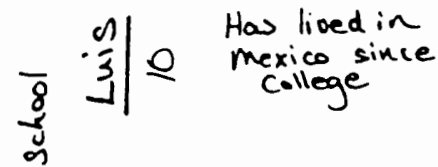

$$
\begin{aligned}
& \begin{array}{l}
\text { fo } \\
y \mid
\end{array}
\end{aligned}
$$$$
\lambda \frac{y}{y} \mid r
$$

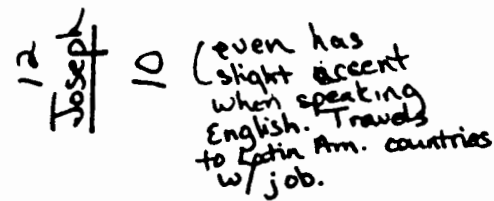

$\circ$ व.

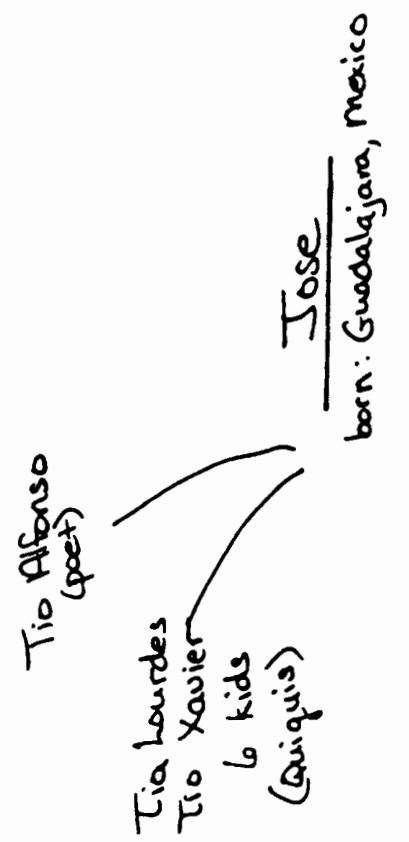

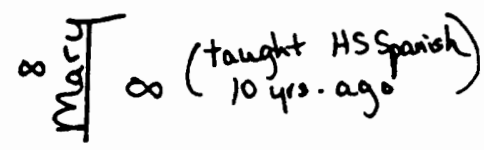

b $\frac{\$}{8}$

$\left.m \frac{+}{2}\right|_{p} ^{+} \infty \begin{aligned} & \text { (uses Spanish } \\ & \text { during pr job) }\end{aligned}$

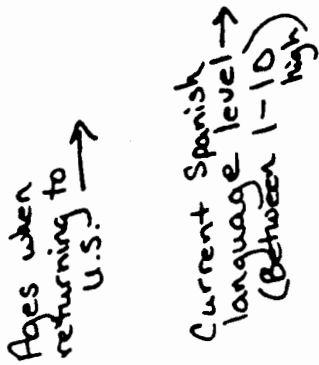


APPENDIX G

ROSE'S OFFICE 


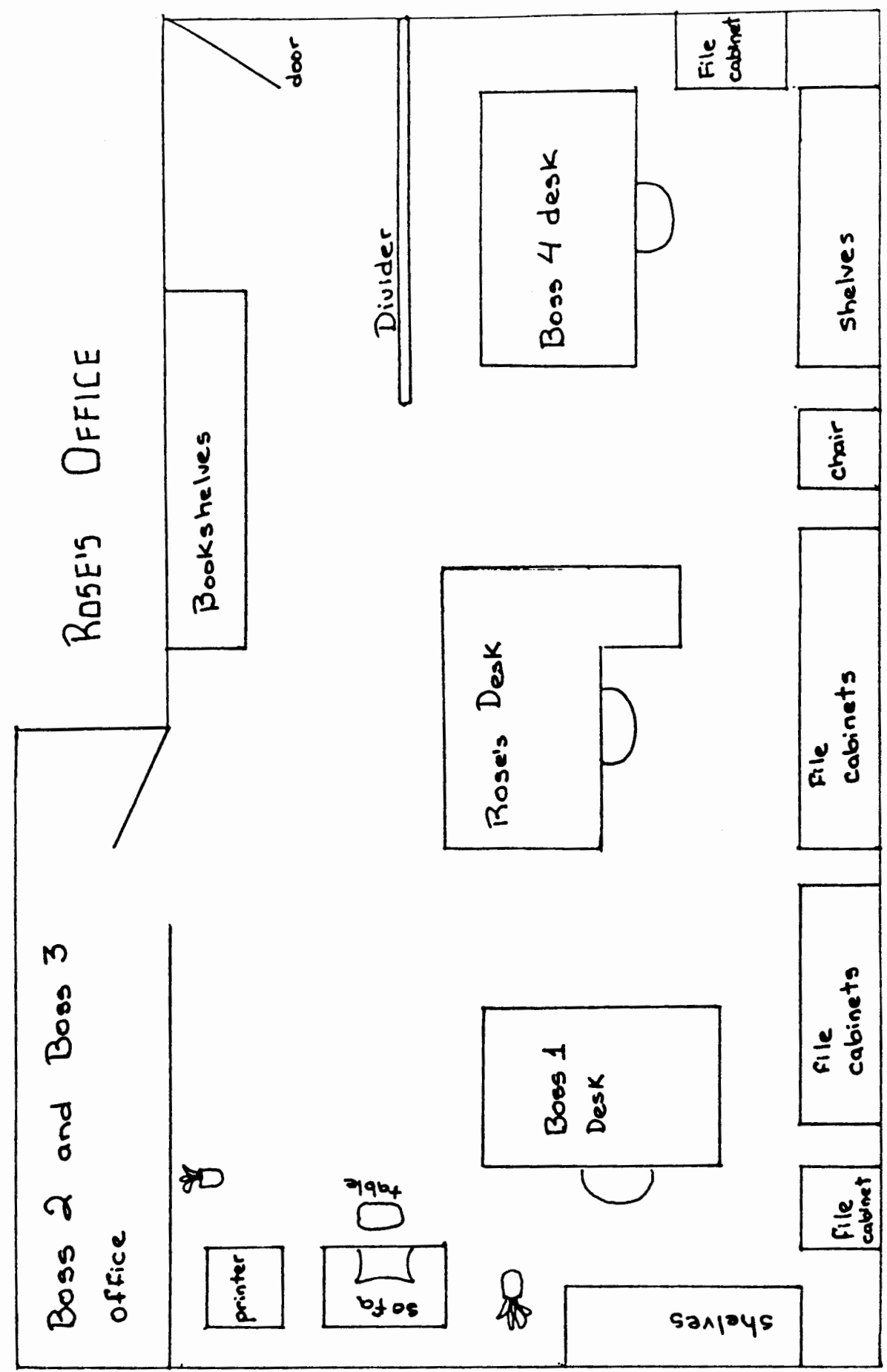

